\title{
Dietary parp-1 inhibitors as anti-inflammatory compounds
}

Citation for published version (APA):

Geraets, L. (2008). Dietary parp-1 inhibitors as anti-inflammatory compounds. [Doctoral Thesis, Maastricht University]. Unibversitaire Pers. https://doi.org/10.26481/dis.20081210lg

Document status and date:

Published: 01/01/2008

DOI:

10.26481/dis.20081210lg

Document Version:

Publisher's PDF, also known as Version of record

\section{Please check the document version of this publication:}

- A submitted manuscript is the version of the article upon submission and before peer-review. There can be important differences between the submitted version and the official published version of record.

People interested in the research are advised to contact the author for the final version of the publication, or visit the DOI to the publisher's website.

- The final author version and the galley proof are versions of the publication after peer review.

- The final published version features the final layout of the paper including the volume, issue and page numbers.

Link to publication

\footnotetext{
General rights rights.

- You may freely distribute the URL identifying the publication in the public portal. please follow below link for the End User Agreement:

www.umlib.nl/taverne-license

Take down policy

If you believe that this document breaches copyright please contact us at:

repository@maastrichtuniversity.nl

providing details and we will investigate your claim.
}

Copyright and moral rights for the publications made accessible in the public portal are retained by the authors and/or other copyright owners and it is a condition of accessing publications that users recognise and abide by the legal requirements associated with these

- Users may download and print one copy of any publication from the public portal for the purpose of private study or research.

- You may not further distribute the material or use it for any profit-making activity or commercial gain

If the publication is distributed under the terms of Article $25 \mathrm{fa}$ of the Dutch Copyright Act, indicated by the "Taverne" license above, 


\section{DIETARY PARP-1 INHIBITORS AS ANTI-INFLAMMATORY COMPOUNDS}

Liesbeth Geraets 
(c) Liesbeth Geraets, Maastricht 2008

ISBN 978-90-5278-779-4

Production: Datawyse / Universitaire Pers Maastricht

The studies presented in this thesis were financially supported by the Dutch Technology Foundation STW and performed within the Nutrion and Toxicology Research Institute Maastricht (NUTRIM) which participates in the Graduate School VLAG (Food Technology, Agrobiotechnology, Nutrition and Health Sciences), accredited by the Royal Netherlands Academy of Arts and Sciences (KNAW). 


\section{DIETARY PARP-1 INHIBITORS AS ANTI-INFLAMMATORY COMPOUNDS}

\section{Proefschrift}

ter verkrijging van de graad van doctor aan de Universiteit Maastricht, op gezag van de Rector Magnificus, Prof. mr. G.P.M.F. Mols, volgens het besluit van het College van Decanen,

in het openbaar te verdedigen

op woensdag 10 december 2008 om 12.00 uur

door

Liesbeth Geraets

geboren te Brunssum op 9 maart 1980

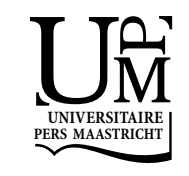




\section{Promotores}

Prof. dr. A. Bast

Prof. dr. E.F.M. Wouters

\section{Copromotor}

Dr. Ir. G.J. Hageman

\section{Beoordelingscommissie}

Prof. dr. F.J. van Schooten (voorzitter)

Prof. dr. Ir. E.E. Blaak

Prof. dr. W.A. Buurman

Prof. dr. B. Frei (Oregon State University, USA)

Prof. dr. F.P. Nijkamp (Universiteit Utrecht) 


\section{CONTENTS}

$\begin{array}{ll}\text { Abbreviations } & 7\end{array}$

$\begin{array}{lll}\text { Chapter } 1 \quad \text { General Introduction } & 9\end{array}$

Chapter 2 Caffeine metabolites are inhibitors of the nuclear

enzyme poly(ADP-ribose) polymerase- 1 at physiological concentrations

Chapter 3 Dietary flavones and flavonoles are inhibitors of poly(ADP-ribose) polymerase- 1 in pulmonary epithelial cells

Chapter $4 \quad$ Flavone as PARP-1 inhibitor: its effect on

lipopolysaccharide induced gene-expression

Chapter 5 Anti-inflammatory effects of specific PARP-1 inhibiting flavonoids in a mouse model of lipopolysaccharide induced acute pulmonary inflammation

Chapter 6 The caffeine metabolite 1,7-dimethylxanthine inhibits the lipopolysaccharide-induced inflammatory response in mouse lungs and ex vivo in blood of COPD patients

Chapter 7

General Discussion

References

Samenvatting

Appendix

Dankwoord

130

About the author

Publications 



\section{ABBREVIATIONS}

$\begin{array}{ll}\text { AIF } & \text { apoptosis inducing factor } \\ \text { AP-1 } & \text { activator protein-1 } \\ \text { BAL } & \text { broncheoalveolar lavage } \\ \text { BER } & \text { base excision repair } \\ \text { BRCT } & \text { BRCA1 C-terminus like } \\ \text { CBP } & \text { cAMP responsive element binding protein-binding protein } \\ \text { COPD } & \text { chronic obstructive pulmonary disease } \\ \text { CYP } & \text { cytochrome P450 } \\ \text { DBD } & \text { DNA binding domain } \\ \text { ELISA } & \text { enzyme linked immuno sorbent assay } \\ \text { ESR } & \text { electron spin resonance } \\ \text { FEV } & \text { forced expiratory volume in one second } \\ \text { FVC } & \text { forced vital capacity } \\ \text { HDAC } & \text { histone deacetylase } \\ \text { HO } & \text { heme oxygenase } \\ \mathrm{H}_{2} \mathrm{O}_{2} & \text { hydrogen peroxide } \\ \text { IKB } & \text { inhibitor kappa B } \\ \text { IKK } & \text { IkB kinase } \\ \text { IL } & \text { interleukin } \\ \text { iNOS } & \text { inducible nitric oxide synthase } \\ \text { IT } & \text { intratracheal } \\ \text { LPS } & \text { lipopolysaccharide } \\ \text { MAPK } & \text { mitogen-activated protein kinases } \\ \text { MIP } & \text { macrophage inflammatory protein } \\ \text { MNNG } & \text { N-methyl-N'-nitro-N-nitrosoguanidine } \\ \text { MPO } & \text { myeloperoxidase } \\ \text { NF- }- \text { B } & \text { nuclear factor-kappa B } \\ \text { NLS } & \text { nuclear localization signal } \\ \text { PAR-polymer } & \text { poly(ADP-ribose) polymer } \\ \text { PARG } & \text { poly(ADP-ribose) glycohydrolase } \\ \text { PARP-1 } & \text { poly(ADP-ribose) polymerase-1 } \\ \text { PDE4 } & \text { phosphodiesterase 4 } \\ \text { PI-3kinase } & \text { phosphoinositide 3-kinase } \\ \text { PKC } & \text { protein kinase C } \\ \text { ROS } & \text { reactive oxygen species } \\ \text { SAP } & \text { serum amyloid p component } \\ \text { SOD } & \text { superoxide dismutase } \\ \text { TEAC } & \text { trolox equivalent antioxidant capacity } \\ \text { TNF- } \alpha & \text { tumor necrosis factor-alpha } \\ & \end{array}$





\section{CHAPTER 1}

General Introduction 


\section{POLY(ADP-RIBOSE) POLYMERASE-1}

The enzyme poly(ADP-ribose) polymerase-1 (PARP-1; also known as poly(ADP-ribose) synthetase and poly(ADP-ribose) transferase, E.C. 2.4.2.30) is one of the most abundant nuclear proteins present in eukaryotes (reviewed in [1, 2]). PARP-1 is a $116 \mathrm{kDa}$ protein consisting of three domains: the $\mathrm{N}$-terminal DNA-binding domain (DBD) containing two zinc fingers, the automodification domain and the C-terminal catalytic domain (Figure 1). PARP-1 is a member of the PARP enzyme family, which until now consists of 17 homologues with PARP-1 as the most extensively studied member [3]. Each PARP homologue is different in domain structure, ability to bind to DNA, cellular localization and function.

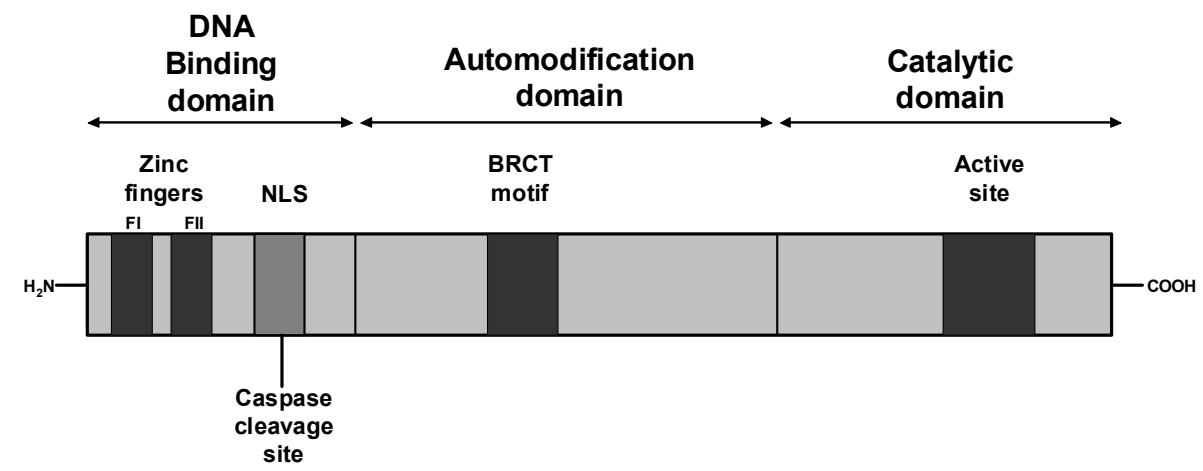

Figure 1. Schematic representation of the organisation of human PARP-1. The amino (N)-terminal DNA binding domain contains 2 zinc fingers (FI and FII), which are responsible for DNA binding, a nuclear localization signal (NLS) containing the caspase-cleavage site. The automodification domain, which contains a BRCT (BRCA1 C-terminus like) motif and also serves as the binding place for the auto-poly(ADP-ribosyl)ation reaction. The C-terminal region holds the catalytic domain of PARP-1, which includes the active site and the $\mathrm{NAD}^{+}$-binding site.

PARP-1 functions as a DNA damage signalling molecule binding to both singleas well as double-stranded DNA breaks. Upon binding to the damaged DNA, PARP-1 forms homodimers and catalyzes the transfer of ADP-ribose molecules from its substrate $\mathrm{NAD}^{+}$to acceptor proteins (Figure 2). The ADP-ribose molecules form poly(ADP-ribose) polymers (PAR-polymers) and bind to various target proteins including PARP-1 itself (automodification domain). Poly(ADPribosyl)ation is a dynamic process, as follows from a very short half-life $(<1$ min) of the PAR-polymer. The catabolism of the PAR-polymer is regulated by two enzymes, poly(ADP-ribose) glycohydrolase (PARG) and ADP-ribosyl protein lyase. PARG cleaves the ribose-ribose bonds of both linear and multi- 


\section{A}

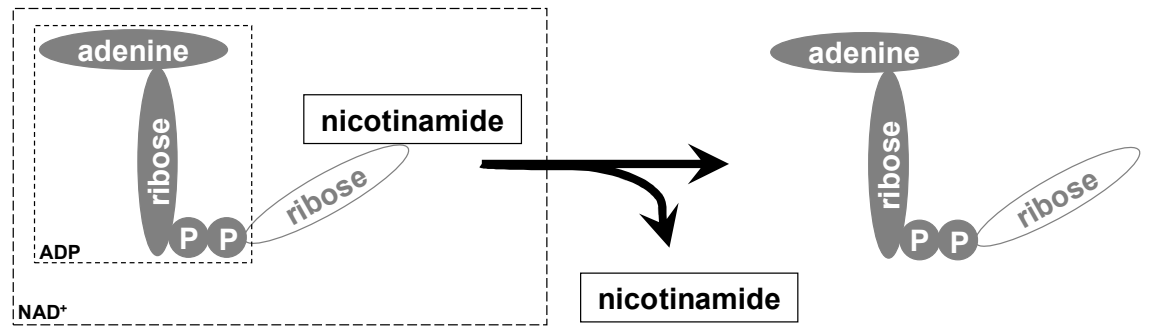

B

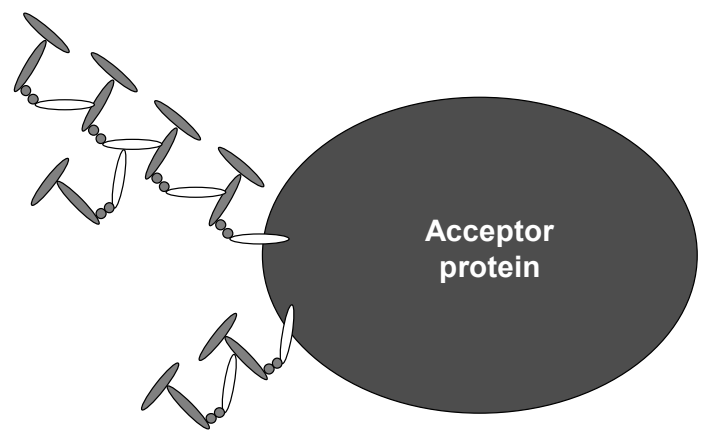

Figure 2. The poly(ADP-ribosyl)ation reaction catalyzed by PARP-1. A) Nicotinamide is cleaved from $\mathrm{NAD}^{+}$and $\mathrm{B}$ ) the ADP-ribose subunits form poly(ADP-ribose)polymers (adapted from [4])

branched portions of poly(ADP-ribose) and ADP-ribosyl protein lyase removes the protein proximal ADP-ribose monomer. The regulation of PARP- 1 activity is primarily regulated at the level of its catalytic activity. The best-characterized mechanism for the downregulation of enzyme activity is through autopoly(ADP-ribosyl)ation at the automodification domain of PARP-1. Furthermore, the formation of nicotinamide as a result of cleavage of ADP-ribose from $\mathrm{NAD}^{+}$exerts a weak negative feedback inhibitory effect on PARP-1. Most of the biological effects of PARP-1 relate to the various aspects of the ADP-ribosylation process: first, covalent poly(ADP-ribosyl)ation that influences the function of target proteins; second, the physical association of PARP with nuclear proteins to form functional complexes; third, the lowering of the cellular level of its substrate $\mathrm{NAD}^{+}$.

\section{DNA repair}

PARP-1 has long been known primarily for its role in facilitating DNA repair. This is supported by studies with knockout cells and mice which showed delayed and less efficient DNA base excision repair (BER) [5, 6]. Various mechanisms seem to be involved in the regulation of the DNA BER pathway by PARP-1. PARP-1 interacts with multiple nuclear components of the singlestrand break repair and BER complexes, such as XRCC1, DNA polymerase and 
DNA ligase III, but also PARP-2 seems to be involved [7, 8]. In addition, the formation of the negatively charged poly(ADP-ribose) polymers and the transfer of these polymers to acceptor proteins like histones triggers chromatin-structure relaxation [9]. This remodeling of the chromatin architecture increases the access of DNA repair enzymes to the damaged DNA [10].

\section{Signal transduction and gene expression}

An important physiological role of PARP-1 is the ability to regulate transcription, and various mechanisms are involved in this role. Poly(ADP-ribosyl)ation confers negative charges to histones, which leads to electrostatic repulsion from the DNA [9]. This also leads to loosening of the chromatin and makes various genes more accessible to the transcriptional machinery. Furthermore, PARP-1 participates in enhancer/promoter-binding complexes, such as its co-activator function of the nuclear factor-kappa B (NF-KB) mediated transcription [11].

\section{Cell death}

PARP-1 has been implicated in both apoptosis and necrosis (Figure 3). Initial studies focused on its potential role in apoptosis, because PARP-1 was one of the first identified substrates of caspases [12]. During apoptosis, caspase 3 and 7 cleave PARP-1 into two fragments, which separates its DNA binding domain from the catalytic domain and subsequently inactivates the enzyme. At present, this PARP-1 cleavage is seen as a marker of apoptosis and is independent from its catalytic acitivity and not influenced by pharmacological inhibition of the enzyme. PARP-1 cleavage prevents the overactivation of PARP-1 and thereby maintains cellular energy for certain energy-sensitive steps of apoptosis.

Recently, in addition to the caspase-mediated apoptotic pathway, an alternative intrinsic cell death pathway has been illustrated. This apoptosis inducing factor (AIF)-mediated caspase-independent cell death pathway appears to be regulated by PARP-1 [13]. PARP-1 activation was shown to induce translocation of AIF from the mitochondria to the nucleus, leading to DNA condensation and fragmentation and cell death.

The most distinctive feature of necrosis is the disintegration of the plasma membrane. Leakage of cell content from necrotic cells into the surrounding tissue exacerbates the inflammatory process and may contribute to organ injury. Cellular ATP and $\mathrm{NAD}^{+}$are important determinants of the mode of cell death, and PARP-1 directly regulates cell necrosis by regulating the levels of cellular energetic pools [14]. 


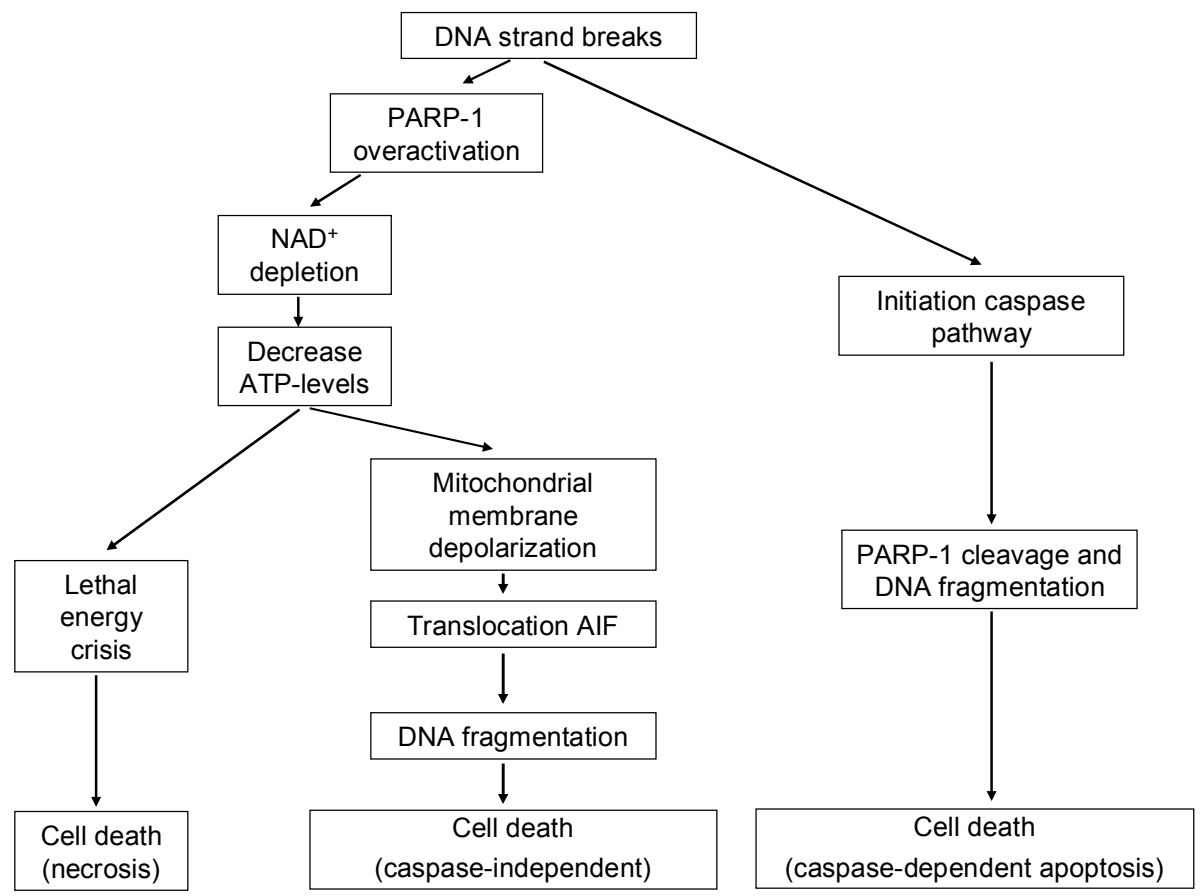

Figure 3. The role of PARP-1 in cell death

\section{Inflammation}

Studies with knockout cells and mice pointed toward the regulatory role of PARP-1 in the NF-KB mediated gene-expression [11, 15]. Subsequently it has been observed that the enzyme activity of PARP-1 was not required for full activation of NF-KB, but PARP-1 was found to interact with histone acetyl transferase $\mathrm{p} 300$ and both subunits of NF-KB (p50 and p65) and synergistically coactivated NF-KB dependent transcription $[16,17]$. In addition, the observation that PARP-1 itself was acetylated by the key activators of NF-KB, p300/cAMP responsive element binding protein (CREB)-binding protein (CBP), pointed towards the important regulatory role in NF-KB dependent geneactivation [18]. However in contrast to these observations, others reported that the enzymatic activity of PARP- 1 and so the synthesis of PAR-polymers facilitated the transcriptional activation properties of NF-KB [19]. Moreover, inhibition of PARP-1 with synthetic inhibitors has been reported to reduce the DNA-binding activity of NF-KB and also the transcription of NF-KB mediated genes [20, 21]. Overall, the contribution of PARP-1 activity to NF-KB activation and to the subsequent transcription of NF-KB mediated genes seems to be partly dependent on the tissues or cell type and the models used to investigate this. 
PARP-1 has also been implicated in activator protein (AP)-1 mediated transcriptional activity via mitogen-activated protein kinases (MAPK) [22]. Various studies with PARP-1 knockout cells and mice but also studies in which synthetic PARP-1 inhibitors were applied showed the contribution of PARP-1 to these signaling cascades, such as demonstrated by a decreased MAPK activity and reduced AP-1 DNA binding [23-25].

\section{Inflammatory stimuli}

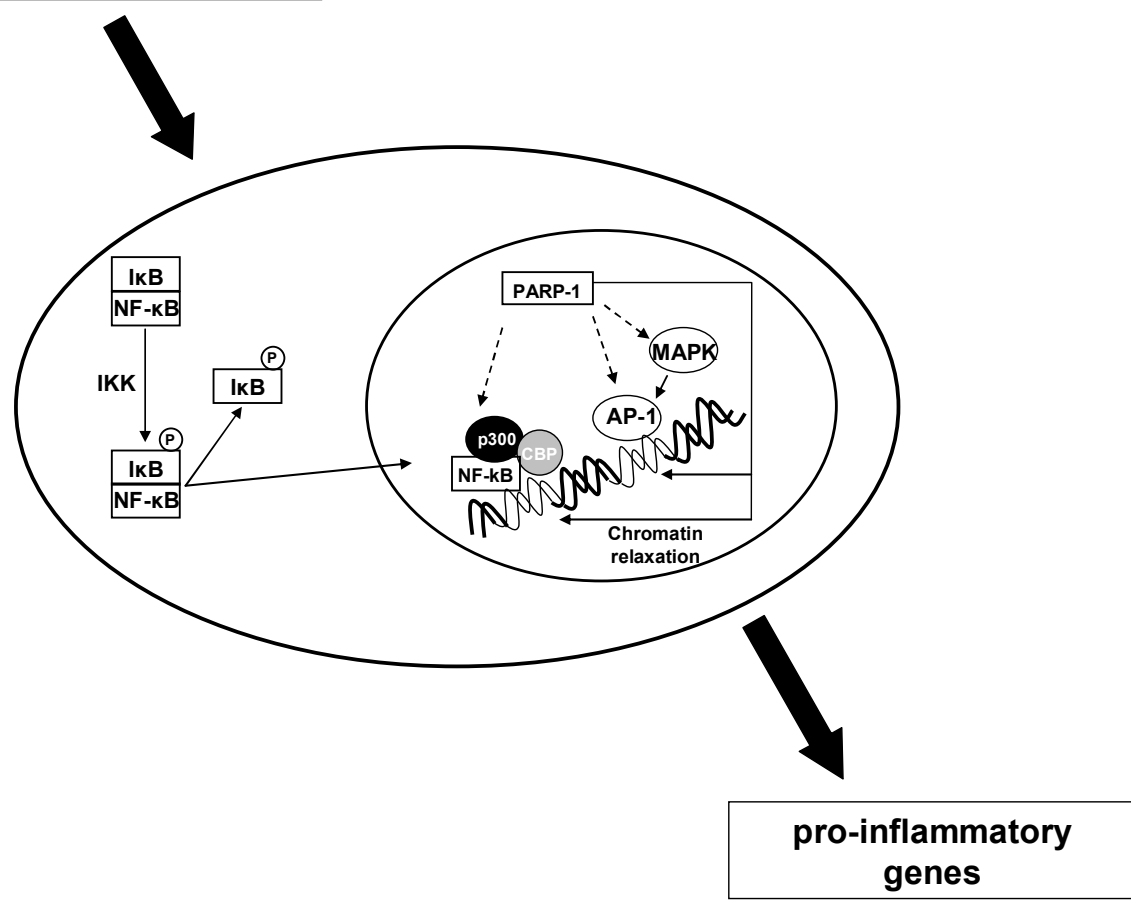

Figure 4. The regulatory role of PARP-1 in inflammation. PARP-1 induces chromatin relaxation and increases DNA accessibility for transcription factors such as NF- $\mathrm{B}$ and AP-1, which are activated upon exposure to inflammatory stimuli. AP-1 activation is mediated by MAP-kinases. Activation of $I \kappa B$ kinase $(I K K)$ induces the phosphorylation of $I \kappa B$, the dissociation of $I \kappa B$ from the $N F-\kappa B / I \kappa B-$ complex and the translocation of NF- $\kappa B$ to the nucleus. In the nucleus, NF- $\kappa B$ binds to the DNA together with the other members of the transcription complex such as p300 and CBP, leading to transcription of pro-inflammmatory genes. PARP-1 interacts with this transcription complex and promotes also acetylation by P300/CBP.

Overall, various mechanisms are responsible for the regulatory role of PARP-1 in inflammation (Figure 4). The role of PARP-1 activation and the protective effects of PARP-1 inhibitors have been demonstrated in various experimental models of inflammation, both acute as well as chronic inflammation, including ovalbumin-induced asthma, myocardial ischemia/reperfusion, stroke and chronic inflammation in diabetes [26-28]. Previously it has been recognized 
that PARP-1 is involved in the lipopolysaccharide (LPS)-induced acute pulmonary inflammation in mice. PARP-1 gene deletion as well as pharmaceutical inhibition of PARP-1 has been shown to attenuate pulmonary inflammation [29]. Recently, Hageman et al. (2001) reported increased oxidative stress and increased inflammation in blood of COPD patients, which were accompanied by an increased number of PAR-polymer positive peripheral blood mononuclear cells, indicating a chronic and systemic PARP-1 activation [30]. Inhibition of PARP-1 might be a potential option for therapeutic application in both acute as well as chronic inflammatory conditions.

\section{PARP-1 inhibitors}

Recently, various consequences of the activation of PARP-1 have been discovered, that are particularly important for the drug development: first, its capacity to promote the transcription of pro-inflammatory genes; second, its capacity to deplete cellular energetic pools, which results in cell dysfunction and necrosis; and third, its role in DNA repair. Subsequently, pharmacological inhibitors of PARP-1 have the potential to down-regulate multiple pathways of inflammation or tissue injury, to reduce cell necrosis in for example stroke or myocardial infarction, and to enhance the cytotoxicity of certain DNAdamaging anticancer drugs [21, 31-33].

Nicotinamide, one of the cleavage products of PARP-1 enzyme reaction, weakly inhibits PARP-1 competitively via product-inhibition. This fact together with the increased understanding of the chrystal structure of the catalytic site of PARP-1 led to the development of pharmaceutical PARP-1 inhibitors that are mainly based on the benzamide pharmacophore (Figure 5). This structure mimics the nicotinamide moiety of $\mathrm{NAD}^{+}$and binds to the catalytic site of the protein. During the past decade, highly potent PARP-1 inhibitors have been synthesized with optimal potency and pharmacokinetics such as phenanthridinones, dihydroisoquinolinones, indoloquinazolinones and phtalazinones $[31,34,35]$. Also, existing medicines have been identified as PARP-1 inhibitors [36]. Significant therapeutic effects of synthetic PARP-1 inhibitors have been demonstrated in models of stroke, myocardial infarction, diabetic endothelial dysfunction, ovalbumin-induced asthma, hepatic ischemia/reperfusion injury, LPS-induced acute pulmonary inflammation and haemorrhagic and endotoxic shock $[24,26,27,29,31,37,38]$. Some of these synthetic inhibitors are currently evaluated in human clinical trials for potential treatment of reperfusion injury induced by myocardial infarction or the potentiation of chemotherapeutic agents $[1,32]$.

Not only synthetic compounds have been identified as PARP-1 inhibitors, also dietary compounds have been evaluated for their PARP-1 inhibiting activity $[39,40]$. Synthetic PARP-1 inhibitors are very potent compounds which may increase the risk of possible negative aspects of PARP-1 inhibition. Considering 
the long-term treatment of chronic diseases, the application of dietary mild PARP-1 inhibitors as nutraceuticals or functional foods would be a potential alternative.<smiles>NC(=O)c1cccnc1</smiles>

nicotinamide<smiles>NC(=O)c1cccc(N)c1</smiles>

3-aminobenzamide<smiles>CNC(=O)Nc1ccc2[nH]c(=O)c3ccccc3c2c1</smiles>

PJ34

Figure 5. Chemical structure of three important PARP-1 inhibitors 1) nicotinamide, 2) 3aminobenamide and 3) PJ34 (N-(6-oxo-5,6-dihydrophenanthridin-2-yl)-N,N-dimethylacetamide. $\mathrm{HCl})$

\section{CHRONIC OBSTRUCTIVE PULMONARY DISEASE (COPD)}

\section{Definition, prevalence}

The project described in this thesis focuses on the identification and evaluation of dietary PARP-1 inhibitors which can be applied in the treatment of chronic pulmonary inflammatory diseases, more specific chronic obstructive pulmonary disease (COPD). Therefore, this multifactorial disease will be described in more detail in this paragraph.

COPD is a preventable and treatable disease with some significant extrapulmonary effects that may contribute to the severity of individual patients. Its pulmonary component is characterized by airflow limitation that is not fully reversible. The airflow limitation is usually progressive and associated with an abnormal inflammatory response of the lungs to noxious particles or gases [41]. COPD can be characterized by chronic and progressive dyspnea, cough and sputum production and includes different disease conditions varying from 
chronic obstructive bronchitis with obstruction of small airways to emphysema with enlargement of air spaces, destruction of lung parenchyma, loss of lung elasticity and closure of small airways. In addition, COPD has also significant extrapulmonary (systemic) effects that lead to comorbidities and which may contribute to the severity of the disease in individual patients and may enormously impair the quality of life [41].

COPD can be classified into 4 stages, which indicate the severity of the disease (Table 1). According to the World Health Organisation (WHO) estimates, 80 million people have moderate to severe COPD. The WHO predicts that by 2020 COPD will rise to the $5^{\text {th }}$ most prevalent disease and to the $3^{\text {rd }}$ most common cause of death worldwide. Increases in cigarette smoking and environmental pollution in developing countries, but also reduced mortality from other diseases like cardiovascular diseases will explain the dramatic increase in COPD [42, 43].

Table 1. Classification of COPD severity

\begin{tabular}{ll}
\hline Stage & Spirometric characteristic \\
\hline Stage I: mild & $\mathrm{FEV}_{1} / \mathrm{FVC}<0.70$ \\
& $\mathrm{FEV}_{1} \quad 80 \%$ predicted \\
Stage II: moderate & $\mathrm{FEV}_{1} / \mathrm{FVC}<0.70$ \\
& $50 \% \quad \mathrm{FEV},<80 \%$ predicted \\
Stage III: severe & $\mathrm{FEV}_{1} / \mathrm{FVC}<0.70$ \\
& $30 \% \quad \mathrm{FEV} \mathrm{F}_{1}<50 \%$ predicted \\
Stage IV: very severe & $\mathrm{FEV}_{1} / \mathrm{FVC}<0.70$ \\
& $\mathrm{FEV}_{1}<30 \%$ predicted or $\mathrm{FEV}_{1}<50 \%$ predicted plus chronic respiratory \\
& failure
\end{tabular}

$\mathrm{FEV}_{1}$ : forced expiratory volume in one second

FVC: forced vital capacity

\section{Pathology}

In COPD, pathological changes can be found throughout the airways, lung parenchyma and pulmonary vasculature and include both chronic inflammation as well as structural changes. The chronic inflammatory response is characterized by increased numbers of specific inflammatory cell types in different parts of the lungs such as neutrophils, macrophages and Tlymphocytes and the production of inflammatory mediators, proteinases and reactive nitrogen and oxygen species by the airway and alveolar epithelial cells. These pathological changes lead to corresponding physiological characteristics of the disease, including mucus hypersecretion and ciliary dysfunction, resulting in chronic cough and sputum production. Furthermore, airflow limitation, pulmonary hyperinflation, gas exchange abnormalities, pulmonary hypertension and cor pulmonale are important physiological changes observed in COPD patients. 
In addition to the pulmonary effects, COPD is increasingly associated with significant systemic effects such as systemic inflammation and oxidative stress, cachexia and skeletal muscle weakness [44]. These systemic effects have important clinical relevance and are significant contributors to the impaired quality of life and mortality risk of COPD patients.

\section{Risk factors}

Cigarette smoking has world-wide been recognized as the most important risk factor for the development of COPD. Age at which smoking starts, total packyears smoked and current smoking status can all determine mortality from COPD. However, also occupational exposure to organic dusts is an important environmental risk factor for COPD. Furthermore, epidemiological studies show that there is increasing evidence that also non-smokers may develop chronic airflow obstruction $[45,46]$. It has been recognized that the interaction between host factors and environmental exposure is responsible for basically all risk for COPD. The best-documented genetic risk factor is a rare hereditary deficiency of $\alpha_{1}$-antitrypsin, which has been shown to result in accelerated development of emphysema and decline in lung function in non-smokers and smokers [47]. Airway hyperresponsiveness and asthma are also identified as risk factors for the development of COPD, although it is not yet known how they influence the development of COPD [48].

\section{Treatment}

Smoking cessation is at present the only effective measure that will reduce the risk for and slow down the progression of COPD. Most therapeutics in COPD therapy are aimed at bronchodilation and for this purpose $\beta 2$-agonists, anticholinergics and methylxanthines are prescribed. In addition to this treatment, inhaled or systemic glucocorticoids are often used for symptomatic patients during exacerbations. However, the effectiveness of these drugs is limited.

Not only bronchoconstriction, but also chronic local and systemic inflammation are important characteristics of the health status of COPD patients. However, no successful treatment has been developed yet for this increased inflammation. Potential candidates such as tumor necrosis factor-alpha (TNF- $\alpha$ ) blockers (Infliximab) have been evaluated but were not beneficial or caused serious side-effects $[49,50]$.

Alternative therapies, which need to be applied chronically, are necessary. Dietary mild PARP-1 inhibitors might therefore be potential candidates for the treatment of chronic inflammatory diseases such as COPD. Furthermore, additional effects such as antioxidant activity might contribute to the beneficial effects of these compounds. 


\section{FLAVONOIDS}

Flavonoids are a class of food-derived polyphenolic compounds ubiquitously present in fruit, vegetables, red wine and tea. The chemical structure of most flavonoids is characterized by a three-ring structure, containing two aromatic rings $(A+B)$ and one heterocyclic ring $(C)$ (Figure 6). The various flavonoids can be divided in different subclasses like flavones, flavonoles, flavanoles, flavanones, isoflavonoids, anthocyanidins and chalcones (Figure 6).

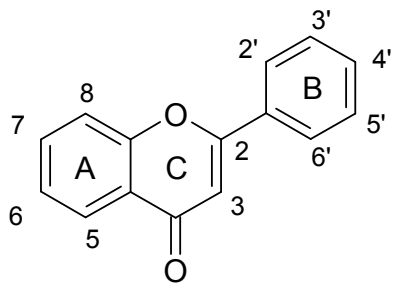

flavone<smiles>O=c1c(O)c(-c2ccccc2)oc2ccccc12</smiles>

flavonol<smiles>O=C1CC(c2ccccc2)Oc2ccccc21</smiles>

flavanone<smiles>OC1Cc2ccccc2OC1c1ccccc1</smiles>

flavanol<smiles>Oc1cc2ccccc2[o+]c1-c1ccccc1</smiles>

anthocyanidin<smiles>Oc1ccccc1CC=Cc1ccccc1</smiles>

chalcone<smiles>c1ccc(C2COc3ccccc3C2)cc1</smiles>

isoflavonoids

Figure 6. Chemical structure of the various subclasses of flavonoids 


\section{Intake, absorption and metabolism}

The total amount of flavonoids consumed has been estimated at several hundreds mg per day for the Dutch population [51]. The flavonol and flavone intake in the Netherlands was determined at 23-24 mg/day [51, 52].

In foods, flavonoids are mainly present as glycosides and initially it was thought that the aglycones were the only form able to be taken up in the gastrointestinal tract [53]. However, currently it is considered that also flavonoid glycosides can be absorbed without preceding hydrolysis [54, 55]. After absorption, flavonoids are extensively metabolized in various organs such as small intestine and liver, resulting in the formation of sulfated, glucuronidated or methylated compounds [56].

\section{Beneficial effects}

In epidemiological studies, the intake of flavonoids has been related to a reduced risk for various diseases including cardiovascular and chronic inflammatory diseases [51, 57]. These positive health effects have been ascribed to their well known antioxidant effects, but also to their anti-inflammatory effects and inhibiting effects on a wide range of enzymes [58, 59]. Both the antioxidant effects as well as their enzyme inhibiting effects are ascribed to the hydroxylation pattern of flavonoids. The presence and position of hydroxyl groups in flavonoids are an important determinant of the antioxidant properties of these compounds [58]. It has become clear that flavonoids may exert their beneficial effects also via modulation of different components of intracellular signalling cascades such as MAPK, phosphoinositide 3-kinase (PI 3-kinase) or protein kinase C (PKC) [60]. Not only the aglycones and glycosides seem to be responsible for these effects, but also the conjugates and metabolites which are formed upon absorption may still be biologically active [61].

\section{Flavonoids and pulmonary inflammation}

Various epidemiological studies have been performed to investigate the effect of flavonoid intake on incidence of pulmonary inflammatory diseases such as COPD or asthma [62, 63]. Tabak et al. (2001) studied the intake of catechins, flavonols and flavones from the diet in relation to impairment of pulmonary functions in COPD. Their results indicated that flavonol and flavone intake was found to be independently associated with chronic cough only. However, a reduced risk of a high intake of catechins and solid fruits for developing COPD was observed [63]. In an epidemiological study performed by Knekt et al. (2002), incidence of asthma was found to be inversely related to a higher intake of the flavonoids quercetin, naringenin, and hesperitin [62]. Experimental animal studies provided support for these epidemiological findings and therapeutic effects of various flavonoids on allergic airway inflammation were observed [64, 65]. 


\section{CAFFEINE AND OTHER METHYLXANTHINES}

Methylxanthines are a group of methylated heterocyclic aromatic organic compounds, which are mostly found in drinks such as coffee, cocoa, cola, black teas, and food products such as chocolates. Important dietary methylxanthines are caffeine (1,3,7-trimethylxanthine), 1,7-dimethylxanthine (paraxanthine), theophylline (1.3-dimethylxanthine) and theobromine (3,7-dimethylxanthine).

\section{Absorption and metabolism}

Caffeine is rapidly and almost completely absorbed in the stomach and small intestine and distributed to all tissues. Caffeine metabolism occurs primarily in the liver where the activity of the cytochrome P450 isoform CYP1A2 accounts for almost $95 \%$ of the primary metabolism of caffeine (Figure 7). Caffeine is demethylated to its major metabolites 1,7-dimethylxanthine, theophylline and theobromine. Further demethylation of 1,7-dimethylxanthine results mainly in the formation of 1-methylxanthine and 1-methyl uric acid. 3-Methylxanthine is formed after demethylation of theobromine and theophylline [66, 67].

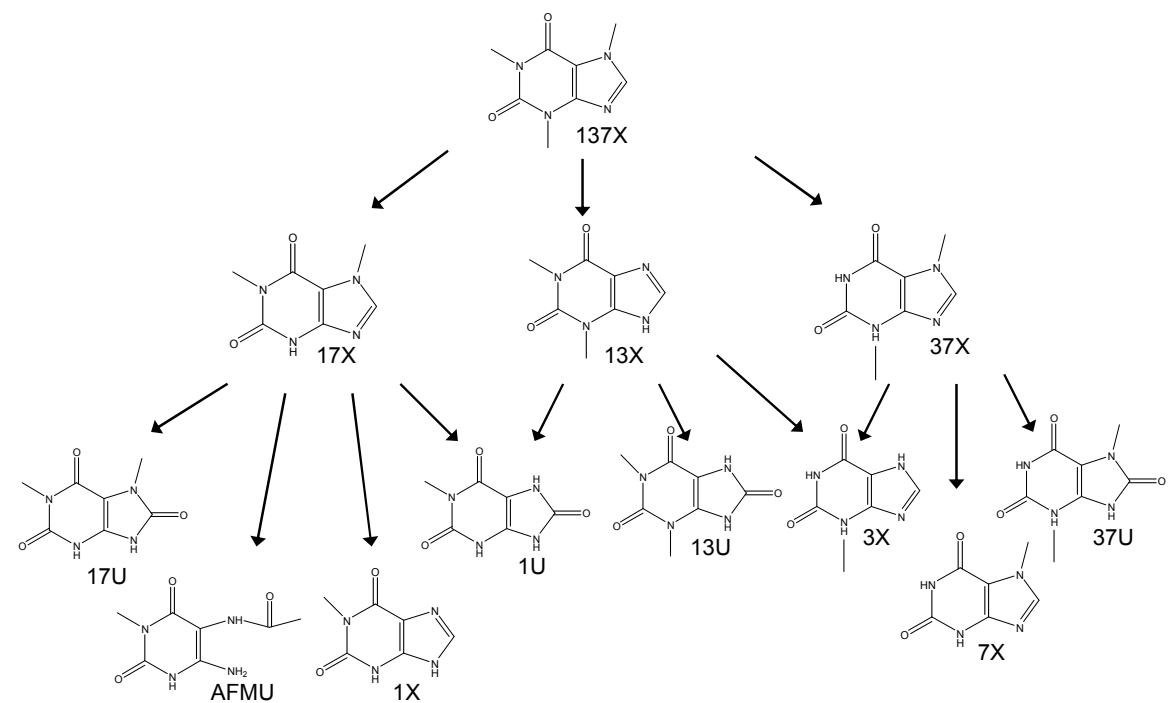

Figure 7. Metabolism of caffeine in humans

$1 X=1$-methylxanthine, $3 X=3$-methylxanthine, $7 X=7$-methylxanthine, $13 X=1,3$-dimethylxanthine (theophylline), $17 X=1,7$-dimethylxanthine (paraxanthine), 37X=3,7-dimethylxanthine (theobromine), $137 \mathrm{X}=1,3,7$-trimethylxanthine (caffeine), $1 \mathrm{U}=1$-methyl uric acid, $3 \mathrm{U}=3$-methyl uric acid, $7 \mathrm{U}=7$-methyl uric acid, $13 \mathrm{U}=1,3$-dimethyl uric acid , $17 \mathrm{U}=1,7=$ dimethyl uric acid, $37 \mathrm{U}=3,7-$ dimethyl uric acid, AFMU = 5-acetylamino-6-formylamino-3-methyluracil 


\section{Methylxanthines and pulmonary inflammation}

The dietary methylxanthine theophylline together with its synthetic analog aminophylline is used in addition to corticosteroids in the treatment of COPD because of its bronchodilator effects. In addition, various therapeutic mechanisms for potential anti-inflammatory effects of theophylline and also other methylxanthines have been described, such as inhibition of phosphodiesterase 4 (PDE4) enzymes, antagonism of adenosine receptors and induction of histone deacetylase (HDAC) [68-70]. By inhibiting PDE4, methylxanthines block the hydrolysis of CAMP, leading to elevated intracellular cAMP levels and, thus, suppression of the proinflammatory activity of these cells, including cytokine, chemokine, and IgE production, enabling selective targeting of inflammation. PDE4 inhibitors have been successfully applied in the treatment of inflammatory diseases such as COPD [71, 72]. The endogenous nucleoside adenosine has also been implicated in the pathogenesis of pulmonary inflammatory diseases such as asthma and COPD [73, 74] and it is generally assumed that also other methylxanthines than theophylline exert an important part of their effect via antagonism of the adenosine receptors [70]. Theophylline has also been depicted as an inducer of HDAC [69], which has been shown to result in restored steroid responses in alveolar macrophages of COPD patients [75]. Theophylline appears to have an effect on HDAC both in vivo and in vitro, though only at low concentrations, 10-100 times lower than those given for the bronchodilatory effects [69]. Nevertheless, since it was found that the health status of COPD patients deteriorated after discontinuing theophylline treatment, it is often still prescribed in addition to corticosteroids and $\beta 2$-agonists [76-78].

\section{AIM AND OUTLINE OF THIS THESIS}

The hypothesis of this $\mathrm{PhD}$ research described in this thesis is that dietary mild PARP-1 inhibitors are able to attenuate NF- $\mathrm{kB}$ mediated gene-expression and therefore may have beneficial effects in chronic inflammatory diseases such as COPD.

The aims of the project described in this thesis were:

1) to identify PARP-1 inhibiting food compounds using the purified PARP-1 enzyme

2) to evaluate the PARP-1 inhibiting effects of these compounds in vitro in cultured pulmonary epithelial cells and vascular endothelial cells and, furthermore, to investigate the effect of these PARP-1 inhibiting compounds on oxidative stress-induced necrotic cell death and LPS-induced inflammation in these cultured cells

3) to study the effects of the oral administration of dietary PARP-1 inhibitors in 
a mouse model of LPS-induced acute pulmonary inflammation

4) to study the ex vivo anti-inflammatory effects of a dietary PARP-1 inhibitor in LPS-stimulated blood of COPD patients and healthy control subjects

These resulted in research that is described in the following chapters. In chapter 2, the results are presented of the in vitro identification and evaluation of caffeine metabolites as PARP-1 inhibitors. Also, the effects of these compounds on oxidative stress-induced depletion of intracellular $\mathrm{NAD}^{+}$-levels and necrotic cell death in cultured epithelial and endothelial cells are presented in this chapter.

In chapter 3, it is described how various flavonoids were evaluated in vitro for their PARP-1 inhibiting activity using the purified enzyme. Furthermore, selected PARP-1 inhibiting flavonoids were further investigated for their PARP-1 inhibiting effects in $\mathrm{N}$-methyl- $\mathrm{N}^{\prime}$-nitro-N-nitrosoguanidine (MNNG)-exposed cultured pulmonary epithelial cells. Also, the effect of these flavonoids on NF$\kappa \mathrm{B}$ mediated production of interleukin (IL)-8 is presented.

In chapter 4 the in vitro effects of the PARP-1 inhibiting flavonoid flavone on $\mathrm{NF}-\kappa \mathrm{B}$ mediated gene-expression in LPS-stimulated pulmonary epithelial cells are dealt with.

Chapter 5 describes an in vivo study in which PARP-1 inhibiting flavonoids are applied in a mouse model of LPS-induced acute pulmonary inflammation. Also, these food-derived compounds were compared to the anti-inflammatory steroid drug dexamethasone.

In chapter 6, results of the in vivo application and evaluation of the PARP-1 inhibitor 1,7-dimethylxanthine in a mouse model of LPS-induced acute pulmonary inflammation are presented. The ex vivo effects of 1,7-dimethylxanthine on inflammation in LPS-stimulated blood of COPD patients and healthy subjects are described in this chapter as well.

In Chapter 7 the present findings together with their potential implications are discussed. 



\section{CHAPTER 2}

\section{Caffeine metabolites are inhibitors of the nuclear enzyme poly(ADP-ribose) polymerase- 1 at physiological concentrations}

Biochemical Pharmacology 2006, 72, 902-910

Liesbeth Geraets

Harald JJ Moonen Emiel FM Wouters

Aalt Bast

Geja J Hageman 


\section{ABSTRACT}

The activity of the nuclear enzyme poly(ADP-ribose) polymerase-1 (PARP-1) (E.C.2.4.2.30), which is highly activated by DNA strand breaks, is associated with the pathophysiology of both acute as well as chronic inflammatory diseases. PARP-1 overactivation and the subsequent extensive turnover of its substrate $\mathrm{NAD}^{+}$put a large demand on mitochondrial ATP-production. Furthermore, due to its reported role in nuclear factor kappa $\mathrm{B}(\mathrm{NF}-\mathrm{\kappa B})$ and activator protein-1 (AP-1) mediated production of pro-inflammatory cytokines, PARP-1 is considered an interesting target in the treatment of these diseases.

In this study the PARP- 1 inhibiting capacity of caffeine and several metabolites as well as other (methyl)xanthines was tested using an ELISA-assay with purified human PARP-1. Caffeine itself showed only weak PARP-1 inhibiting activity, whereas the caffeine metabolites 1,7-dimethylxanthine, 3-methylxanthine and 1-methylxanthine, as well as theobromine and theophylline showed significant PARP-1 inhibiting activity. Further evaluation of these compounds in $\mathrm{H}_{2} \mathrm{O}_{2}$ treated A549 lung epithelial and RF24 vascular endothelial cells revealed that the decrease in $\mathrm{NAD}^{+}$-levels as well as the formation of the poly(ADP-ribose) polymer was significantly prevented by the major caffeine metabolite 1,7dimethylxanthine. Furthermore, $\mathrm{H}_{2} \mathrm{O}_{2}$-induced necrosis could be prevented by a high dose of 1,7-dimethylxanthine. Finally, antioxidant effects of the methylxanthines could be ruled out with ESR and measurement of the TEAC.

Concluding, caffeine metabolites are inhibitors of PARP-1 and the major caffeine metabolite 1,7-dimethylxanthine has significant PARP-1 inhibiting activity in cultured epithelial and endothelial cells at physiological concentrations. This inhibition could have important implications for nutritional treatment of acute and chronic inflammatory pathologies, like prevention of ischemia-reperfusion injury or vascular complications in diabetes. 


\section{INTRODUCTION}

Poly(ADP-ribose) polymerase-1 (PARP-1, E.C.2.4.2.30), a nuclear enzyme present in eukaryotes, is highly activated upon induction of DNA strand breaks and activation results in the hydrolysis of $\mathrm{NAD}^{+}$to form poly(ADP-ribose) polymers and nicotinamide. PARP-1 has various physiological functions; it is involved in base excision repair (BER), which was indicated by delayed repair in PARP-1 knockout mice and by interaction of PARP-1 with other members of the BER-machinery like XRCC1 and DNA polymerase $[6,7]$. PARP-1 is also a regulator of transcriptional activity, for instance, PARP-1 is reported to play a role in nuclear factor kappa $\mathrm{B}(\mathrm{NF}-\mathrm{\kappa} \mathrm{B})$ and activator protein-1 (AP-1) mediated production of pro-inflammatory cytokines [17, 23, 24, 79-82].

The activity of PARP-1 is associated with the pathophysiology of acute inflammatory diseases like stroke and ischemia-reperfusion and also with chronic inflammation in diabetes and with pulmonary diseases such as chronic obstructive pulmonary disease (COPD) [29, 30, 83, 84]. PARP-1 overactivation, as a result of ROS-induced DNA damage, and the subsequent extensive turnover of its substrate $\mathrm{NAD}^{+}$puts a large demand on mitochondrial ATPproduction and cellular energy status [85]. This can result in an energy crisis and lead to a necrotic cell death [86]. PARP-1 is therefore considered an interesting target in the treatment of these diseases. Many potent synthetic PARP-1 inhibitors have been developed during the last years, but several studies showed that food components also have PARP-1 inhibiting activity [27, 39, 40, 87, 88]. These involve the methylxanthine theophylline (1,3dimethylxanthine, 13X), which has been reported to have PARP-1 inhibiting activity [89]. Theophylline is one of the major metabolites of caffeine (1,3,7trimethylxanthine), which is present in cocoa and beverages like coffee, tea and cola, and is extensively metabolized in the human body after oral intake. Caffeine is demethylated by the hepatic enzyme cytochrome P4501A2 (CYP1A2) to its major metabolites 1,7-dimethylxanthine (paraxanthine, 17X), theobromine (3,7-dimethylxanthine, 37X) and theophylline. Further demethylation of 1,7-dimethylxanthine by CYP1A2 results mainly in the formation of 1 methylxanthine (1X) and 1-methyl uric acid (1U). 3-Methylxanthine (3X) is formed after demethylation of theobromine and theophylline [66, 67].

The aim of this study was to test caffeine and several metabolites as well as other (methyl)xanthines (Figure 1) as possible inhibitors of PARP-1. First, the PARP-1 inhibitory activity of the compounds was tested using an assay with the purified enzyme. Second, the effect of the PARP-1 inhibitors on hydrogen peroxide $\left(\mathrm{H}_{2} \mathrm{O}_{2}\right)$-induced $\mathrm{NAD}^{+}$-depletion and necrosis was tested in vitro in cultured pulmonary epithelial and vascular endothelial cells. 
<smiles>O=c1[nH]c(=O)c2nc[nH]c2[nH]1</smiles>

xanthine<smiles>O=c1[nH]cnc2[nH]cnc12</smiles>

hypoxanthine<smiles>Cn1c(=O)[nH]c2[nH]cnc2c1=O</smiles>

1-methylxanthine (1X)<smiles>Cn1c(=O)[nH]c2[nH]c(=O)[nH]c2c1=O</smiles>

1-methyl uric acid (1U)<smiles>Cn1c(=O)[nH]c(=O)c2[nH]cnc21</smiles>

3-methylxanthine

(3X)<smiles>Cc1nc2[nH]c(=O)[nH]c(=O)c2[nH]c1=O</smiles>

7-methylxanthine 8-methylxanthine 1,3-dimethylxanthine 1,7-dimethylxanthine (7X) $(8 X)$ (theophylline; 13X) (paraxanthine; 17X)

1,7-dimethyl uric acid $(17 \mathrm{U})$<smiles>Cn1c(=O)c2c(ncn2CCO)n(C)c1=O</smiles>

3,7-dimethylxanthine 7-(2-hydroxyethyl)(theobromine; 37X)

$$
\text { theophylline }
$$
(biophylline)<smiles>Cn1c(=O)c2c(ncn2C)n(C)c1=O</smiles><smiles>OCC1OC2(n3cnc4c(O)ncnc43)CC1C(O)C2O</smiles>

1,3,7-trimethylxanthine inosine (caffeine; 137X)

Figure 1. Molecular structure of the tested compounds

\section{MATERIAL AND METHODS}

\section{Materials}

Caffeine, xanthine, 1-methylxanthine, 3-methylxanthine, 7-methylxanthine, 8methylxanthine, 1,7-dimethylxanthine, 1-methyluric acid, 1,7-dimethyluric acid, theophylline, theobromine, hypoxanthine, inosine, tween 20, acetic acid, 3,3',5,5'-tetramethylbenzidine, $\mathrm{H}_{2} \mathrm{O}_{2}$, bovine serum albumine (BSA), heparin, Dulbecco's Modified Eagle's Medium (DMEM), propidium iodide, trolox and 2,2'-azinobis(3-ethylbenzthiazoline-6-sulfonic acid) (ABTS) were all obtained from Sigma (St. Louis, MO, USA). Biofylline, $\beta-N A D^{+}$and 1,4 -dithiothreitol (DTT) were obtained from MP Biomedicals (Irvine, CA, USA). Human rPARP-1 and biotinylated $\mathrm{NAD}^{+}$were purchased from Trevigen (Gaithersburg, MD, USA). F-12K Nutrient Mixture (Kaighn's Modification), fetal bovine serum, glutamate, trypsin, Penicillin/Streptomycin and HBSS were all obtained from Invitrogen Life Technologies (Grand Island, NY, USA). Peroxidase-labeled streptavidin was purchased from Zymed (San Francisco, CA, USA). DMPO and 
$\mathrm{FeSO}_{4}$ were obtained from Merck (Darmstadt, Germany). Polyvinylchloride microtiter plates and endothelial cell growth supplement were obtained from BD Biosciences (San Jose, CA, USA). 2,2'-Azino-bis(2-amidinopropane) dihydrochloride (ABAP) was obtained from Brunschwig Chemicals (Amsterdam, the Netherlands). The $10 \mathrm{H}$ hybridoma was kindly provided by Dr. M. Miwa, via Riken Cell Bank, Tsukuba Institute BioResource Center (Ibaraki, Japan). The cell supernatant containing mouse monoclonal anti-PAR polymer antibody $10 \mathrm{H}$ was produced by Dr. W. Buurman (University of Maastricht, Maastricht, the Netherlands). Polyclonal goat anti-mouse immunoglobulin/FITC and fluorescent mounting medium were obtained from DAKO (Glostrup, Denmark). The ApoGlow kit was obtained from Cambrex (Verviers, Belgium).

\section{PARP-1 inhibition ELISA}

The capacity of the compounds to inhibit PARP-1 was first determined using an inhibition assay, as described by Decker et al. [90] and Brown and Marala [91] with minor modifications. In short, human rPARP was incubated with a reaction mixture containing $50 \mu \mathrm{M} \beta-\mathrm{NAD}^{+}\left(10 \%\right.$ biotinylated $\beta-\mathrm{NAD}^{+}, 90 \%$ unlabelled $\left.\beta-\mathrm{NAD}^{+}\right), 1 \mathrm{mM}$ DTT and $1.25 \mu \mathrm{g} / \mathrm{ml}$ nicked DNA. Nicked DNA was prepared as follows, according to the method of Aposhian et al [92] with some minor modifications: Calf thymus DNA was incubated with $10 \mathrm{ng} / \mathrm{ml}$ DNase I at $37^{\circ} \mathrm{C}$ during 40 minutes. The length of the DNA-fragments (500 bp) was estimated using gel electrophoresis.

To determine the optimal substrate concentration and incubation temperature for the PARP-1 assay, human rPARP-1 was incubated with various concentrations $\beta-\mathrm{NAD}^{+}\left(0-150 \mu \mathrm{M} ; 10 \%\right.$ biotinylated $\beta-\mathrm{NAD}^{+}, 90 \%$ unlabelled $\left.\beta-\mathrm{NAD}^{+}\right)$ at two different temperatures $\left(4-37^{\circ} \mathrm{C}\right.$; Figure 2$)$.

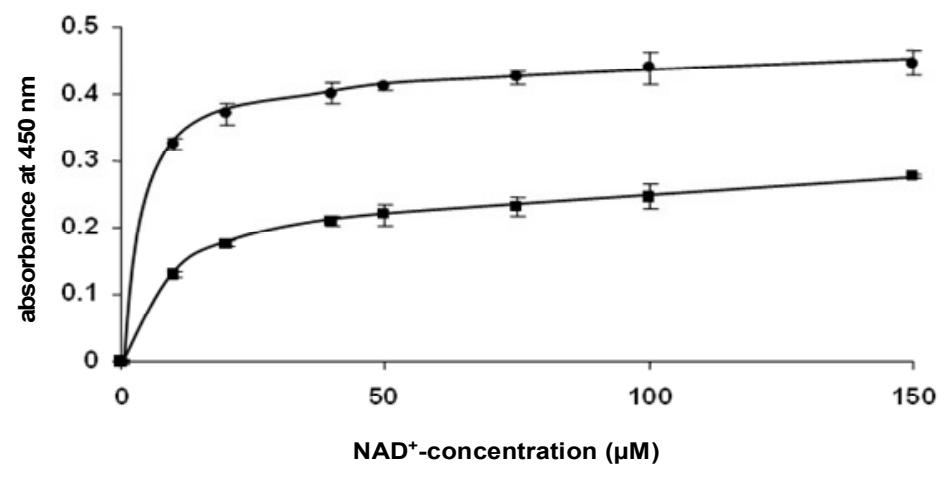

Figure 2. PARP-1 activity expressed as absorbance at $450 \mathrm{~nm}$ after incubating $400 \mathrm{ng} / \mathrm{ml}$ human rPARP-1 for one hour in the presence of various concentrations $\beta-\mathrm{NAD}^{+}, 1 \mathrm{mM}$ DTT and 1.25 $\mu \mathrm{g} / \mathrm{ml}$ nicked DNA at $4^{\circ} \mathrm{C}(\bullet)$ and $37^{\circ} \mathrm{C}(\mathbf{\bullet})$. 
Based on this optimization, rPARP-1 was incubated with $50 \mu \mathrm{M} \beta-\mathrm{NAD}^{+}$at $4^{\circ} \mathrm{C}$. Using these conditions, $100 \mu \mathrm{M} 3$-aminobenzamide and nicotinamide were used as positive controls and inhibited the enzyme $85.1 \pm 0.9$ and $73.5 \pm$ $3.6 \%$, respectively. To determine background activity, the enzyme was also incubated with a reaction mixture without $\beta-\mathrm{NAD}^{+}$.

After incubations with the reaction mixture, the plates were washed and the formation of poly(ADP-ribose) polymers was detected after a one hour incubation at room temperature with peroxidase-labeled streptavidin, followed by a 15 min incubation with 3,3',5,5'-tetramethylbenzidine (TMB) in the presence of $\mathrm{H}_{2} \mathrm{O}_{2}$ at $37^{\circ} \mathrm{C}$. This reaction was stopped by adding $0.75 \mathrm{M} \mathrm{HCl}$ and the absorbance was measured at $450 \mathrm{~nm}$. PARP-1 inhibition of several compounds was evaluated by addition of these compounds to the reaction mixture. Measurements were done in 3-fold.

\section{Cell culture}

A549 human lung epithelial cells were grown at $37^{\circ} \mathrm{C}$ in a humidified $5 \% \mathrm{CO}_{2}$ atmosphere and were cultured in Dulbecco's Modified Eagles Medium (DMEM) with $4.5 \mathrm{~g} / \mathrm{L}$ glucose, 10\% fetal bovine serum (FBS), $2 \mathrm{mM}$ glutamine and 50 units $/ \mathrm{ml}$ of penicillin and $50 \mu \mathrm{g} / \mathrm{ml}$ of streptomycin. RF24 human vascular endothelial cells were grown at $37^{\circ} \mathrm{C}$ in a humidified $5 \% \mathrm{CO}_{2}$ atmosphere in gelatine-coated culture flasks and were cultured in $\mathrm{F}-12 \mathrm{~K}$ Nutrient Mixture (Kaighn's Modification) supplemented with $10 \%$ fetal bovine serum, $0.1 \mathrm{mg} / \mathrm{ml}$ heparin and 50 units $/ \mathrm{ml}$ of penicillin and $50 \mu \mathrm{g} / \mathrm{ml}$ of streptomycin. During culturing at low densities, the medium was supplemented with $0.015 \mathrm{mg} / \mathrm{ml}$ endothelial cell growth supplement.

\section{Cellular NAD ${ }^{+}$assay}

Cells were plated in a 96-wells plate (approximately $3 \times 10^{4}$ cells/well) and cultured for $24 \mathrm{~h}$ before exposure. $\mathrm{H}_{2} \mathrm{O}_{2}$ was used to induce DNA strand breaks, activate PARP-1 and deplete cellular NAD ${ }^{+}$levels. To determine the optimal $\mathrm{H}_{2} \mathrm{O}_{2}$-concentration and incubation period for the cells, cells were first treated with different concentrations $\mathrm{H}_{2} \mathrm{O}_{2}(0-300 \mu \mathrm{M})$ for different periods of time (0-60 minutes), as previously described [89]. Maximal decreases in NAD ${ }^{+}$ levels in both A549 and RF24 cells were reached after treatment with $300 \mu \mathrm{M}$ $\mathrm{H}_{2} \mathrm{O}_{2}$ during 30 minutes. The PARP-1 inhibitor 3-aminobenzamide strongly prevented the decrease in $\mathrm{NAD}^{+}$-levels and served in all the experiments as a positive control. During the experiments, cells were preexposed to the methylxanthines for $15 \mathrm{~min}$ and subsequently exposed to $300 \mu \mathrm{M} \mathrm{H} \mathrm{H}_{2} \mathrm{O}_{2}$ and the methylxanthines for $30 \mathrm{~min}$. The maximal DMSO-concentration was $0.1 \%$ and was also used as a control. After the exposure, the cells were lysed in ethanol (50 $\mathrm{\mu l} /$ well) and stored at $-80^{\circ} \mathrm{C}$. During this lysis, $20 \mathrm{mM}$ isonicotinic acid hydrazine was used to inhibit NAD-glycohydrolase and to prevent $\mathrm{NAD}^{+}$- 
hydrolysis [93]. After lysing the cells, intracellular NAD ${ }^{+}$was determined using the $\mathrm{NAD}^{+}$-cycling method, as described by Jacobson and Jacobson [94] with minor modifications. After thawing and lysis of the cells, $100 \mu$ reaction mixture without ethanol was added to the wells. The final reaction mixture in the microtiter plate contained $2.86 \mathrm{M}$ ethanol, $114 \mathrm{mM}$ bicine, $4.8 \mathrm{mM}$ EDTA, $0.95 \mathrm{mg} / \mathrm{ml} \mathrm{BSA}, 47.6 \mathrm{mg} / \mathrm{ml}$ alcohol dehydrogenase, $1.9 \mathrm{mM}$ phenazine ethosulphate and $0.48 \mathrm{mM}$ MTT. The reaction was measured in time spectrophotometrically at $540 \mathrm{~nm}$ at $37^{\circ} \mathrm{C}$ during 15 minutes. A standard curve $(0-1.5$ $\mu M)$ was included to calculate the $\mathrm{NAD}^{+}$-levels in the cells. The calculated $\mathrm{NAD}^{+}$-levels for each experiment were average values of at least 4 measurements.

\section{Immunofluorescent staining of PAR-polymers}

To determine the effect of 1,7-dimethylxanthine on the formation of the PARpolymer, A549 cells (approximately $0.8 \times 10^{6}$ cells/well in 6-wellsplate) were 15 min pretreated with 1,7-dimethylxanthine and thereafter treated with $\mathrm{H}_{2} \mathrm{O}_{2}$ for 5 min. After the incubation, the cells were trypsinized, washed with PBS and fixed in methanol. After fixation, cells were stained as described by Hageman et al. [30] with some modifications. Fixed cells were washed with $0.1 \%$ BSA in PBS and incubated with $100 \mu \mathrm{l}$ mouse monoclonal anti-PAR polymer antibody $10 \mathrm{H}$ for one hour at room temperature. After washing with $0.1 \% \mathrm{BSA}$, the cells were incubated with $100 \mu$ polyclonal goat anti-mouse immunoglobulin/FITC for one hour at room temperature. After washing again with $0.1 \%$ BSA, the cells were incubated for 15 minutes with $200 \mu \mathrm{l} 20 \mu \mathrm{g} / \mathrm{ml}$ propidium iodide. Cells were transferred to slides and were mounted with fluorescent mounting medium. At least 100 cells per slide were evaluated for the presence of PAR polymers in their nucleus using fluorescence microscopy and Lucia GF 4.80 software. Subsequently, the percentage of PAR polymer positive cells was calculated.

\section{Measurement of the ADP:ATP ratio}

To determine the effect of 1,7-dimethylxanthine on $\mathrm{H}_{2} \mathrm{O}_{2}$-induced cell death, A549 and RF24 cells (approximately $3 \times 10^{4}$ cells/well in 96-wellsplate) were 30 min pretreated with 1,7-dimethylxanthine and thereafter treated with $\mathrm{H}_{2} \mathrm{O}_{2}$ for 8 hours. After one hour incubation with $\mathrm{H}_{2} \mathrm{O}_{2}$ at $37^{\circ} \mathrm{C}$, FBS was supplied to a $10 \%$ final concentration and cells were incubated for additional 7 hours. After the incubation, the ADP:ATP ratio was determined using the ApoGlow kit. The assay is based on the bioluminescent measurement of the adenylate nucleotides and can be used to determine the mode of cell death [95]. After 8 hours incubation, cells were lysed and processed for ATP and ADP measurements according to the instruction manual. 


\section{Electron spin resonance spectroscopy}

Electron spin resonance (ESR) studies were performed at room temperature using a Bruker EMX 1273 spectrometer equipped with an ER 4119HS high sensitivity cavity and $12 \mathrm{~kW}$ power supply operating at $\mathrm{X}$ band frequencies. The following instrument conditions were used: scan range, $60 \mathrm{G}$; center magnetic field, $3490 \mathrm{G}$; modulation amplitude, $1.0 \mathrm{G}$; microwave power, 50 $\mathrm{mW}$; receiver gain, $10^{5}$; modulation frequency, $100 \mathrm{KHz}$; microwave frequency, $9.85 \mathrm{GHz}$; time constant, $40.96 \mathrm{~ms}$; scan time, $20.97 \mathrm{~s}$; number of scans, 25. 5,5-Dimethyl-1-pyrroline N-oxide (DMPO) was used for trapping hydroxyl radicals and was purified in nitrogen flushed milli $\mathrm{Q}$ water by mixing with $30 \mathrm{mg} / \mathrm{ml}$ charcoal during $20 \mathrm{~min}$ at $35^{\circ} \mathrm{C}$. This procedure was used three times to remove background ESR signals. Finally, the concentration of DMPO was determined spectrophotometrically at $234 \mathrm{~nm}$. Incubation mixtures (total volume $200 \mu \mathrm{l})$ consisted of $\mathrm{FeSO}_{4}(0.5 \mathrm{mM}), \mathrm{H}_{2} \mathrm{O}_{2}(0.55 \mathrm{mM})$ and DMPO (100 $\mathrm{mM})$ in the absence or presence of methylxanthines $(100 \mu \mathrm{M})$. Quercetin was used as a positive control. ESR spectra were recorded using $100 \mu \mathrm{l}$ capillary glass tubes. Quantitation of the spectra (in arbitrary units) was performed by peak integration using the WIN-EPR spectrum manipulation program.

\section{TEAC assay}

The TEAC assay (Trolox Equivalent Antioxidant Capacity assay) was used to test the total radical scavenging capacity of the compounds. This assay is based on the ability of a compound to scavenge the stable ABTS radical $\left(\mathrm{ABTS} \bullet^{+}\right)$. The blue-green $\mathrm{ABTS} \bullet{ }^{+}$was produced through the reaction between $0.36 \mathrm{mM}$ ABTS and $1.84 \mathrm{mM} \mathrm{ABAP}$ in $145 \mathrm{mM}$ sodium phosphate buffer, $\mathrm{pH} 7.4$, at $70^{\circ} \mathrm{C}$ until the absorption of the solution reached $0.70 \pm 0.02$ at $734 \mathrm{~nm}$. In the assay, $50 \mu \mathrm{l}$ of the tested compounds was added to $950 \mu \mathrm{l}$ of the ABTS $\bullet$ solution. The reduction in absorbance at $734 \mathrm{~nm}$ was measured in time for 5 min and was compared to a blank where $50 \mu$ l of the solvent was added to 950 $\mu \mathrm{l}$ of $\mathrm{ABTS} \bullet^{+}$solution. A calibration curve was constructed using different concentrations of the synthetic antioxidant trolox $(0-20 \mu \mathrm{M})$. Uric acid was used as a positive control. The TEAC value of the methylxanthines was defined as the concentration $(\mathrm{mM})$ of trolox having an antioxidant capacity equivalent to $1 \mathrm{mM}$ methylxanthine.

\section{RESULTS}

\section{Enzyme assay}

To asses the effect of the methylxanthines on PARP-1 activity, purified rPARP-1 was incubated with various methylxanthines. In Table 1 data are shown of PARP-1 inhibition by the various methylxanthines $(100 \mu \mathrm{M})$. 
Table 1 Percentage PARP-1 inhibition and $\mathrm{IC}_{50}$ values of the tested compounds.

\begin{tabular}{lll}
\hline Compound & $\begin{array}{l}\% \text { inhibition } \\
(100 \mu \mathrm{M})\end{array}$ & $\mathrm{IC} 50(\mu \mathrm{M})$ \\
\hline xanthine & $\mathrm{n} . \mathrm{i}$. & $\mathrm{n} . \mathrm{d}$. \\
hypoxanthine & $16.2 \pm 6.2$ & $>200$ \\
1-methylxanthine & $46.2 \pm 0.0$ & $145.0 \pm 2.8$ \\
1-methyl uric acid & n.i. & n.d. \\
3-methylxanthine & $49.6 \pm 4.3$ & $115.2 \pm 11.2$ \\
7-methylxanthine & $24.5 \pm 4.2$ & $172.3 \pm 3.4$ \\
8-methylxanthine & $18.5 \pm 4.1$ & $>200$ \\
theophylline & $43.2 \pm 2.0$ & $194.8 \pm 23.3$ \\
1,7-dimethylxanthine & $68.5 \pm 1.2$ & $15.0 \pm 0.97$ \\
1,7-dimethyl uric acid & n.i. & n.d. \\
theobromine & $40.5 \pm 1.3$ & $160.2 \pm 0.5$ \\
biophylline & $10.8 \pm 5.5$ & $>200$ \\
caffeine & $8.0 \pm 4.7$ & $>200$ \\
inosine & n.i. & n.d. \\
\hline
\end{tabular}

n.i.= no inhibition

n.d.=not determined

PARP-1 activity was measured after incubating $400 \mathrm{ng} / \mathrm{ml}$ human rPARP-1 for one hour in the presence of $50 \mu \mathrm{M} \beta-\mathrm{NAD}^{+}, 1 \mathrm{mM}$ DTT and $1.25 \mu \mathrm{g} / \mathrm{ml}$ nicked DNA at $4^{\circ} \mathrm{C}$. Values are presented as averages \pm SE of 2 replicate experiments with $n=3$ measurements. These results reveal 1,7-dimethylxanthine to be a very potent inhibitor of PARP-1 (68.5 $\pm 1.2 \%)$. The 1-, 3-, 7-, 1,3- and 3,7methylated xanthines (1-methylxanthine, 3-methylxanthine, 7-methylxanthine, theophylline and theobromine, respectively) moderately inhibited PARP-1. Xanthine, 1-methyl uric acid, 1,7-dimethyl uric acid and inosine showed no inhibition at all. The parent compound 1,3,7-trimethylxanthine (caffeine) showed only a very weak inhibition. For methylxanthines that inhibited PARP-1 activity more than $50 \%$ at the tested concentrations, an $\mathrm{IC}_{50}$ was determined (Table 1). The strongest PARP-1 inhibitor was found to be 1,7-dimethylxanthine with an $\mathrm{IC}_{50}$ of $15.0 \mu \mathrm{M}$. Other $\mathrm{IC}_{50}$ were 115.2, 145.0, 160.2, 172.3 and 194.8 $\mu \mathrm{M}$ for 3-methylxanthine, 1-methylxanthine, theobromine, 7-methylxanthine and theophylline, respectively.

\section{NAD ${ }^{+}$-levels}

Methylxanthines, which showed PARP-1 inhibition in the enzyme-assay $\left(\mathrm{IC}_{50}<200 \mu \mathrm{M}\right)$, were also screened for their effect on $\mathrm{NAD}^{+}$-levels in $\mathrm{H}_{2} \mathrm{O}_{2}$ treated A549 cells. Also, the parent compound caffeine was further evaluated in the A549 cells. The $\mathrm{H}_{2} \mathrm{O}_{2}$-induced depletion of the intracellular NAD ${ }^{+}$-stores was used as a measure of PARP-1 activation. In the A549 cells, pre-incubation with $100 \mu \mathrm{M}$ 3-methylxanthine and 1,7-dimethylxanthine resulted in significantly higher NAD+-levels, when compared to cells treated with $300 \mu \mathrm{M} \mathrm{H}_{2} \mathrm{O}_{2}$ (Figure 3). 


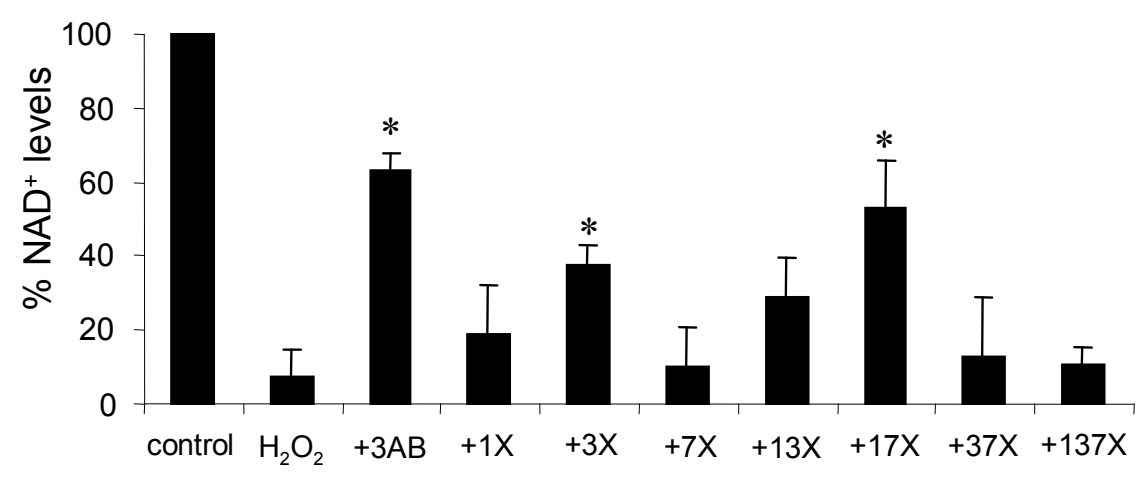

Figure 3. $\mathrm{NAD}^{+}$levels in $\mathrm{A} 549$ human pulmonary epithelial cells after 30 min incubation with 300 $\mu \mathrm{M} \mathrm{H}_{2} \mathrm{O}_{2}$ with or without 15 min pretreatment with $100 \mu \mathrm{M}$ of the indicated methylxanthines or 3aminobenzamide (3AB). Values are expressed as \% of control incubation (without $\mathrm{H}_{2} \mathrm{O}_{2}$ ) and are averages \pm SE of at least 2 replicate experiments with $n=4$ measurements.

* indicates a statistically significant difference according to Student's t-test $(\mathrm{P}<0.05)$ as compared to incubation with $\mathrm{H}_{2} \mathrm{O}_{2}$ without methylxanthines or 3-aminobenzamide

To further evaluate the PARP-1 inhibiting activity of 1,7-dimethylxanthine, both A549 and RF24 cells were exposed for 30 minutes to $300 \mu \mathrm{M} \mathrm{H}_{2} \mathrm{O}_{2}$ after preincubating for 15 minutes with different concentrations 1,7-dimethylxanthine (Figure 4). In these cells, 1,7-dimethylxanthine significantly prevented the $\mathrm{H}_{2} \mathrm{O}_{2}$-induced decrease in $\mathrm{NAD}^{+}$-levels in a dose-dependent manner.

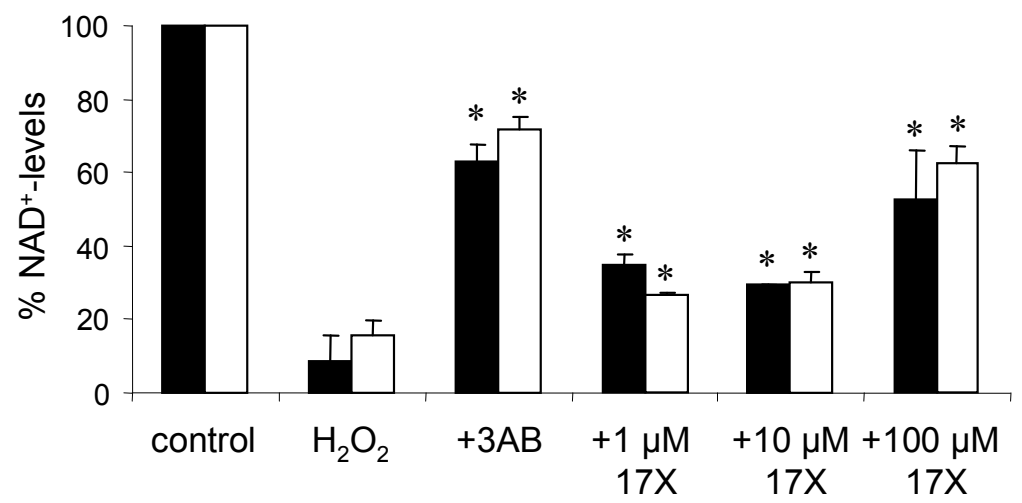

Figure 4. $\mathrm{NAD}^{+}$levels in $\mathrm{A} 549$ human pulmonary epithelial (black bars) and RF24 human vascular endothelial cells (white bars) after 30 min incubation with $300 \mu \mathrm{M} \mathrm{H}_{2} \mathrm{O}_{2}$ with or without 15 min pretreatment with 1, 10 and $100 \mu \mathrm{M}$ 1,7-dimethylxanthine (17X) or $100 \mu \mathrm{M}$ 3-aminobenzamide (3AB). Values are expressed as \% of control incubation (without $\mathrm{H}_{2} \mathrm{O}_{2}$ ) and are averages $\pm \mathrm{SE}$ of at least 2 replicate experiments with $n=4$ measurements.

* indicates a statistically significant difference according to Student's t-test $(\mathrm{P}<0.05)$ as compared to incubation with $\mathrm{H}_{2} \mathrm{O}_{2}$ without 1,7-dimethylxanthine or 3-aminobenzamide 


\section{PAR-polymer formation}

To further confirm the PARP-1 inhibiting activity of 1,7-dimethylxanthine, A549 cells were exposed to $300 \mu \mathrm{M} \mathrm{H}_{2} \mathrm{O}_{2}$ for 5 minutes after pre-incubating for 15 minutes with 1,7-dimethylxanthine (Figure 5). A significantly decreased number of PAR-polymer positive cells was observed after incubation with $100 \mu \mathrm{M} 1$,7dimethylxanthine, confirming the results of the enzyme assay and the NAD ${ }^{+}$ measurements.

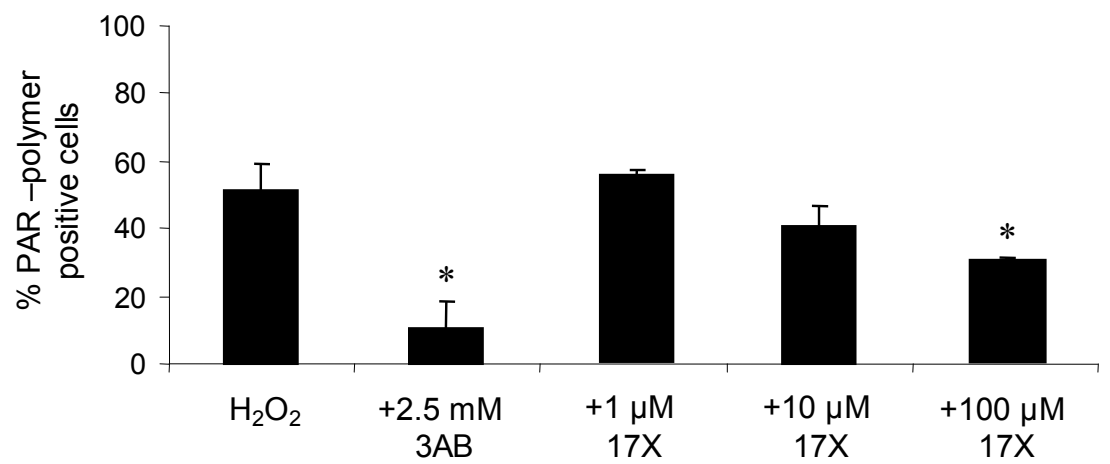

Figure 5. Percentage of PAR-polymer positive A549 cells after 5 min incubation with $300 \mu \mathrm{M} \mathrm{H}_{2} \mathrm{O}_{2}$ with or without 15 min pretreatment with 1, 10 and $100 \mu \mathrm{M}$ 1,7-dimethylxanthine (17X) or $2.5 \mathrm{mM}$ 3 -aminobenzamide $(3 \mathrm{AB})$. Results are averages \pm SE of 2 replicate experiments with $n=2$ measurements.

* indicates a statistically significant difference according to Student's t-test $(\mathrm{P}<0.05)$ as compared to incubation with $\mathrm{H}_{2} \mathrm{O}_{2}$ without 1,7-dimethylxanthine or 3-aminobenzamide

\section{ADP:ATP ratio}

To investigate the effect of 1,7-dimethylxanthine on $\mathrm{H}_{2} \mathrm{O}_{2}$-induced cell death, the ADP:ATP ratio was determined. ADP:ATP ratios for cells undergoing apoptosis are expected to be higher than control values but below 1 , while much higher values characterize necrotic cells [95]. Incubation of both the epithelial and the endothelial cells with $10 \mathrm{mM} \mathrm{H}_{2} \mathrm{O}_{2}$ increased the ADP:ATP ratio to values of $2.1 \pm 0.4$ and $9.1 \pm 0.8$ respectively, indicating necrotic cell death. Treatment of the cells with lower concentrations $\mathrm{H}_{2} \mathrm{O}_{2}$ failed to increase the ADP:ATP ratio. Pretreatment of epithelial and endothelial cells with $1 \mathrm{mM}$ 1,7-dimethylxanthine reduced necrosis, as shown by a statistically significant lower ADP:ATP ratio of $0.6 \pm 0.4$ and $2.0 \pm 0.8$ respectively (Figure 6). 


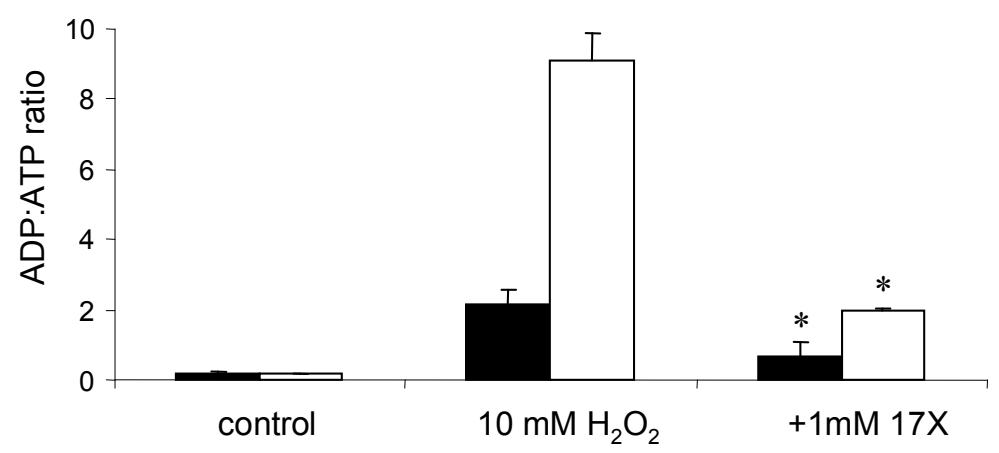

Figure 6. ADP:ATP ratio in A549 (black bars) and RF24 (white bars) cells after 8 hours incubation with $10 \mathrm{mM} \mathrm{H}_{2} \mathrm{O}_{2}$ with or without 30 min pretreatment with $1 \mathrm{mM} \mathrm{1,7-dimethylxanthine} \mathrm{(17X).}$ Results are averages \pm SE of 3 measurements.

* indicates a statistically significant difference according to Student's t-test $(\mathrm{P}<0.05)$ as compared to incubation with $\mathrm{H}_{2} \mathrm{O}_{2}$ without 1,7-dimethylxanthine

\section{Electron spin resonance spectroscopy}

To rule out antioxidant effects of the methylxanthines which were tested in the A549 and RF24 cells, scavenging of hydroxyl radicals was measured using ESR spectroscopy. First, hydroxyl radicals were generated by $\mathrm{H}_{2} \mathrm{O}_{2}$ in the presence of $\mathrm{FeSO}_{4}$. In combination with the spin-trap DMPO, stable DMPO-OH adducts were formed. Addition of the methylxanthines $(100 \mu \mathrm{M})$ did not decrease the observed DMPO-OH signal (Figure 7).

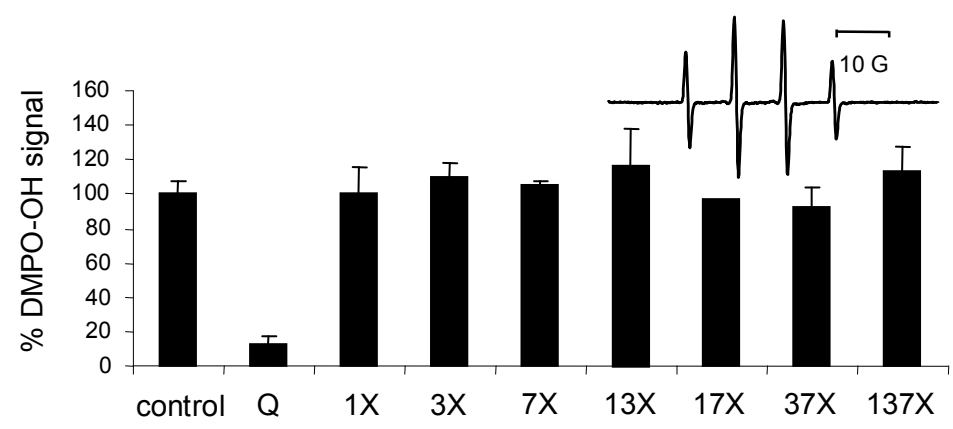

Figure 7. Hydroxyl radicals, generated by $\mathrm{FeSO}_{4}$ and $\mathrm{H}_{2} \mathrm{O}_{2}$, are not scavenged by $100 \mu \mathrm{M}$ methylxanthines. Values are expressed as \% of control $\left(\mathrm{FeSO}_{4}+\mathrm{H}_{2} \mathrm{O}_{2}+\mathrm{DMPO}\right)$ and are presented as averages \pm SE of duplicate measurements. $Q=$ quercetin $(100 \mu \mathrm{M})$. Insert: ESR spectrum for the hydroxyl radical spin adduct (DMPO-OH). 


\section{TEAC assay}

The total radical scavenging capacity of the methylxanthines was assessed using the TEAC assay. In Table 2 TEAC values of the methylxanthines are presented. The TEAC values are very low and negligible, which indicates that these methylxanthines do not have significant antioxidant effects.

Table 2. TEAC values for the methylxanthines.

\begin{tabular}{ll}
\hline Compound & TEAC \\
\hline 1-methylxanthine & $0.14 \pm 0.02$ \\
3-methylxanthine & $0.06 \pm 0.01$ \\
7-methylxanthine & $0.05 \pm 0.01$ \\
theophylline & $0.06 \pm 0.01$ \\
1,7-dimethylxanthine & $0.05 \pm 0.01$ \\
theobromine & $0.05 \pm 0.02$ \\
caffeine & $0.05 \pm 0.01$ \\
uric acid & $1.06 \pm 0.02$
\end{tabular}

Values are expressed as $\mathrm{mM}$ trolox equivalents for $1 \mathrm{mM}$ methylxanthine and are presented as average \pm S.E. of two duplicate measurements

\section{DISCUSSION}

The present study revealed that the major caffeine metabolite 1,7dimethylxanthine is a PARP-1 inhibitor and is more potent than the parent compound caffeine. The potency of caffeine, caffeine metabolites and other methylxanthines to inhibit PARP-1 was investigated using purified human rPARP-1 and cultured pulmonary epithelial and vascular endothelial cells. A previous study already reported that the methylxanthine theophylline can inhibit PARP-1 [89]. Results from our enzyme studies have shown that the major caffeine metabolite 1,7-dimethylxanthine is even more potent in inhibiting PARP-1. The parent compound caffeine showed only very weak inhibition in spite of its application as a PARP-1 inhibitor $[96,97]$. Other methylxanthines tested in this study, such as 1-methylxanthine and 3-methylxanthine, also inhibited the purified enzyme showing decreased formation of the PARpolymer, indicating a decreased consumption of the substrate $\mathrm{NAD}^{+}$. This decreased depletion of $\mathrm{NAD}^{+}$was also observed in cultured epithelial and endothelial cells treated with a high concentration of $\mathrm{H}_{2} \mathrm{O}_{2}$. In both cell lines, the inhibiting activity of 1,7-dimethylxanthine was demonstrated by higher $\mathrm{NAD}^{+}$-levels upon treatment with $\mathrm{H}_{2} \mathrm{O}_{2}$ in presence of this methylxanthine. Also, a significantly reduced number of PAR-polymer positive cells was detected after pre-incubation with 1,7-dimethylxanthine. Results from these cell studies confirm that PARP-1 is significantly inhibited by the major caffeine metabolite 1,7-dimethylxanthine. Also, the caffeine metabolite 3-methyl- 
xanthine prevented the decline in $\mathrm{NAD}^{+}$-levels in the A549 cells.

The presence of one or two methyl groups appears important for inhibition of the purified PARP-1 enzyme. The dimethylxanthine 1,7-dimethylxanthine clearly inhibited PARP-1 $\left(\mathrm{IC}_{50}: 15.0 \mu \mathrm{M}\right)$. Also 1-methylxanthine, 3methylxanthine, 7-methylxanthine, theophylline (1,3-dimethylxanthine) and theobromine (3,7-dimethylxanthine) inhibited PARP-1 ( $\mathrm{IC}_{50}$ : 145.0, 115.2, $172.3,184.8$ and $160.2 \mu \mathrm{M}$ respectively), in contrast to xanthine which did not show any PARP-1 inhibition. However, this inhibition appeared not dependent solely on the number or the position of the methyl groups. 1-Methylxanthine and 3-methylxanthine showed stronger inhibition when compared to the dimethylxanthines theophylline and theobromine. 1,7-Dimethylxanthine could inhibit the enzyme stronger than theophylline (1,3-dimethylxanthine), while 7-methylxanthine was less potent in inhibiting PARP-1 as compared to 3-methylxanthine. Furthermore, the trimethylxanthine caffeine showed very weak inhibition. The metabolites of 1-methylxanthine and 1,7-dimethylxanthine, 1-methyl uric acid and 1,7-dimethyl uric acid respectively, showed no inhibiting activity. Application of a Free-Wilson analysis could not indicate a strong association between specific methyl groups and inhibiting activity. In conclusion, no obvious structure-activity relationship with regard to the position of the methyl groups and PARP-1 inhibiting effects could be observed. The presence of a methyl group clearly increases the inhibiting potency of the xanthines, but the number of methyl groups also appears to be a limiting factor. Since the human body is exposed daily to oxygen radicals which can damage cells and tissues, treatment with hydrogen peroxide in this in vitro model is considered a physiologically relevant model of PARP-1 activation. Possible antioxidant activity of the methylxanthines, however, had to be ruled out, since the observed effects on cellular $\mathrm{NAD}^{+}$could be due to scavenging activity of the methylxanthines. Using ESR-spectroscopy and the TEAC assay, scavenging of (hydroxyl) radicals by the methylxanthines was determined. None of the methylxanthines tested showed any relevant radical scavenging activity at the concentrations used in the cell studies, suggesting that even at concentrations of 1 or $10 \mu \mathrm{M}$ the observed effects on the cellular $\mathrm{NAD}^{+}$-levels were most likely due to PARP-1 inhibition.

We showed that incubation of epithelial and endothelial cells with $10 \mathrm{mM}$ $\mathrm{H}_{2} \mathrm{O}_{2}$ for 8 hours induced necrotic cell death as indicated by a dramatically increased ADP:ATP ratio of approximately $2.1 \pm 0.4$ and $9.1 \pm 0.8$ respectively. Treatment of cells with 1,7-dimethylxanthine significantly reduced the ADP:ATP ratio. The $\mathrm{H}_{2} \mathrm{O}_{2}$ concentration used was rather high, but lower concentrations failed to significantly increase the ADP:ATP ratio in these cells (data not shown). After incubation with $1 \mathrm{mM}$ 1,7-dimethylxanthine, necrotic cell death was reduced and, in the epithelial cells, also a shift to apoptosis could be observed, indicated by decreased ADP:ATP ratio values between 
control values and 1. Several studies showed that PARP-1 activation is required for a necrotic type of cell death and that PARP-1 inhibition or PARP-1 gene deletion can prevent or reduce induction of necrosis $[37,86,98]$. These studies indicate that inhibition of PARP-1 could have therapeutic value in pathophysiology of diseases like ischemia-reperfusion injury or stroke. Complete inhibition of PARP-1 is not considered favourable, since PARP-1 has been demonstrated to be involved in repair of DNA damage [99, 100]. It is therefore thought advisable to have residual PARP-1 activity to allow for efficient repair of damaged DNA. Moderate inhibition of PARP-1 activation appears to be the best practice.

In diabetes, PARP-1 has been reported to be involved in the development of diabetic vascular dysfunction. Animal studies showed that, in PARP-1 knockout mice or in wildtype mice treated with PARP-1 inhibitors, the endothelial dysfunction was reversed [27, 83]. Also, the importance of PARP-1 in the process of beta-cell death has already been extensively studied [101]. Recently, a number of epidemiological studies showed a strong relation between intake of specific food components and risk for type 2 diabetes [102, 103]. In the study of Salazar-Martinez et al. [103], long term coffee consumption was associated with a lower risk for type 2 diabetes. In their study, also a high intake of caffeine was related to a decreased risk for type 2 diabetes [103]. They suggested that a possible mechanism for the observed inverse association could be the presence of antioxidants in coffee and their effect on glucose metabolism and insulin resistance. Since caffeine is extensively metabolized in the human body after oral intake, the formation of caffeine metabolites and the possible effect of these metabolites on the risk of diabetes should also be taken into account. Results of our study demonstrate that 1,7-dimethylxanthine, the major metabolite of caffeine, and not caffeine itself has clear PARP-1 inhibiting activity. By inhibiting PARP-1, this caffeine metabolite could reduce endothelial tissue damage and inflammatory processes, which are known features of diabetes [104, 105]. Even at concentrations as low as 10 and $1 \mu \mathrm{M}, 1,7-$ dimethylxanthine significantly prevented the $\mathrm{H}_{2} \mathrm{O}_{2}$-induced decrease in $\mathrm{NAD}^{+}$levels in both pulmonary epithelial and in vascular endothelial cells. These concentrations are considered to be physiological plasma levels. Tang-Liu et al. [66] reported that oral intake of caffeine in a dose representing moderate coffee intake (4 cups/day), resulted in maximal plasma levels of approximately $20 \mu \mathrm{M}$ 1,7-dimethylxanthine lasting for several hours after intake.

In conclusion, caffeine metabolites and in particular 1,7-dimethylxanthine have PARP-1 inhibiting activity at physiological concentrations. Inhibition of PARP-1 could have important implications for the development of vascular dysfunction and inflammation, processes which are observed in the progression of diabetes. Furthermore, PARP-1 inhibition is also shown to be relevant in other pathologies like ischemia-reperfusion, stroke and pulmonary inflammatory diseases 
such as COPD and asthma [26, 30, 37, 84]. It is therefore suggested that dietary PARP-1 inhibitors like the caffeine metabolite 1,7-dimethylxanthine may contribute to treatment or prevention of vascular complications in diabetes but also other pathologies like mild ischemia-reperfusion damage and stroke. 


\section{CHAPTER 3}

\section{Dietary flavones and flavonoles are inhibitors of poly(ADP-ribose) polymerase-1 in pulmonary epithelial cells}

Journal of Nutrition 2007, 137(10), 2190-2195

Liesbeth Geraets Harald JJ Moonen Karen Brauers Emiel FM Wouters Aalt Bast

Geja J Hageman 


\section{ABSTRACT}

The nuclear enzyme poly(ADP-ribose) polymerase-1 (PARP-1) which was initially known to be highly activated by oxidative stress-induced DNA strand breaks, has been shown to be involved in the pathophysiology of acute and chronic inflammatory diseases. PARP-1 deficiency in mice led to the discovery of its co-activating function in the nuclear factor-kappa $\mathrm{B}(\mathrm{NF}-\mathrm{\kappa B})$ mediated gene-expression, and in addition, pharmaceutical inhibition of PARP-1 was shown to reduce the production of inflammatory mediators. In this study, the in vitro PARP-1 inhibiting effect of various flavonoids was investigated. The flavonoids myricetin, tricetin, gossypetin, delphinidin, quercetin and fisetin were identified as significant inhibitors of the purified enzyme. Further evaluation of these compounds in MNNG-treated human pulmonary epithelial cells showed that the formation of the PAR-polymers, as well as the decrease in $\mathrm{NAD}^{+}$-levels was reduced by quercetin, fisetin and tricetin. Finally, interleukin (IL)-8 production of lipopolysaccharide (LPS)-stimulated human pulmonary epithelial cells could be significantly reduced by these flavonoids. The results of this study indicate that specific flavonoids have PARP- 1 inhibiting activity in addition to the earlier described antioxidant effects. PARP-1 inhibition and preservation of cellular $\mathrm{NAD}^{+}$and energy production could play a role in the anti-inflammatory activity of these specific flavonoids. In addition, these results indicate additional mechanisms by which flavonoids can exert antiinflammatory activity. Furthermore, these results indicate possibilities to use food-derived flavonoids in the treatment of chronic inflammatory diseases. 


\section{INTRODUCTION}

The nuclear enzyme poly(ADP-ribose) polymerase-1 (PARP-1; E.C. 2.4.2.30), which catalyzes the formation of poly(ADP-ribose) polymers (PAR-polymers) from its substrate $\mathrm{NAD}^{+}$, has been described to be involved in the pathophysiology of both acute as well as chronic inflammatory diseases [26, 29, 30, 83, 84]. PARP-1 is known to be highly activated by oxidative stress-induced DNA strand breaks. Overactivation as a result of extensive DNA damage causes massive PAR-polymer formation and consequently a rapid depletion of cellular $\mathrm{NAD}^{+}$and ATP levels. If the resulting cellular energy crisis cannot be resolved, PARP-1 overactivation may lead to cell death.

Initially, the formation of the PAR-polymers was known to facilitate repair of damaged DNA [5, 6, 100]. Results of various studies indicate that the process of poly(ADP-ribosyl)ation may also facilitate transcriptional activity [106]. The formation of the negatively charged PAR-polymers and the transfer of these polymers to acceptor proteins like histones initiate electrostatic repulsion between histones and DNA. The subsequent remodeling of the chromatin architecture enhances the accessibility of genes for the transcriptional machinery and thus enhances transcription [106]. More recently, PARP-1 has also been shown to be involved in the regulation of the nuclear factor-kappa B (NF$\kappa \mathrm{B})$ and activator protein-1 (AP-1) mediated transcription of inflammatory cytokines and chemokines [11, 15, 82]. Pharmaceutical inhibition of PARP-1 was demonstrated to have beneficial effects in various animal models for inflammatory diseases such as endotoxic shock or pulmonary inflammation $[29,34]$. The aim of this study was to evaluate dietary flavonoids for their PARP-1 inhibiting activity. Flavonoids are polyphenolic compounds found in fruits and vegetables and plant-derived products like red wine and tea, and can be divided into different subclasses like anthocyanidins, flavonols and flavones. The intake of dietary flavonoids has been related to a reduced risk for several diseases like cardiovascular and chronic inflammatory diseases [51, 57]. These positive health effects associated with the intake of flavonoids have been ascribed to their well-known antioxidant properties and to inhibiting effects on a wide range of enzymes [58, 59]. Also, anti-inflammatory effects of flavonoids could contribute to these beneficial effects [59].

In this study, in first instance the PARP-1 inhibiting activity of a wide range of flavonoids was investigated using the purified enzyme. Secondly, the most promising compounds were further evaluated in cultured pulmonary epithelial cells that were treated with $\mathrm{N}$-methyl- $\mathrm{N}^{\prime}$-nitro- $\mathrm{N}$-nitrosoguanidine (MNNG) to induce PARP-1 activation and NAD $\mathrm{Ne}^{+}$-depletion. Finally, the effect of the PARP1 inhibiting flavonoids on NF-KB mediated production of interleukin (IL)-8 was investigated in lipopolysaccharide (LPS)-stimulated pulmonary epithelial cells. 


\section{MATERIAL AND METHODS}

\section{Materials}

Naringin, fisetin, rutin, morin, quercetin, taxifolin, (+)-catechin, myricetin, phenol, hydroquinone, resorcinol, Tween 20, acetic acid, 3,3',5,5' tetramethylbenzidine, hydrogen peroxide $\left(\mathrm{H}_{2} \mathrm{O}_{2}\right)$, 3-aminobenzamide, MNNG, bovine serum albumine (BSA), Dulbecco's Modified Eagle's Medium (DMEM) and LPS (O26:B6) were all obtained from Sigma (St. Louis, MO, USA). Baicalein, 4,2',4'-trihydroxychalcone, fustin, tricetin, gossypetin, 3',5,7-trihydroxy3,4'-dimethoxyflavone, 3,5,7,3', $4^{\prime}$-pentamethoxyflavone were obtained from ICC (Hillsborough, NJ, USA). Delphinidin and cyanidin were obtained from Extrasynthese (Genay, France). Genistein was obtained from Alexis (Lausen, Switzerland). Naringenin, kaempferol, $\beta-\mathrm{NAD}^{+}$and 1,4-dithiothreitol (DTT) were obtained from MP Biomedicals (Irvine CA, USA). Catechol was obtained from Janssen Chimica (Geel, Belgium). Human rPARP-1 and biotinylated NAD were purchased from Trevigen (Gaithersburg, MD, USA). HBSS, fetal bovine serum, trypsine and Penicillin/Streptomycin were all obtained from Invitrogen Life Technologies (Grand Island, NY, USA). N-(6-oxo-5,6-dihydrophenanthridin-2-yl)-N,N-dimethyl-acetamide (PJ34) was obtained from Merck (Darmstadt, Germany). Peroxidase-labeled streptavidin was purchased from Zymed (San Francisco, CA, USA). Polyvinylchloride microtiter plates were obtained from BD Biosciences (San Jose, CA, USA). The 10H hybridoma was kindly provided by Dr. M. Miwa, via Riken Cell Bank, Tsukuba Institute BioResource Center (Ibaraki, Japan). The cell supernatant containing mouse monoclonal anti-PAR polymer antibody $10 \mathrm{H}$ was produced by Dr. W. Buurman (University of Maastricht, Maastricht, the Netherlands). FITC-conjugated goat anti-mouse immunoglobulin and fluorescent mounting medium were obtained from DAKO (Glostrup, Denmark).

\section{PARP-1 inhibition ELISA}

The capacity of the compounds to inhibit PARP-1 was first determined using an enzyme inhibition assay, as described by others [90, 91] with minor modifications as previously described [107]. In short, human rPARP was incubated in a 96-well microtiterplate with a reaction mixture containing $50 \mu \mathrm{M} \beta-\mathrm{NAD}^{+}$ $\left(10 \%\right.$ biotinylated $\beta-\mathrm{NAD}^{+}, 90 \%$ unlabelled $\left.\beta-\mathrm{NAD}^{+}\right), 1 \mathrm{mM}$ DTT and 1.25 $\mathrm{mg} / \mathrm{L}$ nicked DNA. The formation of the PAR-polymers was detected with peroxidase-labeled streptavidin and 3,3',5,5'-tetramethylbenzidine (TMB). PARP-1 activity was expressed as absorbance at $450 \mathrm{~nm}$. PARP-1 inhibition of flavonoids was evaluated by addition of these compounds to the reaction mixture. The type of PARP-1 inhibition, specific or non-specific, by flavonoids was analyzed in incubations of PARP-1 and putative inhibitors with various concentrations of $\beta-\mathrm{NAD}^{+}$after which Lineweaver Burk plots were constructed. 


\section{Cell culture}

A549 lung epithelial cells were grown at $37^{\circ} \mathrm{C}$ in a humidified $5 \% \mathrm{CO}_{2}$ atmosphere and were cultured in Dulbecco's Modified Eagles Medium (DMEM) with $4.5 \mathrm{~g} / \mathrm{L}$ glucose, 10\% fetal bovine serum (FBS), $2 \mathrm{mM}$ glutamine and 50000 units/L of penicillin and $50 \mathrm{mg} / \mathrm{L}$ of streptomycin.

\section{Cellular NAD ${ }^{+}$assay}

PARP-1 activation in cultured cells was measured as previously described [107]. MNNG was used to induce DNA strand breaks, activate PARP-1 and deplete intracellular NAD ${ }^{+}$levels. Cells were incubated in a 96-well microtiterplate with $25 \mu \mathrm{M}$ MNNG during $30 \mathrm{~min}$ in the presence or absence of flavonoids, added 15 minutes before the MNNG-treatment. The flavonoids used were not cytotoxic as demonstrated using the $\mathrm{LDH}$ leakage test with incubation periods up to $24 \mathrm{~h}$ (data not shown) [108]. To minimize a possible indirect protective effect of the flavonoids via scavenging of hydroxyl radicals and reduced formation of DNA strand breaks, the alkylating agent MNNG instead of $\mathrm{H}_{2} \mathrm{O}_{2}$ was used in this assay to induce PARP-1 activity. The PARP-1 inhibitor 3-aminobenzamide strongly prevented the decrease in $\mathrm{NAD}^{+}$-levels and served in all experiments as a positive control. Intracellular $\mathrm{NAD}^{+}$was determined using the $\mathrm{NAD}^{+}$-cycling method based on the method from Jacobsen and Jacobsen (1997) [94].

\section{Immunohistochemical staining of PAR-polymers}

To confirm the PARP-1 inhibiting effects of flavonoids, the formation of PARpolymers was measured. A549 cells (approximately $0.8 \times 10^{6}$ cells/well in a 6 well plate) were treated with MNNG for $5 \mathrm{~min}$ in the presence or absence of flavonoids, which were added $15 \mathrm{~min}$ before the MNNG-treatment. The synthetic PARP-1 inhibitors 3-aminobenzamide and PJ34 were used as positive controls. After the incubation, the cells were trypsinized, washed with PBS and fixed in methanol. After fixation, cells were stained for PAR-polymers as previously described [107]. At least 100 cells per slide were evaluated for the presence of PAR-polymers in their nucleus using fluorescence microscopy and Lucia GF 4.80 software (Nikon, Düsseldorf, Germany). Subsequently, the percentage of PAR-polymer positive cells was calculated.

\section{LPS-treatment and IL-8 measurement}

A549 cells were treated with $100 \mu \mathrm{g} / \mathrm{L}$ LPS for $16 \mathrm{~h}$ in absence or presence of flavonoids, which were added 30 min before the LPS-treatment. After incubation, medium was collected and centrifuged (10 min, $\left.2000 \times \mathrm{g}, 4^{\circ} \mathrm{C}\right)$ and supernatant was stored at $-80^{\circ} \mathrm{C}$ until measurement of IL-8 with ELISA kits (CLB/Sanquin, The Netherlands). Cells were trypsinized and processed for immunohistochemical staining of the PAR-polymer as described above. 


\section{Statistics}

Experiments were performed in triplicate and results are reported as means \pm SEM. The effect of the various flavonoids on MNNG-induced $\mathrm{NAD}^{+}$-depletion and PAR-polymer formation and LPS-induced IL-8 release compared to the condition without flavonoids was statistically analysed using ANOVA followed by Dunnett's post hoc testing. Differences were considered to be statistically significant if $P<0.05$.

\section{RESULTS}

\section{PARP-1 enzyme inhibition}

To determine the extent of PARP-1 inhibition by several flavonoids, human rPARP-1 was incubated with the flavonoids $(100 \mu \mathrm{M})$ for one hour (Table 1 ). PARP-1 was potently inhibited by the flavonoids myricetin (93\%) and tricetin (80\%). Also flavonoids gossypetin (73\%), delphinidin $(62 \%)$, quercetin $(62 \%)$ and fisetin $(60 \%)$ were found to be strong PARP-1 inhibitors. Baicalein, naringin or (+)-catechin showed less than $10 \%$ inhibition. The phenolic compounds phenol, catechol, resorcinol and hydroquinone were also evaluated for their PARP-1 inhibiting activity and showed respectively 8, 12, 9 and $5 \%$ inhibition. The methylated metabolites of quercetin, 3',5,7-trihydroxy-3, 4'dimethoxyflavone and 3,5,7,3',4'-pentamethoxyflavone, showed weak or no PARP-1 inhibition, whereas 4,2',4'-trihydroxychalcone and rutin showed no inhibition at all. For the flavonoids myricetin, tricetin, quercetin and fisetin, which showed the most potent PARP-1 inhibiting activity, Lineweaver Burk plots were constructed using various concentrations NAD ${ }^{+}$. Inhibition of PARP1 by myricetin, quercetin and fisetin was revealed to be of a mixed type, with competitive as well as non-competitive characteristics. Inhibition of PARP-1 by tricetin was shown to be mostly competitive (data not shown). 
Table 1 Characteristics and PARP-1 inhibition of flavonoids tested in this study

\begin{tabular}{|c|c|c|c|c|c|}
\hline Flavonoid & Class & $\begin{array}{l}\text { Hydroxylation } \\
\text { pattern }\end{array}$ & $\begin{array}{l}\text { Methoxylation } \\
\text { pattern }\end{array}$ & $\begin{array}{l}\text { C2-C3 } \\
\text { double } \\
\text { bond }\end{array}$ & $\begin{array}{l}\text { \% PARP-1 } \\
\text { inhibition } \\
(100 \mu \mathrm{M})\end{array}$ \\
\hline $4,2^{\prime}, 4^{\prime}$-trihydroxychalcone & chalcone & $4,2^{\prime}, 4^{\prime}$ & & + & n.i. \\
\hline baicalein & flavone & $5,6,7$ & & + & $5 \pm 4$ \\
\hline naringenin & flavanone & $5,7,4^{\prime}$ & & - & $21 \pm 3$ \\
\hline naringin $^{1}$ & flavanone & $5,4^{\prime}$ & & - & $2 \pm 0$ \\
\hline genistein & Isoflavone & $5,7,4^{\prime}$ & & + & $14 \pm 4$ \\
\hline kaempferol & flavonol & $3,5,7,4^{\prime}$ & & + & $27 \pm 4$ \\
\hline fisetin & flavonol & $3,7,3^{\prime}, 4^{\prime}$ & & + & $60 \pm 1$ \\
\hline fustin & flavanone & $3,7,3^{\prime}, 4^{\prime}$ & & - & $11 \pm 2$ \\
\hline morin & flavonol & $3,5,7,2^{\prime}, 4^{\prime}$ & & + & $42 \pm 7$ \\
\hline quercetin & flavonol & $3,5,7,3^{\prime}, 4^{\prime}$ & & + & $62 \pm 3$ \\
\hline rutin $^{2}$ & flavonol & $5,7,3^{\prime}, 4^{\prime}$ & & + & n.i. \\
\hline taxifolin & flavanone & $3,5,7,3^{\prime}, 4^{\prime}$ & & - & $20 \pm 2$ \\
\hline (+)-catechin & flavanol & $3,5,7,3^{\prime}, 4^{\prime}$ & & - & $4 \pm 4$ \\
\hline cyanidin & anthocyanidin & $3,5,7,3^{\prime}, 4^{\prime}$ & & - & $20 \pm 3$ \\
\hline tricetin & flavone & $5,7,3^{\prime}, 4^{\prime}, 5^{\prime}$ & & + & $80 \pm 0$ \\
\hline myricetin & flavonol & $3,5,7,3^{\prime}, 4^{\prime}, 5^{\prime}$ & & + & $93 \pm 3$ \\
\hline delphinidin & anthocyanidin & $3,5,7,3^{\prime}, 4^{\prime}, 5^{\prime}$ & & - & $62 \pm 4$ \\
\hline gossypetin & flavone & $3,5,7,8,3^{\prime}, 4^{\prime}$ & & + & $73 \pm 4$ \\
\hline $\begin{array}{l}\text { 3',5,7,-trihydroxy-3,4'- } \\
\text { dimethoxyflavone }\end{array}$ & & $3^{\prime}, 5,7$ & $3,4^{\prime}$ & + & $13 \pm 2$ \\
\hline $\begin{array}{l}3,5,7,3^{\prime}, 4^{\prime} \text { - } \\
\text { pentamethoxyflavone }\end{array}$ & & & $3,5,7,3^{\prime}, 4^{\prime}$ & + & n.i. \\
\hline
\end{tabular}

${ }^{1}$ naringin is a naringenin glycoside with a rhamnoglucoside group at position 7

${ }^{2}$ rutin is a quercetin glycoside with a rhamnoglucoside group at position 7

n.i. $=$ no inhibition

PARP-1 activity was measured after incubating $400 \mu \mathrm{g} / \mathrm{L}$ PARP-1 for $1 \mathrm{~h}$ in the presence of 1.25 $\mathrm{mg} / \mathrm{L}$ nicked DNA, $50 \mu \mathrm{M} \mathrm{NAD}^{+}$and $100 \mu \mathrm{M}$ flavonoid at $4^{\circ} \mathrm{C}$

\section{Effects on MNNG-induced NAD+-depletion}

Specific flavonoids, which showed most significant inhibition in the enzyme assay, were further evaluated for their PARP-1 inhibiting activity in MNNGtreated human lung epithelial cells. Treatment of these cells with $25 \mu \mathrm{M}$ MNNG activated PARP-1 and induced depletion of cellular NAD+-levels to approximately $23 \%$ of control levels after $30 \mathrm{~min}$. MNNG-induced depletion of intracellular $\mathrm{NAD}^{+}$-stores was used as a parameter of PARP-1 activation. Depletion of the $\mathrm{NAD}^{+}$-levels was found to be significantly attenuated in presence of the flavonoids quercetin, fisetin and tricetin at a concentration of $100 \mu \mathrm{M}$ (Figure 1). Delphinidin, gossypetin, myricetin and morin, which also showed significant inhibition of the purified enzyme, failed to prevent the MNNG-induced decrease in $\mathrm{NAD}^{+}$-levels (data not shown). 


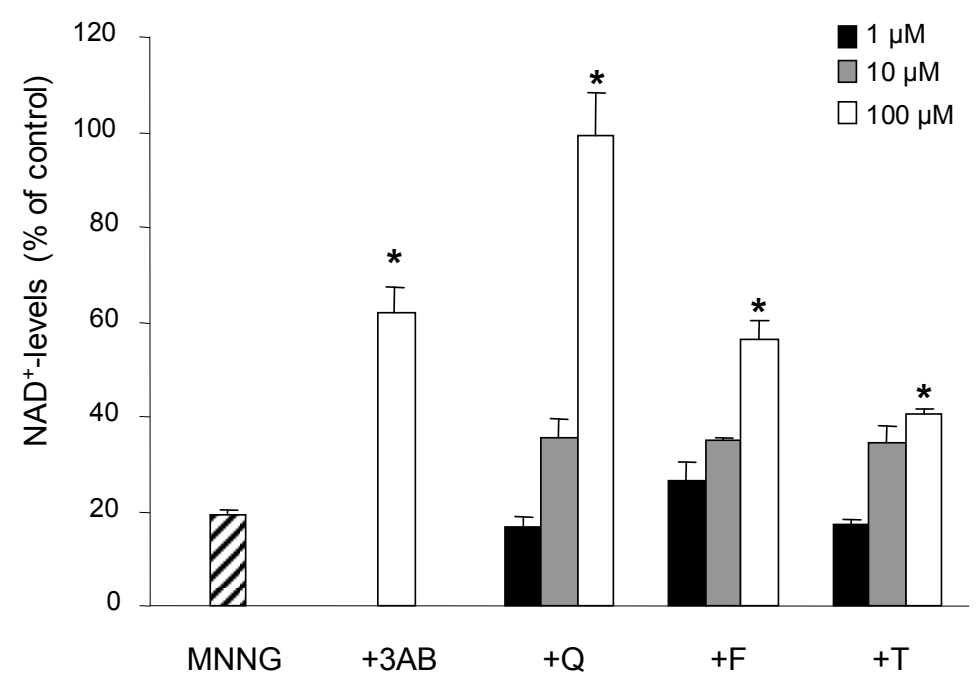

Figure 1. NAD ${ }^{+}$levels in MNNG-treated A549 lung epithelial cells exposed to $25 \mu \mathrm{M} M N N G$ for $30 \mathrm{~min}$ in the presence of 1,10 and $100 \mu \mathrm{M}$ of the flavonoids quercetin $(\mathrm{Q})$, fisetin $(\mathrm{F})$ and tricetin (T) or $100 \mu \mathrm{M} 3$-aminobenzamide (3AB). Values are expressed as a percentage of the control incubation (without MNNG and flavonoids or $3 \mathrm{AB}$ ), and are the mean \pm SEM of 3 replicate experiments.

$* \mathrm{P}<0.05$ vs incubation with MNNG alone

\section{PAR-polymer formation}

To confirm the PARP-1 inhibiting effect of the flavonoids quercetin, fisetin and tricetin, A549 cells were treated with MNNG in the presence of these flavonoids. Subsequently, the formation of PAR-polymers was detected using immunocytochemical staining. Due to the very rapid catabolism of PARpolymers by poly(ADP-ribose) glycohydrolase (PARG) [106], incubation time of MNNG was reduced to 5 minutes. In control cells, no PAR-polymer formation was observed. Treatment of the cells with MNNG induced a massive increase in the number of PAR-polymer positive cells (24\%). Preincubation of the cells with quercetin, fisetin and tricetin for 15 min dose-dependently inhibited PARpolymer formation after MNNG treatment (Figure 2A), indicating that the attenuated depletion in $\mathrm{NAD}^{+}$levels was primarily due to direct PARP-1 inhibition. The synthetic PARP-1 inhibitors PJ34 and 3-aminobenzamide were included as positive controls and PJ34 was found to almost completely reverse PAR-polymer formation (Figure 2B). 

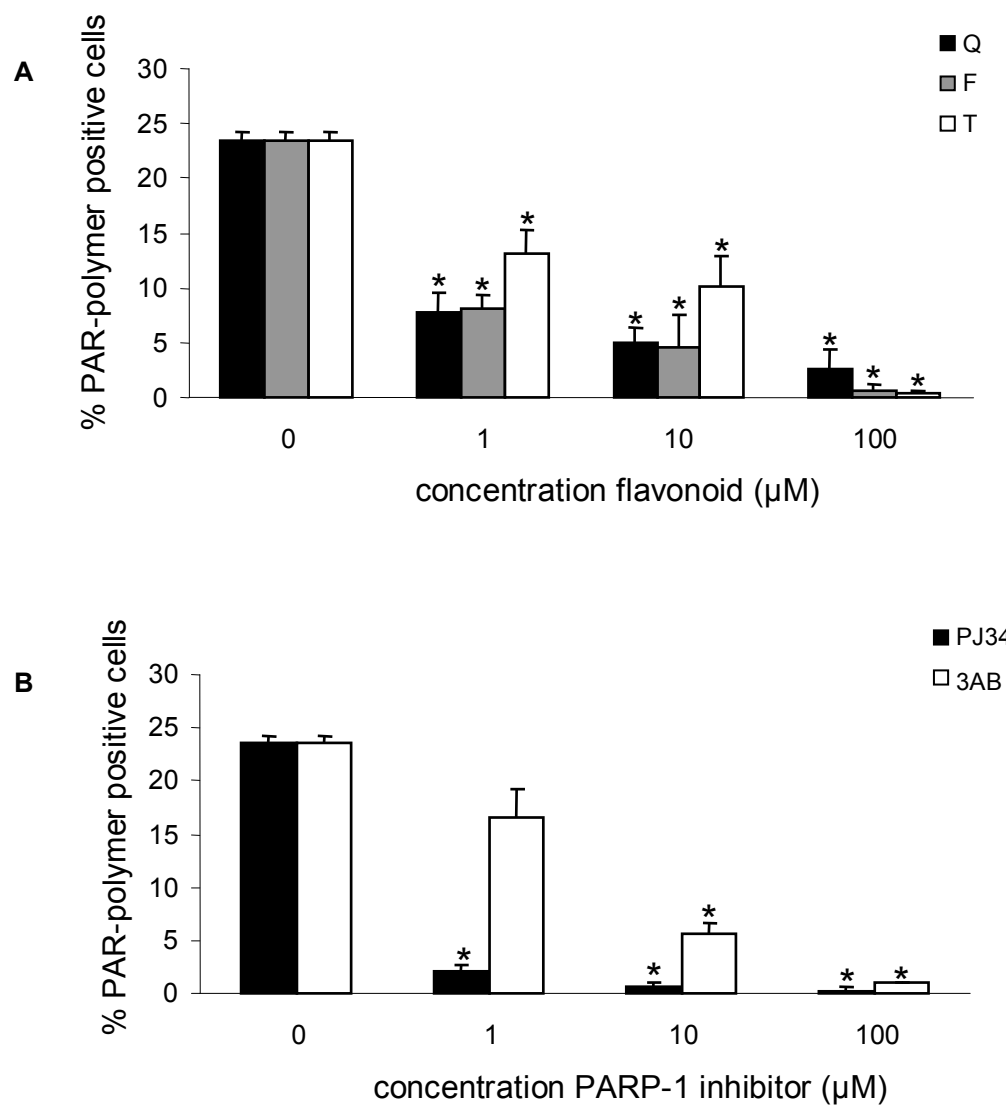

Figure 2. PAR-polymer formation in MNNG-treated A549 lung epithelial cells exposed to $25 \mu \mathrm{M}$ MNNG for $5 \mathrm{~min}$ in the presence of $\mathrm{A}$ ) the flavonoids quercetin (Q), fisetin (F) and tricetin (T) and B) the synthetic PARP-1 inhibitors PJ34 and 3-aminobenzamide (3AB). Values are the mean \pm SEM of 3 replicate experiments.

* $\mathrm{P}<0.05$ vs incubation with MNNG alone

\section{Effects on LPS-induced IL-8 production}

The flavonoids quercetin, fisetin and tricetin, which attenuated both the decrease in $\mathrm{NAD}^{+}$levels as well as the formation of PAR-polymers, were further studied for their effect on LPS-induced IL-8 production in A549 cells. Quercetin, fisetin as well as tricetin significantly reduced IL-8 production (Figure 3A). The synthetic PARP-1 inhibitor PJ34 showed a similar antiinflammatory activity (Figure 3B). Immunohistochemical staining of PARpolymers was applied to determine PARP-1 activation during LPS treatment of A549 cells. No detectable PAR-polymer formation could be measured in the A549 cells after treatment with $100 \mu \mathrm{g} / \mathrm{L}$ LPS from $5 \mathrm{~min}$ up to $24 \mathrm{~h}$ after stimulation (data not shown). 
A

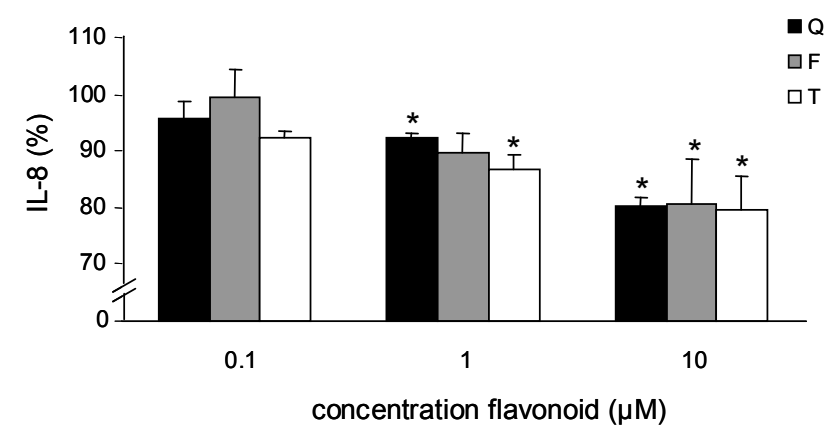

B

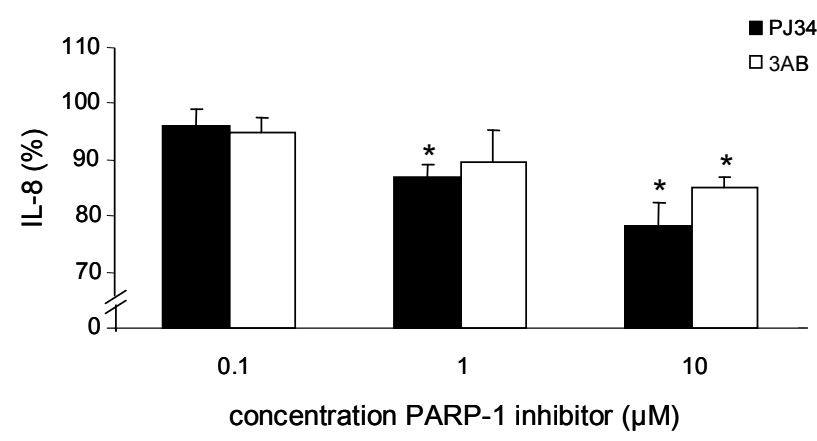

Figure 3. IL-8 production in LPS-stimulated A549 lung epithelial cells treated with $100 \mu \mathrm{g} / \mathrm{L}$ LPS for $16 \mathrm{~h}$ in the presence of $\mathrm{A})$ the flavonoids quercetin $(\mathrm{Q})$, fisetin $(\mathrm{F})$ and tricetin $(\mathrm{T})$ and $\mathrm{B})$ the synthetic PARP-1 inhibitors PJ34 and 3-aminobenzamide (3AB). Values are expressed as the percentage of IL-8 production in LPS-stimulated A549 cells alone (control). Values are the mean \pm SEM of 3 replicate experiments.

$* \mathrm{P}<0.05$ vs incubation with LPS alone

\section{DISCUSSION}

In this study, the flavonoids quercetin, fisetin and tricetin were found to significantly inhibit the nuclear enzyme PARP-1. This inhibition was not only observed with the purified PARP-1 enzyme, but also in MNNG-treated human pulmonary epithelial cells. Furthermore, a dose-dependent decrease in IL-8 production was observed after LPS-treatment of the A549 cells in presence of quercetin, fisetin and tricetin. These data indicated that their PARP-1 inhibiting activity may contribute to anti-inflammatory effects via inhibition of NF-kB mediated gene-expression.

The inducible transcription factor NF- $\mathrm{kB}$ plays an important role in the inflammatory and immune response and regulates the production of pro-inflammatory cytokines and chemokines like IL-8 [109]. PARP-1 has been reported to be a 
co-activator of NF- $\mathrm{B}[11,15]$. However, whether PARP-1 enzyme activity or the protein itself is required for complete activation of NF- $\kappa B$ is still a matter of debate [16, 19]. Nevertheless, pharmaceutical PARP-1 inhibitors were successfully applied in various in vitro and in vivo models of inflammation and were found to reduce the production of $\mathrm{NO}$ and pro-inflammatory cytokines like TNF- $\alpha$, IL-6 and IL-8 [26, 29, 33, 34].

The precise mechanisms through which flavonoids inhibit the production of pro-inflammatory cytokines remain to be elucidated. Their antioxidant properties are in general believed to be primarily responsible for the antiinflammatory effects. Reactive oxygen species (ROS) have been described to be involved in the pathology of inflammatory diseases [110, 111]. In addition, ROS have been described to induce activation of redox-sensitive transcription factors like AP-1 and NF- $\mathrm{BB}$ [112], subsequently leading to increased production of several inflammatory mediators and chemokines, including IL-8. In various studies, the inhibiting effects of flavonoids on the production of proinflammatory markers were observed. Reduced production of pro-inflammatory cytokines, iNOS expression and NO production have been observed after treatment with the flavonoids quercetin, apigenin and luteolin in LPS or PMA stimulated cultured cells [113-115]. These effects have been found to be associated with inhibition of the NF- $\kappa B$ pathway via reduced phosphorylation of $I \kappa \mathrm{Ba}$ and reduction of the nuclear translocation and DNA-binding of NF- $\mathrm{B}$ [113-115]. In addition, these flavonoids attenuated the production of proinflammatory mediators via regulation of the transcription factor AP-1 [114]. In the present study, specific flavonoids were shown to have significant PARP-1 inhibiting activity. In an attempt to assess PARP-1 activation during LPS treatment of A549 cells, we applied immunocytochemical staining of the cells at various time points, ranging from $5 \mathrm{~min}$ to $24 \mathrm{~h}$ after treatment. However, no PAR-polymer formation could be detected in these cells, in contrast to cells treated with MNNG. This may be due to the application of a mild stimulus, i.e. $100 \mathrm{ng} / \mathrm{ml}$ LPS, which most likely failed to induce high levels of ROS and measurable PAR-polymer formation. In addition, PAR-polymers are very rapidly catabolized by poly(ADP-ribose) glycohydrolase (PARG) [106], which may also result in non-detectable PAR-polymer formation. After stimulation of A549 cells with IL-1 $\beta$ and TNF- $\alpha$, Erdelyi et al. (2005) also failed to detect PAR-polymer formation, in contrast to the massive PAR-polymer formation observed in $\mathrm{H}_{2} \mathrm{O}_{2}$ treated cells [116]. It remains therefore inconclusive whether inhibition of PARpolymer formation is the mechanism by which flavonoids reduce IL-8 production in LPS-treated A549 cells.

In the present study, inhibition of PARP-1 by flavonoids was revealed to be not solely a competitive type of inhibition. Although inhibition of PARP-1 by tricetin was competitive, myricetin, quercetin and fisetin showed a mixed type of inhibition. These results indicate that PARP-1 activity was not solely reduced 
by an interaction of these flavonoids with the catalytic site of PARP-1, but also by non-specific interactions of the flavonoids with PARP-1. Since it was also suggested by others that the presence of the enzyme and not the enzymatic activity of PARP-1 is required for complete NF- $\mathrm{kB}$ activation [16], non-specific binding of flavonoids to PARP- 1 could probably prevent interaction of PARP-1 with NF- $\mathrm{kB}$ and subsequently also reduce the NF- $\mathrm{kB}$ mediated gene-expression. When tested with the purified enzyme, the flavonoids myricetin, tricetin, gossypetin, delphinidin, quercetin and fisetin clearly inhibited PARP-1 at 100 $\mu \mathrm{mol} / \mathrm{L}$ (approximately $\geq 60 \%$ ), whereas other flavonoids like kaempferol and naringenin showed considerably lower PARP-1 inhibiting activity. Given that in foods, most flavonoids occur predominantly as $\beta$-glycosides and upon ingestion become extensively metabolized into glucuronidated-, sulfated- or methylated conjugates [56, 117], a number of commercially available conjugated flavonoids were screened for their PARP-1 inhibiting activity. The addition of methyl groups to flavonoids like quercetin drastically reduced the inhibiting activity. 3',5,7-Trihydroxy-3,4'-dimethoxyflavone showed only weak inhibition as compared to quercetin, and the inhibiting activity of $3,5,7,3^{\prime}, 4^{\prime}$ pentamethoxyflavone was even more reduced. Glycosylation as in rutin and naringin considerably decreased inhibition as compared to the aglycones quercetin and naringenin. Evaluating the PARP-1 inhibiting activity of phenolic compounds like phenol, catechol, resorcinol and hydroquinone indicated that position of the hydroxyl groups (ortho, meta or para) did not clearly contribute to the PARP-1 inhibiting activity of these compounds. However, the presence of the C2-C3 double bond seemed to influence the PARP-1 inhibiting activity of some flavonoids, since both quercetin and fisetin showed substantially higher PARP-1 inhibiting activity as compared to the flavonoids taxifolin and fustin. Although myricetin showed the strongest PARP-1 inhibiting activity in the enzyme assay, it failed to significantly inhibit PARP-1 in the A549 cells. The Lineweaver Burk plot of myricetin indicated that the inhibition of the purified PARP-1 enzyme by myricetin showed both competitive as well as noncompetitive characteristics, indicating that myricetin also showed non-specific protein binding which might reduce the intranuclear concentration. Furthermore, several non-specific interactions between flavonoids and proteins have been reported [118, 119]. Since PARP-1 is located in the nucleus and PARP-1 inhibitors first need to pass the cell membrane and enter the nucleus to inhibit the enzyme, non-specific interactions could decrease the final intracellular and -nuclear concentration of myricetin or other flavonoids. Alternatively, the flavonoids quercetin and fisetin, which also showed mixed type of inhibition similar to myricetin, did prevent the MNNG-induced PAR-polymer formation and decrease in $\mathrm{NAD}^{+}$-levels. This suggests that these flavonoids pass the cell membrane and enter the nucleus in sufficient amounts to exert PARP-1 inhibiting effects. 
Since PARP-1 is also involved in facilitating DNA-repair, complete inhibition of PARP-1 appears not desirable. For that reason, mild inhibition would be the preferred method of action. The flavonoids quercetin, fisetin and tricetin were found to inhibit PARP-1, both in the enzyme assay as well as in A549 cells. By mildly inhibiting the enzyme activity of PARP-1, these flavonoids would protect against $\mathrm{NAD}^{+}$- and ATP-depletion, reducing the risk of cell death-induced inflammation. Moreover, the reduction of LPS-induced IL-8 release at similar levels indicated an anti-inflammatory effect via NF-kB. Furthermore, low level of PARP-1 activity would allow for repair of DNA damage. In addition, it was previously observed that administration of the potent synthetic PARP- 1 inhibitor INO-1001 in a porcine model of thoracic aortic cross-clamping-induced I/R injury did not impair DNA repair [120]. DNA damage in peripheral blood mononuclear cells was evaluated by the COMET assay, both in vivo as well as ex vivo, and no differences between the INO-1001 treated group and vehicletreated group were found. Also, expression of the cyclin-dependent kinase inhibitor (CDKI) gene p27 in the kidney was evaluated. Expression of p27 was increased equally in both the vehicle-treated and INO-1001 treated group and it was suggested that both DNA damage and repair was found not to be impaired by treatment with the PARP-1 inhibitor INO-1001 [120].

Apples, grapes, onions and Ginkgo Biloba are dietary sources of PARP-1 inhibiting flavonoids quercetin, fisetin and tricetin [121]. In industrialized societies like Western Europe and USA, the estimated intake of flavonols and flavones is reported to range from 20 to $34 \mathrm{mg}$ /day [52, 122, 123]. The repeated intake of food supplements containing high doses of flavonoids (e.g. $1 \mathrm{~g}$ quercetin/day) has been shown to increase plasma concentrations, reaching levels in the low micromolar range [55, 124, 125]. This implies that the observed in vitro effects were achieved at concentrations that may be reached in vivo after the use of supplements.

Specifically in the treatment of chronic inflammatory diseases such as chronic obstructive pulmonary disease (COPD), long-term use of dietary supplements is considered to be promising, since no effective treatment has been developed yet. In COPD patients, we previously reported increased oxidative stress and increased inflammatory cytokines including IL-8, which were accompanied by an increased percentage of PAR-polymer positive peripheral blood mononuclear cells, indicating a chronic and systemic PARP-1 activation [30]. As a consequence of chronic PARP-1 activation, $\mathrm{NAD}^{+}$turnover will be increased implying an increased demand on ATP production for resynthesis of $\mathrm{NAD}^{+}$. This increased turnover of $\mathrm{NAD}^{+}$and demand for energy may contribute to exercise intolerance and muscle weakness, which greatly impair the quality of life of COPD patients. Reduction of oxidative stress and inhibition of PARP-1 by food-derived compounds might reduce this chronic state of energy consumptive cycles and ameliorate systemic inflammatory conditions. Dietary 
flavonoids like quercetin, fisetin and tricetin would be potential candidates, not only based on their antioxidant effects but also based on their PARP-1 inhibiting as well as anti-inflammatory effects as described in this current study. 


\section{CHAPTER 4}

\section{Flavone as PARP-1 inhibitor: its effect on lipopolysaccharide induced gene-expression}

European Journal of Pharmacology 2007, 573, 241-248

Liesbeth Geraets

Harald JJ Moonen

Karen Brauers

Ralph WH Gottschalk

Emiel FM Wouters

Aalt Bast

Geja J Hageman 


\section{ABSTRACT}

The nuclear enzyme poly(ADP-ribose) polymerase-1 (PARP-1) which was initially known for its role in the repair of oxidative stress-induced DNA damage, has also been reported to play a mediating role in the inflammatory response. Studies with PARP-1 knockout models have shown that PARP-1 is a co-activator of nuclear factor-kappa $\mathrm{B}(\mathrm{NF}-\mathrm{kB})$, although this appears not to require its enzyme activity. In addition, drug-induced inhibition of the enzyme activity of PARP-1 was observed to reduce the production of pro-inflammatory mediators. In this study, the flavonoid compound flavone was demonstrated to significantly inhibit the enzyme activity of PARP-1. Further evaluation of flavone in $\mathrm{N}$-methyl- $\mathrm{N}^{\prime}$-nitro- $\mathrm{N}$-nitrosoguanidine (MNNG)-treated human pulmonary epithelial and vascular endothelial cells revealed that both the decrease in $\mathrm{NAD}^{+}$levels, as well as the formation of PAR-polymers was dosedependently attenuated by flavone. In addition, flavone was found to reduce the lipopolysaccharide (LPS)-induced interleukin (IL)-8 production in pulmonary epithelial cells, which was confirmed by transcription analysis. Furthermore, transcription of IкBa was significantly increased by flavone. The results of the present study indicate that the flavonoid flavone could be a potential candidate for application in treatment of chronic inflammatory diseases. PARP1 inhibition could have beneficial effects in such diseases as chronic obstructive pulmonary disease (COPD) and diabetes, by preservation of cellular $\mathrm{NAD}^{+}$ levels and attenuating inflammatory conditions. 


\section{INTRODUCTION}

The nuclear enzyme poly(ADP-ribose) polymerase-1 (PARP-1; E.C. 2.4.2.30) which catalyzes the formation of poly(ADP-ribose) polymers (PAR-polymers) from its substrate $\mathrm{NAD}^{+}$, was initially known for its facilitating role in the repair of DNA damage [5]. Currently it is recognized that PARP-1 is also involved in the regulation of the nuclear factor-kappa $\mathrm{B}(\mathrm{NF}-\mathrm{\kappa B})$ and activator protein 1 (AP-1) mediated production of pro-inflammatory cytokines. Studies with PARP1 knockout models showed that PARP-1 is a co-activator of NF-kB $[11,15]$. It has been observed that the enzyme activity of PARP-1 was not required for full activation of NF-KB [16]. However, others reported that the synthesis of PARpolymers facilitated the transcriptional activation properties of NF-KB [19]. Moreover, inhibition of PARP-1 with synthetic inhibitors has been reported to reduce the DNA-binding activity of NF- $\mathrm{KB}$ and also the transcription of NF- $\mathrm{\kappa B}$ mediated genes [20, 21].

The flavonoid quercetin has previously been reported to have PARP-1 inhibiting activity [126]. In addition, for flavonoids in general, it was shown that their antioxidant effects and the enzyme inhibiting effects are largely dependent on their hydroxylation pattern [58, 59]. By screening specific polyphenolic compounds for their effect on PARP-1 activity, we identified a distinctive flavonoid compound, without hydroxyl groups, as a PARP-1 inhibitor. Furthermore, common structural features of competitive PARP-1 inhibitors include a carboxamide-group attached to an aromatic ring or the carbamoyl group built in a polyaromatic heterocyclic skeleton, and this is not characteristic of flavone or flavonoids in general. In the present study, data are presented which demonstrate that this dietary flavonoid flavone (Figure 1), a polyphenolic compound reported to be present in dill weeds and oats [127], is a very potent PARP-1 inhibitor. The aim of this study is to elaborate further on the PARP-1 inhibiting effect and to elucidate the supposed effect of this intriguing compound on NF$\kappa \mathrm{B}$ mediated transcription of pro-inflammatory genes.

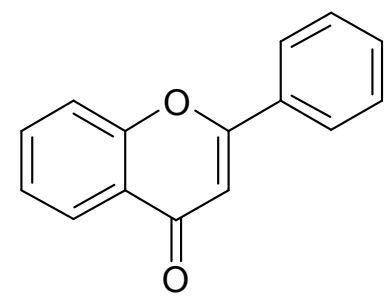

Figure 1. Chemical structure of the flavonoid flavone 
In a series of in vitro experiments, the PARP-1 inhibiting capacity of flavone was first tested using the purified enzyme. Secondly, the effect of flavone on $\mathrm{N}$ methyl-N'-nitro-N-nitrosoguanidine (MNNG)-induced $\mathrm{NAD}^{+}$-depletion and PAR-polymer formation was tested in cultured pulmonary epithelial and vascular endothelial cells. Finally, the effect of flavone on expression and production of NF- $\mathrm{B}$ mediated genes was tested in lipopolysaccharide (LPS)stimulated pulmonary epithelial cells.

\section{MATERIAL AND METHODS}

\section{Materials}

Flavone was obtained from ICC (Hillsborough, NJ, USA). $\beta-N^{+}$and 1,4dithiothreitol (DTT) were obtained from MP Biomedicals (Irvine, CA, USA). Tween 20, acetic acid, 3,3',5,5'-tetramethylbenzidine, hydrogen peroxide $\left(\mathrm{H}_{2} \mathrm{O}_{2}\right)$, 3-aminobenzamide, bovine serum albumine (BSA), MNNG, heparin, Dulbecco's Modified Eagle's Medium (DMEM) and LPS (O26:B6) were all obtained from Sigma (St. Louis, MO, USA). Human rPARP-1 and biotinylated NAD were purchased from Trevigen (Gaithersburg, MD, USA). F-12K Nutrient Mixture (Kaighn's Modification), fetal bovine serum, trypsine, Penicillin/Streptomycin and HBSS were all obtained from Invitrogen Life Technologies (Grand Island, NY, USA). N-(6-oxo-5,6-dihydro-phenanthridin-2-yl)-N,Ndimethylacetamide (PJ34) was obtained from Merck (Darmstadt, Germany). Peroxidase-labeled streptavidin was purchased from Zymed (San Francisco, CA, USA). Polyvinylchloride microtiter plates and endothelial cell growth supplement were obtained from BD Biosciences (San Jose, CA, USA). The $10 \mathrm{H}$ hybridoma was kindly provided by Dr. M. Miwa, via Riken Cell Bank, Tsukuba Institute BioResource Center (Ibaraki, Japan). The cell supernatant containing mouse monoclonal anti-PAR polymer antibody $10 \mathrm{H}$ was produced by Dr. W. Buurman (University of Maastricht, Maastricht, the Netherlands). FITCconjugated goat anti-mouse immunoglobulin and fluorescent mounting medium were obtained from DAKO (Glostrup, Denmark).

\section{PARP-1 inhibition ELISA}

The capacity of flavone to inhibit PARP-1 was first determined using an inhibition assay, as described by others $[90,91]$ with minor modifications as previously described [107]. In short, human rPARP was incubated in a 96-well microtiterplate with a reaction mixture containing $50 \mu \mathrm{M} \beta-\mathrm{NAD}^{+}(10 \%$ biotinylated $\beta-\mathrm{NAD}^{+}, 90 \%$ unlabelled $\left.\beta-\mathrm{NAD}^{+}\right), 1 \mathrm{mM}$ DTT and $1.25 \mu \mathrm{g} / \mathrm{ml}$ nicked DNA. Formation of PAR-polymers was detected using peroxidaselabeled streptavidin and 3,3',5,5'-tetramethylbenzidine (TMB). PARP-1 activity was expressed as absorbance at $450 \mathrm{~nm}$. PARP-1 inhibition by flavone was 
evaluated by addition of flavone to the reaction mixture. The type of PARP-1 inhibition by flavone (competitive or non-competitive) was analyzed by incubating PARP-1 with various concentrations of $\beta-\mathrm{NAD}^{+}$in the presence of flavone after which a Lineweaver Burk plot was constructed.

\section{Cell culture}

A549 lung epithelial cells were grown at $37^{\circ} \mathrm{C}$ in a humidified $5 \% \mathrm{CO}_{2}$ atmosphere and were cultured in DMEM with $4.5 \mathrm{~g} / \mathrm{L}$ glucose, $10 \%$ fetal bovine serum (FBS), $2 \mathrm{mM}$ glutamine, 50 units $/ \mathrm{ml}$ of penicillin and $50 \mu \mathrm{g} / \mathrm{ml}$ of streptomycin. RF24 cells were grown at $37^{\circ} \mathrm{C}$ in a humidified $5 \% \mathrm{CO}_{2}$ atmosphere in gelatin-coated culture flasks and were cultured in $\mathrm{F}-12 \mathrm{~K}$ Nutrient Mixture (Kaighn's Modification) supplemented with 10\% fetal bovine serum, $0.1 \mathrm{mg} / \mathrm{ml}$ heparin and 50 units $/ \mathrm{ml}$ of penicillin and $50 \mu \mathrm{g} / \mathrm{ml}$ of streptomycin. During culturing at low densities the medium was supplemented with 0.03 $\mathrm{mg} / \mathrm{ml}$ endothelial cell growth supplement.

\section{$\mathrm{NAD}^{+}$assay to determine cellular PARP-1 activity}

PARP-1 activation in cultured cells was measured as previously described [107]. MNNG was used to induce DNA strand breaks, activate PARP-1 and deplete intracellular $\mathrm{NAD}^{+}$levels. Cells were treated in a 96-well microtiterplate with $25 \mu \mathrm{M}$ (A549 cells) or $100 \mu \mathrm{M}$ (RF24 cells) MNNG during $30 \mathrm{~min}$ with or without flavone, added 15 minutes before the treatment. Flavone had no cytotoxic effects as demonstrated with the LDH leakage test following incubation periods of up to $24 \mathrm{~h}$ (data not shown) [108]. Intracellular NAD was determined with the $\mathrm{NAD}^{+}$-cycling method based on the method previously described [94].

\section{Immunofluorescent staining of PAR-polymers}

To confirm the PARP-1 inhibiting effects of flavone, the formation of PARpolymers was evaluated by immunocytochemical staining of the polymers. A549 cells (approximately $0.8 \times 10^{6}$ cells/well in 6-well plate) were treated with $25 \mu \mathrm{M}$ MNNG or $100 \mathrm{ng} / \mathrm{ml}$ LPS with or without flavone, added 15 minutes before the treatment. The synthetic PARP-1 inhibitors 3-aminobenzamide and PJ34 were used as positive controls. Following the incubation, the cells were trypsinized, washed with PBS and fixed in methanol. After fixation, cells were stained for PAR-polymers as previously described [107]. Using fluorescence microscopy and Lucia GF 4.80 software (Nikon, Düsseldorf, Germany), a minimum of 100 cells per slide were evaluated for the presence of PARpolymers within the nucleus. Subsequently, the percentage of PAR-polymer positive cells was calculated. 


\section{Treatment of cells with LPS}

To investigate the potential anti-inflammatory effect of flavone on the expression and production of NF- $\kappa \mathrm{B}$ mediated genes, LPS-stimulated A549 cells were used. The effects of flavone on the NF- $\kappa B$ activation, PAR-polymer formation, gene-transcription of IL-8 and inhibitor kappa B alpha $(\mathrm{I} \kappa \mathrm{B} \alpha)$, production of IL8 , tumor necrosis factor-alpha (TNF- $\alpha$ ) and IL-6 were determined at several time points ranging from $15 \mathrm{~min}$ to $24 \mathrm{~h}$. Cells were first incubated in 6-well plates with flavone for 30 minutes, and then stimulated with $100 \mathrm{ng} / \mathrm{ml}$ LPS diluted in DMEM with $0.5 \%$ FBS. After treatment, medium was removed, centrifuged (10 min, $5000 \mathrm{rpm}$ ) and stored at $-80^{\circ} \mathrm{C}$ until analysis of IL-8, TNF- $\alpha$ and IL- 6 with ELISA kits (CLB/Sanquin, The Netherlands). The sensitivity of these kits for IL-8, TNF- $\alpha$ and IL-6 were respectively $1 \mathrm{pg} / \mathrm{ml}, 1 \mathrm{pg} / \mathrm{ml}$ and $0.2 \mathrm{pg} / \mathrm{ml}$. Cells were then washed with HBSS and trypsinized after which cells were either fixed in cold methanol for immunohistochemical staining of the PAR-polymer or nuclear extracts were prepared for NF- $\mathrm{BB}$ analysis or cells were resuspended in Trizol Reagent for stabilization of RNA for real time PCR analysis of IL-8 and $\mathrm{I} \kappa \mathrm{B} \alpha$.

\section{NF-кB nuclear translocation}

Nuclear extracts were prepared as previously described [128]. The nuclear proteins were immediately collected and stored at $-80^{\circ} \mathrm{C}$ until analysis. The protein concentration was determined according to the method of Bradford (BioRad, Veenendaal, The Netherlands). NF- $\kappa$ B activity was determined using the TransAM NF-кB p50 Activation Assay (Active Motif, Rixensart, Belgium).

\section{Gene transcription analysis by quantitative real time PCR}

Total RNA was isolated with Trizol Reagent (Invitrogen, Carlsbad, CA, USA), according to the manufacturer's instructions. Next, the RNeasy $\mathbb{R}$ Mini Kit and RNase free DNase set (Qiagen, Hilden, Germany) were used to purify RNA. Concentration of the total isolated RNA was determined spectrophotometrically at 260 and $280 \mathrm{~nm}$. Reverse transcription reaction was performed using $1 \mu \mathrm{g}$ of total RNA and reverse-transcribed into cDNA using iScript ${ }^{\mathrm{TM}}$ cDNA Synthesis Kit (Biorad Laboratories, Hercules, CA, USA). Subsequently, real time PCR was performed with a MyiQ Single Colour real time PCR detection system (BioRad) using SYBR@ Green Supermix (Biorad), $5 \mu$ diluted (10x) CDNA, and $0.3 \mu \mathrm{M}$ primers in a total volume of $25 \mu \mathrm{l}$. PCR was conducted as follows: denaturation at $95^{\circ} \mathrm{C}$ for $3 \mathrm{~min}$, followed by 40 cycles of $95^{\circ} \mathrm{C}$ for $15 \mathrm{~s}$ and $60^{\circ} \mathrm{C}$ for $45 \mathrm{~s}$. After PCR a melt curve $\left(60-95^{\circ} \mathrm{C}\right)$ was produced for product identification and purity. Two stably expressed genes were included as internal controls; $\beta$-Actin and GAPDH. rtPCR primers were designed using Primer express software (Applied Biosystems). Primer sequences used were as follows: IL-8 5'GGACAAGAGCCAGGAAGAAA (forward) and 5'-AAATTTGGGGTGGAAAGG 
TT (reverse), I $\kappa B \alpha$ 5'-CTACACCTTGCCTGTGAGCA (forward) and 5'-TCCTGA GCATTGACATCAGC (reverse), GAPDH 5'-GAAGGTGAAGGTCGGAGTC (forward) and 5'-GAAGATGGTGATGGGATTTC (reverse), $\beta$-Actin 5'-CCTGGC ACCCAGCACAAT (forward) and 5'-GCCGATCCACACGGAGTACT (reverse). Data were analysed using the MyiQ Software system (BioRad) and were expressed as relative gene expression (fold increase) using the $2^{-\Delta \Delta_{C t}}$ method [129].

\section{TEAC assay}

The antioxidant capacity of flavone was tested using the TEAC assay (Trolox Equivalent Antioxidant Capacity assay), as previously described [130] with some minor modifications. This assay is based on the ability of a compound to scavenge the stable $\mathrm{ABTS}$ radical $\left(\mathrm{ABTS} \bullet^{+}\right)$. The blue-green $\mathrm{ABTS} \bullet^{+}$was produced through the reaction between $0.36 \mathrm{mM}$ ABTS and $1.84 \mathrm{mM}$ ABAP in $145 \mathrm{mM}$ sodium phosphate buffer, $\mathrm{pH} 7.4$, at $70^{\circ} \mathrm{C}$ until the absorption of the solution reached $0.70 \pm 0.02$ at $734 \mathrm{~nm}$. In the assay, $50 \mu \mathrm{l}$ of the test compound was added to $950 \mu \mathrm{l}$ of the $\mathrm{ABTS} \bullet^{+}$solution. The reduction in absorbance at $734 \mathrm{~nm}$ was measured in time for $5 \mathrm{~min}$ and was compared to a blank where $50 \mu \mathrm{l}$ of the solvent was added to $950 \mu \mathrm{l}$ of $\mathrm{ABTS}{ }^{+}$solution. A calibration curve was constructed using different concentrations of the synthetic antioxidant Trolox $(0-20 \mu \mathrm{M})$.

\section{Electron spin resonance spectroscopy}

Electron spin resonance (ESR) studies were performed to evaluate the hydroxyl radical scavenging activity of flavone. The experiments were done at room temperature using a Bruker EMX 1273 spectrometer equipped with an ER $4119 \mathrm{HS}$ high sensitivity cavity and $12 \mathrm{~kW}$ power supply operating at X band frequencies as previously described [107]. 5,5-Dimethyl-1-pyrroline N-oxide (DMPO) was used for trapping hydroxyl radicals. Incubation mixtures (total volume $200 \mu \mathrm{l})$ consisted of $\mathrm{FeSO}_{4}(0.5 \mathrm{mM}), \mathrm{H}_{2} \mathrm{O}_{2}(0.55 \mathrm{mM})$ and DMPO (100 $\mathrm{mM})$ in the absence or presence of flavone. Quercetin $(100 \mu \mathrm{M})$ was used as a positive control and was found to reduce the $\mathrm{DMPO}-\mathrm{OH}$ adduct signal by approximately $87 \%$. ESR spectra were recorded using $100 \mu \mathrm{l}$ capillary glass tubes. Quantification of the spectra (in arbitrary units) was performed by peak integration using the WIN-EPR spectrum manipulation program.

\section{Statistics}

Experiments were performed in triplicate and results are reported as means \pm S.E.M. . Statistical analysis was carried out with SPSS 14.0 using ANOVA. To locate the statistical differences, a Bonferroni post hoc test was used. Differences were considered to be statistically significant at $\mathrm{P}<0.05$. 


\section{RESULTS}

\section{PARP-1 enzyme inhibition}

In an in vitro assay, using the purified enzyme the activity of PARP-1 was observed to be effectively inhibited by $100 \mu \mathrm{M}$ flavone (91 $\pm 1 \%$ inhibition). In the same assay, the known PARP-1 inhibitor 3-aminobenzamide was used as a positive control and for this compound $85 \pm 1 \%$ inhibition was found at a concentration of $100 \mu \mathrm{M}$. To determine the nature of the inhibition, the effect of flavone on PARP-1 inhibition was evaluated using concentrations of $\beta-N^{2} D^{+}$ concentrations ranging from 0 to $250 \mu \mathrm{M}$. The Lineweaver Burk plot, which was obtained, indicated a competitive type of inhibition for flavone (Figure 2).

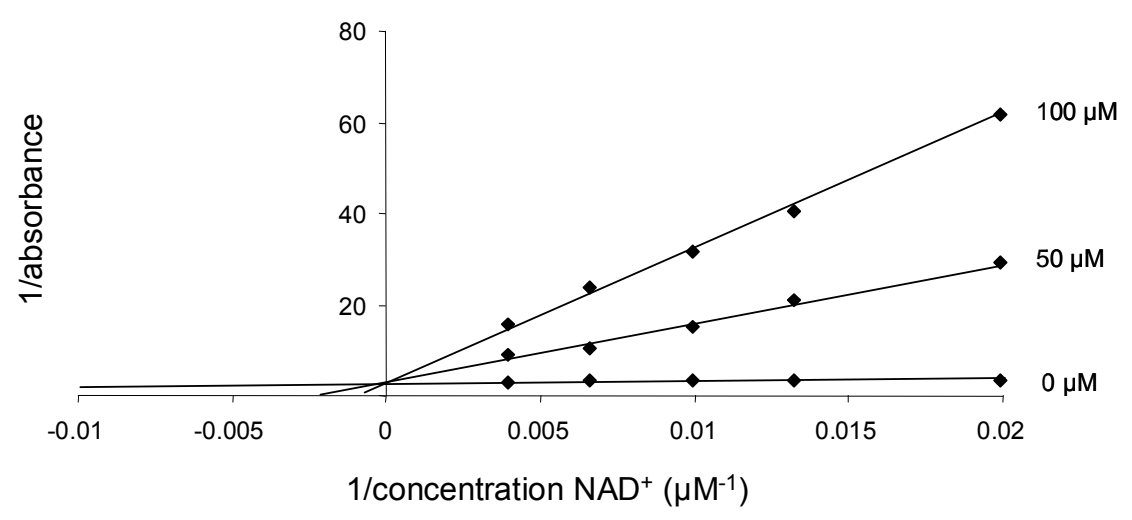

Figure 2. Lineweaver Burk plot for flavone. Human PARP-1 was incubated for one hour in the presence of nicked DNA, 0-250 $\mu \mathrm{M} \mathrm{NAD}^{+}$and various concentrations $(0-50-100 \mu \mathrm{M})$ of flavone.

\section{Effect of flavone on MNNG-induced $\mathrm{NAD}^{+}$-depletion}

To assess the effect of flavone on MNNG-induced NAD+-depletion in cultured cells, A549 pulmonary epithelial cells and RF24 vascular endothelial cells were exposed to MNNG in the presence of flavone. The alkylating agent MNNG induces DNA strand breaks, which subsequently leads to PARP-1 overactivation, extensive formation of PAR-polymers and reduced levels of its substrate $\mathrm{NAD}^{+}$. Because the PAR-polymers are rapidly broken down by poly(ADPribose) glycohydrolase (PARG) [106], measuring changes in NAD levels is a reliable method for measuring PARP-1 activation in cells over longer time periods. Incubation of the A549 and RF24 cells with MNNG decreased the cellular $\mathrm{NAD}^{+}$levels to $23 \pm 3 \%$ and $10 \pm 4 \%$ respectively of basal values (Figure 3A + Figure 3B). Treatment of the A549 cells with flavone inhibited the MNNG-induced decrease in $\mathrm{NAD}^{+}$-levels in a dose-dependent manner (Figure 
$3 \mathrm{~A})$. In the endothelial cells, $100 \mu \mathrm{M}$ flavone attenuated the MNNG-induced decrease in $\mathrm{NAD}^{+}$-levels to $73 \pm 13 \%$, whereas lower concentrations (10 and 1 $\mu \mathrm{M})$ could not prevent the MNNG-induced decrease in $\mathrm{NAD}^{+}$-levels (Figure 3B).
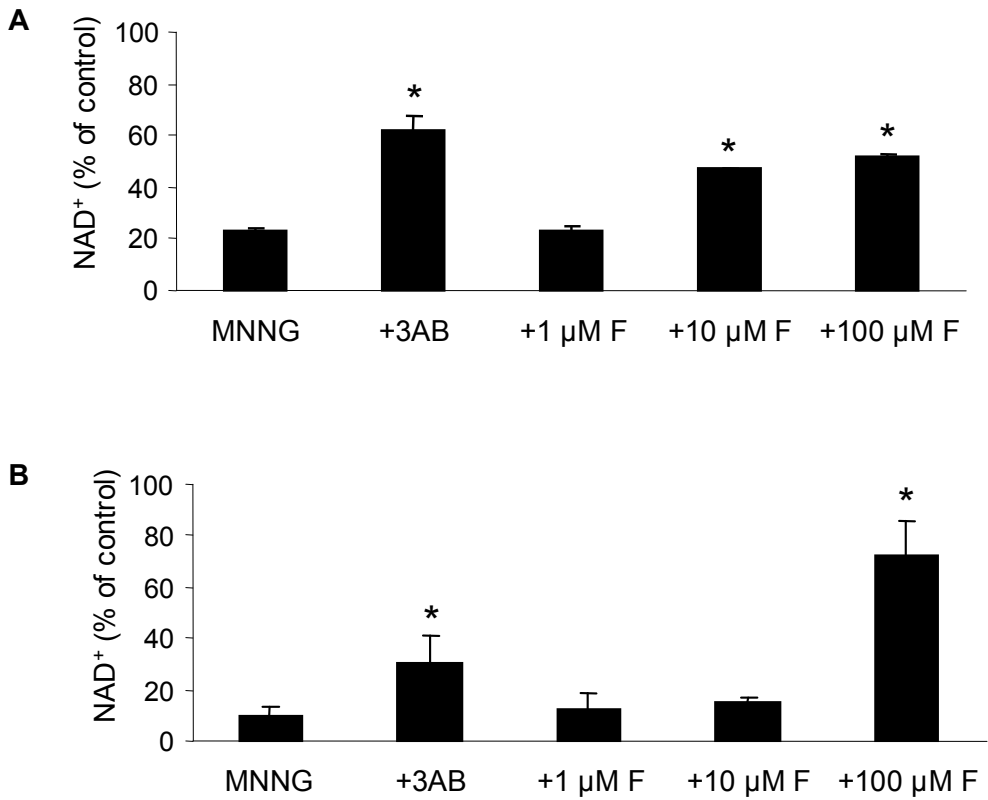

Figure 3. $\mathrm{NAD}^{+}$levels in $\mathrm{A} 549$ human pulmonary epithelial (A) and RF24 human vascular endothelial (B) cells after 30 min incubation with $25 \mu \mathrm{M}$ (A549) and $100 \mu \mathrm{M}$ (RF24) MNNG with or without 15 min pretreatment with 1, 10 and $100 \mu \mathrm{M}$ flavone or $100 \mu \mathrm{M} 3$-aminobenzamide (3AB) (positive control). Values are expressed as $\% \mathrm{NAD}^{+}$, with $100 \%$ representing $\mathrm{NAD}^{+}$levels of control incubation (without MNNG and flavone or $3 \mathrm{AB}$ ) and are mean \pm S.E.M. of 3 replicate experiments.

$* P<0.05$ vs incubation with MNNG without flavone or $3 \mathrm{AB}$.

\section{Effect of flavone on PAR-polymer formation in MNNG-treated A549 cells}

To confirm the PARP-1 inhibiting effect of flavone, PAR-polymer formation was measured in MNNG-treated A549 cells. Due to the very rapid catabolism of PAR-polymers by poly(ADP-ribose) glycohydrolase (PARG) [106], MNNG incubation time was reduced to 5 minutes. No PAR-polymer formation was observed in control cells. Treatment of the cells with MNNG for 5 minutes induced a massive increase of the number of PAR-polymer positive cells to 24 $\pm 1 \%$ (Figure 4 ). 
A
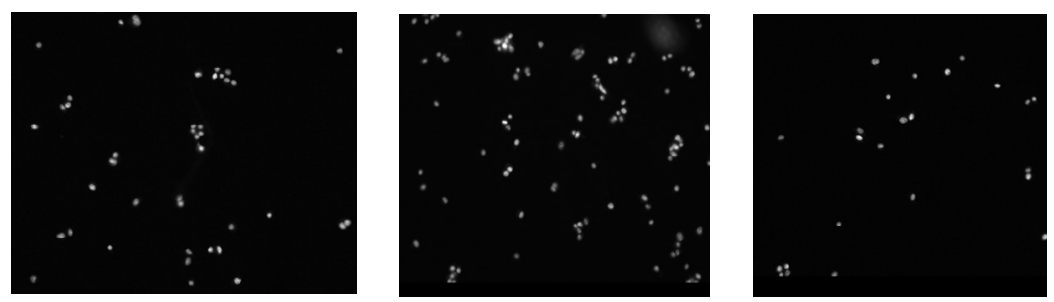

$\mathrm{B}$

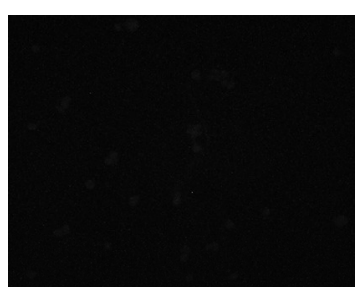

control

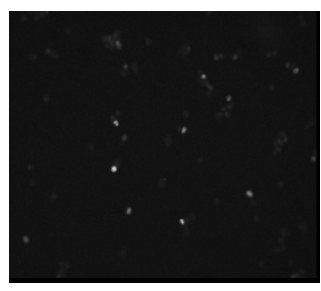

MNNG

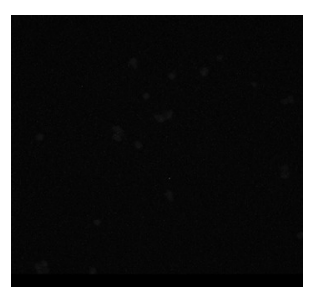

MNNG + $100 \mu \mathrm{M} \mathrm{F}$

Figure 4. Detection of PAR-polymer formation in MNNG-treated A549 cells with or without pretreatment with flavone after immunohistochemical staining. (A) Visualization of all nuclei with propidium iodide; (B) Nuclei stained positive for PAR-polymers. Magnification: 400X

A 15 min pretreatment with $100 \mu \mathrm{M}$ flavone significantly reduced the number of PAR-polymer positive cells to $1 \pm 1 \%$ and a dose-dependent effect could be observed (Figure 4 and Figure 5). The known PARP-inhibitors 3aminobenzamide and PJ34 were included as positive controls at similar concentrations and these also reduced the formation of PAR-polymers dosedependently (Figure 5).

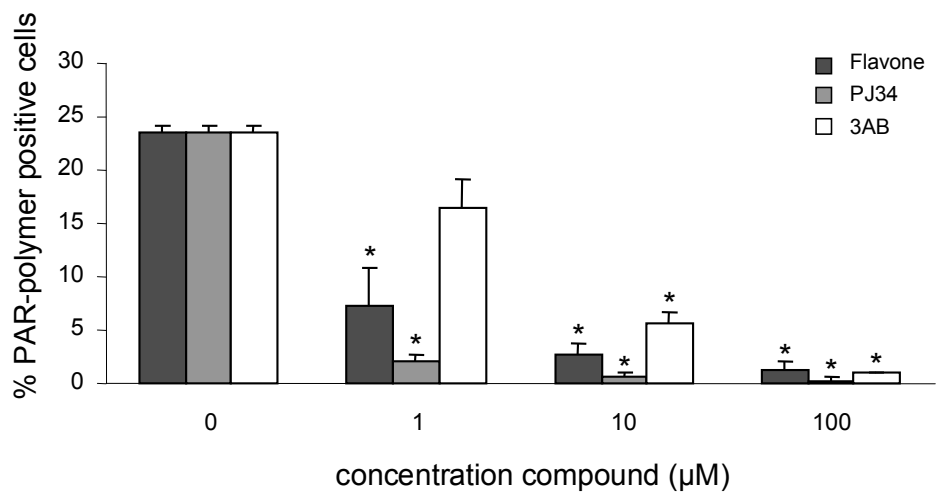

Figure 5. PAR-polymer formation in A549 lung epithelial cells. Cells were exposed to $25 \mu \mathrm{M}$ MNNG for 5 minutes and pre-exposed for 15 minutes to the flavonoid flavone or the synthetic PARP-1 inhibitors PJ34 or 3AB in concentrations of $0,1,10$ and $100 \mu \mathrm{M}$. Values are expressed as percentage PAR-polymer positive cells and are mean \pm S.E.M. of 3 replicate experiments.

${ }^{*} P<0.05$ vs incubation with MNNG without flavone, PJ34 or $3 \mathrm{AB}$. 


\section{Effect of flavone on LPS-stimulated A549 cells}

To investigate the effect of flavone on the inflammatory stress response medi-

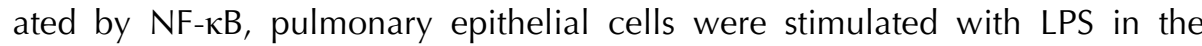
presence of flavone for 8, 16 and 24 h. Stimulation of A549 cells with 100 $\mathrm{ng} / \mathrm{ml}$ LPS resulted in the release of the chemokine IL-8, although other cytokines such as IL-6 and TNF- $\alpha$ could not be detected following stimulation with LPS (data not shown). Treatment of A549 cells with $10 \mu \mathrm{M}$ flavone significantly reduced the LPS-induced IL-8 release at 16 and $24 \mathrm{~h}$ after stimulation to respectively $53 \pm 7 \%$ and $63 \pm 3 \%$ of IL-8 levels of LPS-treated cells. At $24 \mathrm{~h}$ after stimulation, $1 \mu \mathrm{M}$ flavone also significantly reduced the LPS-induced IL-8 release (Figure 6).

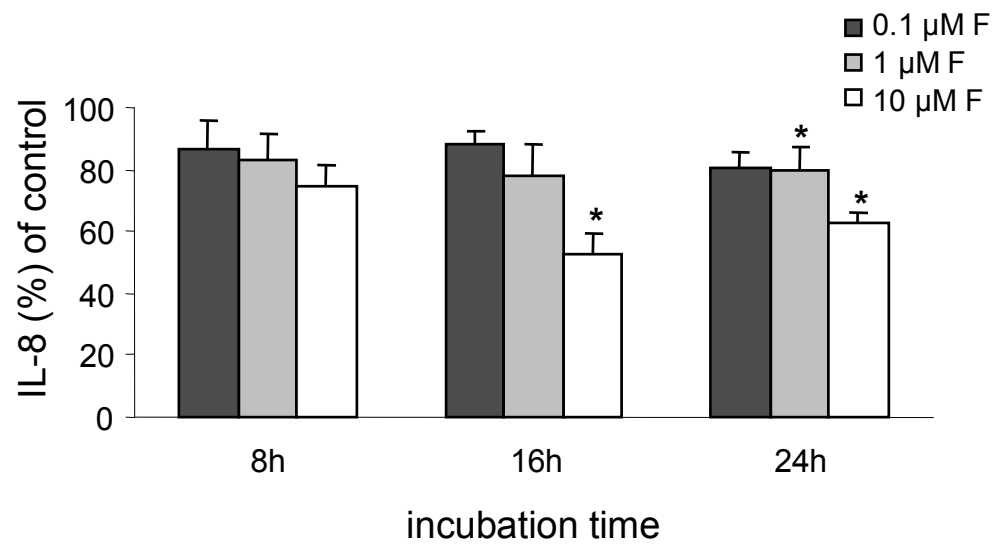

Figure 6. IL-8 production in LPS-stimulated A549 lung epithelial cells. Cells were exposed in a 6well plate to $100 \mathrm{ng} / \mathrm{ml}$ LPS for 8,16 or $24 \mathrm{~h}$ and pre-exposed for 30 minutes to $0,0.1,1$ and $10 \mu \mathrm{M}$ flavone. Values are expressed as percentage IL-8 production, with $100 \%$ representing IL-8 production in LPS-stimulated A549 cells (without flavone) and are mean \pm S.E.M. of 3 replicate experiments.

$* P<0.05$ vs incubation with LPS without flavone.

Real time PCR analysis confirmed the inhibiting effect of flavone on IL-8 transcription in LPS-stimulated A549 cells (Figure 7A). The transcription of $1 \kappa \mathrm{B} \alpha$ was induced after stimulation by LPS, as shown in Figure 7B. At time points $8 \mathrm{~h}$ and $16 \mathrm{~h}$, the transcription of $\mathrm{I}_{\kappa} \mathrm{B} \alpha$ was significantly increased by flavone. 

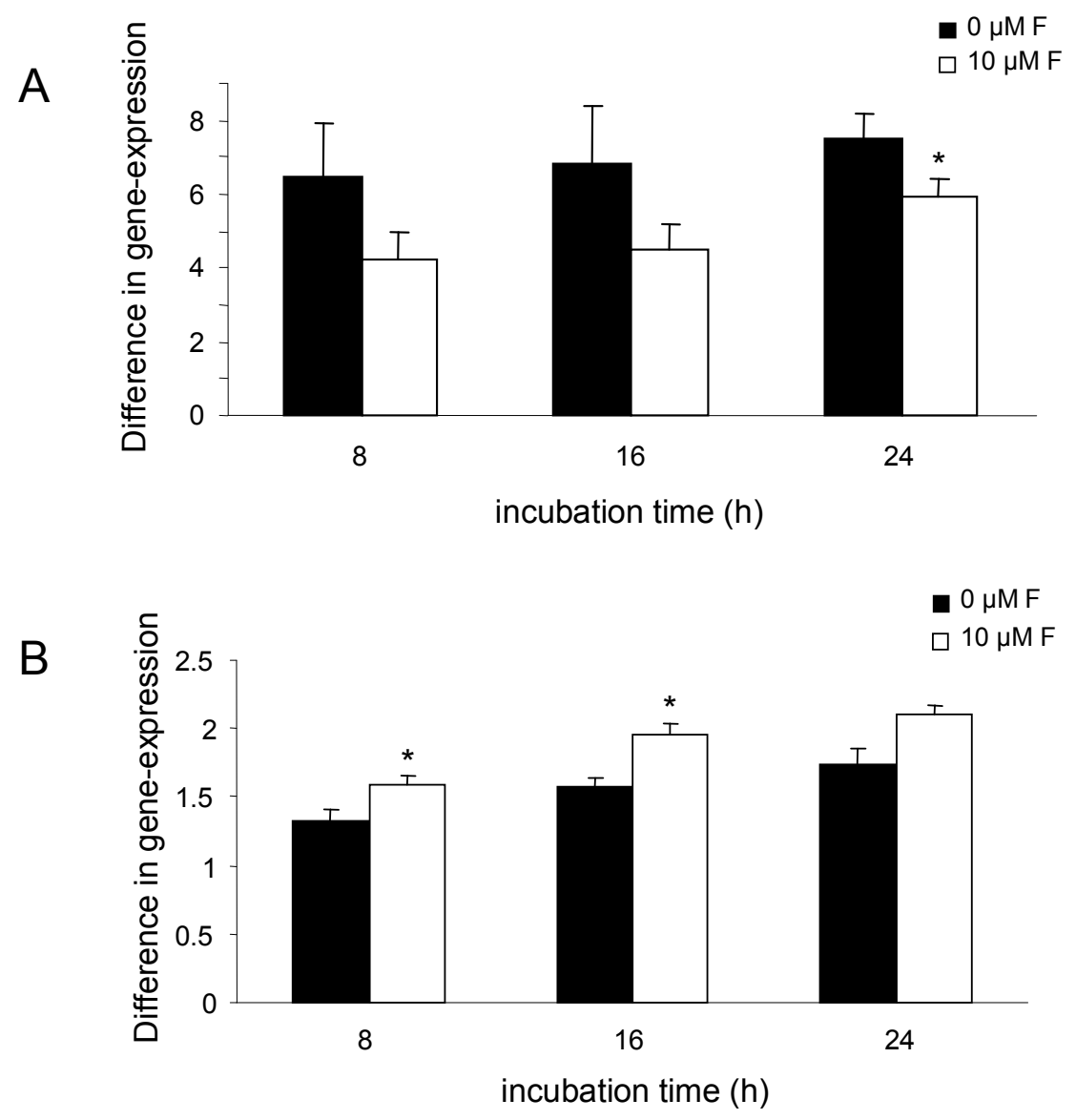

Figure 7. Gene-expression of IL-8 (A) and I $\mathrm{KB} \alpha$ (B) in LPS-stimulated A549 lung epithelial cells. Cells were exposed in a 6-well plate to $100 \mathrm{ng} / \mathrm{ml}$ LPS for 8,16 or $24 \mathrm{~h}$ and pre-exposed for 30 minutes to 0 and $10 \mu \mathrm{M}$ flavone. Gene expression was analysed using quantitative rtPCR and expressed as fold increase over control treatment $(=0 \mathrm{~h}-0 \mathrm{ng} / \mathrm{ml}$ LPS $)$ and are mean \pm S.E.M. of 3 replicate experiments.

$* P<0.05$ vs incubation with LPS without flavone.

However, no significant effect of flavone treatment on NF-kB nuclear translocation could be measured following various incubation times ranging from 15 min up to $24 \mathrm{~h}$ (Figure 8). Using immunocytochemical staining of the PARpolymers, no PARP-1 activation could be detected after treatment of the cells to LPS from 5 min up to $24 \mathrm{~h}$ after stimulation (data not shown). 


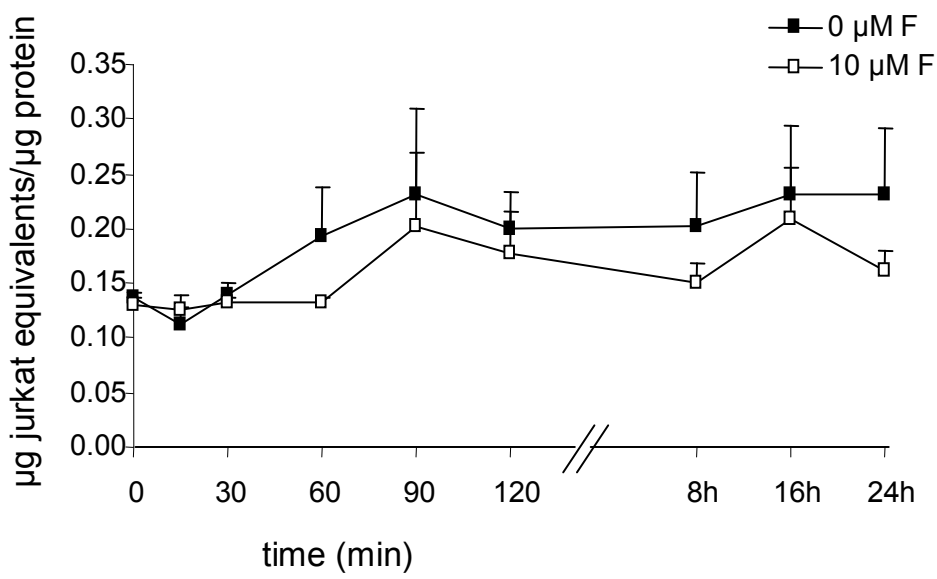

Figure 8. NF- $\kappa B$ nuclear translocation in LPS-stimulated A549 pulmonary epithelial cells after treatment with flavone. Cells were treated for various periods with $100 \mathrm{ng} / \mathrm{ml}$ LPS in the presence of 0 and $10 \mu \mathrm{M}$ flavone. Values are expressed as $\mu \mathrm{g}$ jurkat equivalents/ $\mu \mathrm{g}$ protein and are mean \pm S.E.M. of 3 replicate experiments.

\section{Determination of antioxidant activity of flavone}

To rule out any antioxidant effect of flavone, scavenging of hydroxyl radicals and quantification of the total antioxidant capacity were determined by ESR spectroscopy and the TEAC assay respectively. Hydroxyl radicals were generated by $\mathrm{H}_{2} \mathrm{O}_{2}$ in the presence of $\mathrm{FeSO}_{4}$. In combination with the spin-trap DMPO, stable DMPO-OH adducts were formed. Addition of flavone in various concentrations did not decrease the observed DMPO-OH signal (Figure 9). Addition of flavone to stable ABTS radicals in the TEAC assay did not cause a detectable reduction of the absorbance measured at $734 \mathrm{~nm}$. The TEAC value of flavone could therefore not be quantified.

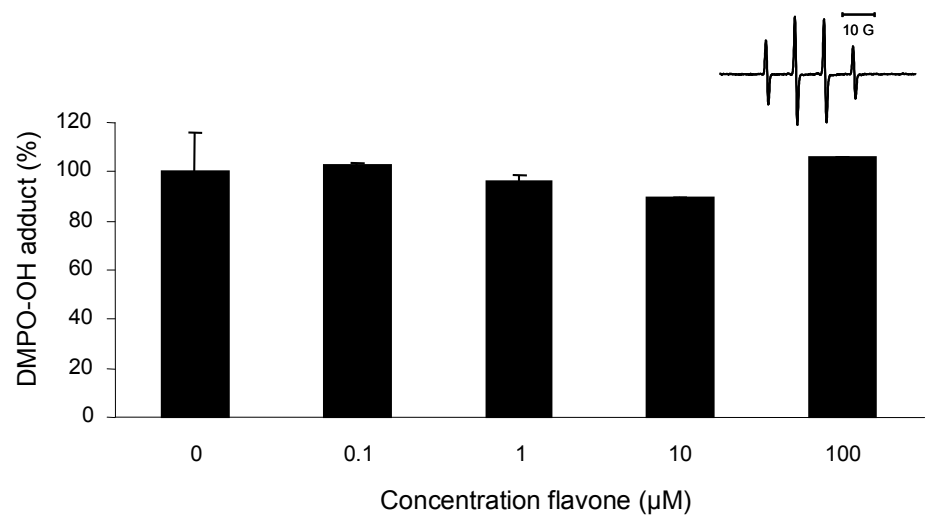

Figure 9. Hydroxyl radicals, generated by $\mathrm{FeSO}_{4}$ and $\mathrm{H}_{2} \mathrm{O}_{2}$, are not scavenged by flavone. Values are expressed as \% of control $\left(\mathrm{FeSO}_{4}+\mathrm{H}_{2} \mathrm{O}_{2}+\mathrm{DMPO}\right)$. Insert: ESR spectrum for the hydroxyl radical spin adduct (DMPO-OH). 


\section{DISCUSSION}

In this study, flavone was identified as an inhibitor of the nuclear enzyme PARP-1. Inhibition of the enzyme by flavone was also observed in experiments showing prevention of $\mathrm{NAD}^{+}$-depletion in MNNG-treated A549 and RF24 cells. This was further confirmed immunocytochemically, by a reduced PAR-polymer formation in MNNG-treated A549 cells in the presence of flavone. In addition, flavone was found to attenuate the LPS-induced inflammatory response in A549 lung epithelial cells.

Increased PARP-1 activation in chronic inflammation has been observed in endothelial cells of diabetes patients and in peripheral blood mononuclear cells of patients with the pulmonary disease COPD [30, 131]. In addition, inhibition of PARP-1 has been shown both in vitro and in vivo to reduce the production or expression of inflammatory mediators like iNOS, but also of pro-inflammatory cytokines like IL-6 and IL-8 in models for pulmonary inflammation, septic shock or streptozotocin-induced diabetes [26, 29, 33, 34]. PARP-1 was found to be required for DNA binding and to act as a co-activator of the transcription factor NF-kB $[11,19]$. However, others reported that the protein itself rather than the enzyme activity was required for NF-kB-mediated transcription [16]. $\mathrm{NF}-\mathrm{kB}$ mediates the gene expression of many cytokines, chemokines and enzymes, and activation of NF-kB was observed in pulmonary inflammatory diseases like asthma and COPD [132].

In this study, the effect of the PARP-1 inhibiting flavonoid flavone on LPSinduced expression and production of pro-inflammatory cytokines was investigated by measuring the production of IL-8, TNF- $\alpha$ and IL- 6 in A549 pulmonary epithelial cells. These cells did not show an increased production of TNF- $\alpha$ and IL-6 in response to LPS, which has also been observed previously [133]. Therefore, evaluation of the anti-inflammatory effect of flavone focussed on IL8. IL-8 is a chemokine released during inflammation and is important in the recruitment and activation of immune and inflammatory cells such as neutrophils [134]. Increasing levels of IL-8 have been observed in plasma and broncheoalveolar lavage (BAL) fluids of patients with pulmonary inflammatory diseases like COPD and asthma [30, 135-137]. In the present study, it was found that flavone dose-dependently reduced IL-8 production and these results were confirmed by transcription analysis of IL-8. Since the transcription factor $\mathrm{NF}-\mathrm{KB}$ is involved in the transcriptional regulation of IL-8 [109], the mechanism underlying the effect of flavone on NF- $\mathrm{kB}$ was investigated. A slight, but not significant, reduction in nuclear translocation and activation of NF- $\mathrm{kB}$ was observed after treatment with flavone. However, transcription analysis of the inhibitor protein $I \kappa B \alpha$ revealed a stimulating effect of flavone on the expression of $I \kappa B \alpha$, which was found to be significantly increased at $8 \mathrm{~h}$ and $16 \mathrm{~h}$. Inhibitor proteins $I \kappa B \alpha$ and $I \kappa B \beta$ regulate activation of $N F-\kappa B$ via a feedback effect. 
Stimulation by extracellular inducers such as cytokines, $\gamma$-radiation or oxidants causes the rapid phosphorylation and degradation of I $\mathrm{kB}$ by $\mathrm{I}_{\mathrm{N}} \mathrm{B}$ kinase (IKK). The unbound activated NF- $\mathrm{KB}$ translocates to the nucleus, where it binds to specific $\kappa B$ consensus sequences in the chromatin and upregulates expression of many genes involved in the immune and inflammatory response. In addition, due to the presence of a $\kappa \mathrm{B}$ recognition sequence in the promotor region of the I $\kappa \mathrm{B} \alpha$-gene, NF- $\kappa \mathrm{B}$ activation induces the up-regulation of I $\mathrm{KB} \alpha$ transcription which eventually leads to a termination of the NF-kB signal [138]. Since PARpolymer formation could not be detected in LPS-stimulated A549 cells, the PARP-1 inhibiting effect of flavone could not be demonstrated at the level of PAR-polymer formation. This may be due to the very rapid catabolism of PARpolymers by poly(ADP-ribose) glycohydrolase (PARG) [106] and the application of a mild LPS-stimulus of $100 \mathrm{ng} / \mathrm{ml}$. PAR-polymer formation was not detected either by Erdelyi et al. (2005) in TNF- $\alpha$ and IL-1 $\beta$ stimulated cells using immunohistochemistry [116].

Using ESR spectroscopy and the TEAC assay, scavenging of (hydroxyl) radicals by flavone was evaluated. As expected, flavone did not show any relevant radical scavenging activity. This implies that the observed anti-inflammatory effects could not be attributed to antioxidant properties.

In conclusion, these data indicate that the flavonoid flavone has significant PARP-1 inhibiting activity, reduces the LPS-induced transcription and production of the pro-inflammatory chemokine IL-8 and increases the transcription of $I \kappa B \alpha$. Since transcription of IL- 8 and $I \kappa B \alpha$ are mediated by $N F-\kappa B$, these data indicate that flavone attenuates the NF- $\mathrm{KB}$ mediated inflammatory response. Whether this is due to its PARP-1 inhibiting activity remains to be determined, since in this study no PAR-polymer formation could be detected after LPSstimulation of A549 cells.

Activation of PARP-1 has been observed in vascular dysfunction in diabetes and COPD [30, 83]. Under conditions of acute exacerbations in COPD and of high blood glucose levels in diabetes, increased oxidative stress and PARP-1mediated decline of intracellular $\mathrm{NAD}^{+}$and ATP contribute to tissue damage and may enhance inflammation. Therefore, attenuation of PARP-1 activation in these conditions might reduce the increased demand for energy, decrease tissue damage and improve inflammatory conditions. Based on the results of the current study, the flavonoid flavone appears to be a promising candidate in the treatment of chronic inflammatory diseases such as COPD and vascular dysfunction in diabetes. 



\title{
CHAPTER 5
}

\author{
Anti-inflammatory effects of specific \\ PARP-1 inhibiting flavonoids in a \\ mouse model of lipopolysaccharide \\ induced acute pulmonary inflammation
}

Liesbeth Geraets Astrid Haegens

Karen Brauers Jane A Haydock Juanita HJ Vernooy Emiel FM Wouters

Aalt Bast

Geja J Hageman 


\section{ABSTRACT}

Dietary flavonoids are currently extensively investigated for their putative positive health effects. Previously, we observed significant in vitro poly(ADPribose) polymerase-1 (PARP-1) inhibiting effects of specific flavonoids in addition to the well-documented antioxidant and anti-inflammatory effects. In addition, it was observed that PARP-1 plays a mediating role in lipopolysaccharide (LPS)-induced acute pulmonary inflammation. Therefore, in the present study, the anti-inflammatory effects of the PARP- 1 inhibiting flavonoids flavone, fisetin and tricetin were evaluated in an in vivo mouse model of LPS-induced acute pulmonary inflammation. Furthermore, the effects of the flavonoids were compared to those of the anti-inflammatory glucocorticoid dexamethasone. The flavonoid fisetin significantly reduced lung myeloperoxidase (MPO)-levels and gene-expression of inflammatory mediators such as interleukin (IL)-6, tumor necrosis factor (TNF)- $\alpha$, IL-1 $\beta$, macrophage inflammatory protein (MIP)$1 \alpha$ and MIP-2. The LPS-induced gene transcription of heme oxygenase (HO)-1 and superoxide dismutase (SOD)2 was also significantly reduced by fisetin. Flavone and tricetin also showed attenuation of inflammatory markers, but appeared to have lower efficacy than fisetin. Both fisetin as well as dexamethasone attenuated the LPS-induced PARP-1 activation in pulmonary epithelial cells. Overall, the anti-inflammatory effects of fisetin in this in vivo model were much more pronounced as compared to the observed effects of dexamethasone. The results of this study indicate that flavonoids such as fisetin might be potential candidates as nutraceuticals in the treatment of pulmonary inflammatory diseases. 


\section{INTRODUCTION}

Flavonoids are a group of polyphenolic compounds, present in fruits, vegetables and beverages such as red wine and tea. Since the intake of flavonoids has been associated with a reduced risk for cardiovascular or chronic inflammatory diseases, this group of naturally occurring compounds is extensively investigated for their putative positive health effects [51, 57]. Recently, we reported that the flavonoids quercetin, tricetin, fisetin and flavone exerted poly(ADPribose) polymerase-1 (PARP-1) inhibiting activity and attenuated the lipopolysaccharide (LPS)-induced interleukin (IL)-8 release in pulmonary epithelial cells $[139,140]$. Furthermore, flavone reduced the nuclear factor-kappa B (NF-kB) mediated gene-transcription of IL-8 and increased the transcription of $I \kappa B \alpha$ in pulmonary epithelial cells, suggesting that the NF-kB mediated inflammatory response was attenuated by flavone [140]. Based on the PARP-1 inhibiting and anti-inflammatory activity, it was suggested that these food-derived compounds might be applied in the treatment of inflammatory diseases, such as chronic obstructive pulmonary disease (COPD). Until now, no effective treatment for these diseases has been developed yet, and these flavonoids may offer a new therapeutic potential. Previously, Liaudet et al. (2002) demonstrated that PARP1 inhibition by synthetic compounds attenuated the LPS-induced acute pulmonary inflammation [29]. Therefore, we aimed at evaluating the PARP-1 inhibiting flavonoids in a model for acute pulmonary inflammation.

In the present study, the effect of the orally administered PARP-1 inhibiting flavonoids flavone, fisetin and tricetin was investigated on intratracheally LPSinduced pulmonary inflammation and oxidative stress in mice. Furthermore, the effects were compared to the anti-inflammatory glucocorticoid dexamethasone.

\section{MATERIAL AND METHODS}

\section{Animals}

Male C57BL/6 mice (12 weeks) were obtained from Charles River (Maastricht, The Netherlands). Animals were housed individually in standard laboratory cages and allowed food and water ad libitum during the experiments. The experiments were approved by the Ethics Committee for Animal Experiments of Maastricht University (Maastricht, The Netherlands).

\section{Experimental protocol}

On 4 consecutive days, mice ( $\mathrm{n}=6 /$ group) received the compounds via oral gavage $(22.2 \mathrm{mg}$ flavone, $28.6 \mathrm{mg}$ fisetin, $30.2 \mathrm{mg}$ tricetin or $2.0 \mathrm{mg}$ dexamethasone/kg bodyweight). The daily administered doses of the flavonoids 
were equal to $100 \mu \mathrm{mol} / \mathrm{kg}$ bodyweight. In a previous in vitro study we found that these flavonoids showed similar PARP-1 inhibiting activity as compared to the synthetic PARP-1 inhibitor 3-aminobenzamide [139, 140].

The anti-inflammatory glucocorticoid dexamethasone was also applied in this model at a reported anti-inflammatory dose of $2 \mathrm{mg} / \mathrm{kg}$ bodyweight/day [141, 142]. Prior to administration, each compound was freshly suspended in soy oil, which was also used as vehicle control ( $5 \mathrm{ml}$ soy oil $/ \mathrm{kg}$ bodyweight). Soy oil was chosen since previous findings indicated that co-administration of lipids such as soy bean or lecithin enhanced and accelerated the oral bioavailability of the flavonoid aglycone quercetin from the diet [143]. At day 4, one hour after the final oral administration mice received LPS intratracheally. Intratracheal (IT) instillation technique was performed via a non-surgical procedure according to Vernooy et al. [144]. Mice were anesthesized by subcutaneous injection with ketamin hydrochloride (Nimatek; Eurovet, Bladel, The Netherlands) and xylazine hydrochloride (Xylaject; Dopharma, Raamsdonksveer, The Netherlands). LPS (O55:B5, Sigma, Darmstadt, Germany), dissolved in $50 \mu \mathrm{l}$ sterile $0.9 \% \mathrm{NaCl}$, was instilled intratracheally $(20 \mu \mathrm{g} /$ mouse) via a canule and syringe $(2 \times 25 \mu \mathrm{l})$, followed by $100 \mu \mathrm{l}$ air. Sham-treated mice were instilled intratracheally with $50 \mu \mathrm{l}$ sterile $0.9 \% \mathrm{NaCl}$. After IT treatment, mice were kept in an upright position for 10 minutes to allow the fluid to spread throughout the lungs. Mice were killed $4 \mathrm{~h}$ and $24 \mathrm{~h}$ after IT treatment while under pentobarbital (Nembutal, Ceva Sante Animale, Naaldwijck, The Netherlands) anesthesia. Blood was collected via heart puncture in EDTA-containing tubes, immediately centrifuged $\left(2000 \mathrm{xg}, 10 \mathrm{~min}, 4^{\circ} \mathrm{C}\right)$ and plasma was stored at $-80^{\circ} \mathrm{C}$. Lungs were removed and lung tissue was snap-frozen for RNA-isolation and myeloperoxidase (MPO) analysis. For immunohistochemical analyses, lung tissue was inflated with $10 \%$ phosphate-buffered formalin $(\mathrm{pH} \mathrm{7.4)}$ through the trachea and subsequently fixed in formalin for $24 \mathrm{~h}$ after which it was further processed for immuno-histochemical staining.

\section{Dose and time finding study}

Initial data were obtained using various time points (2-4-6-8-12-24-48-72-96h) as well as various LPS concentrations (0-10-20-40 $\mu \mathrm{g}$ LPS), with MPO-activity in lung homogenates as primary parameter. These data revealed that the inflammatory response was starting to develop at $4 \mathrm{~h}$ after LPS-treatment. At $24 \mathrm{~h}$ after LPS-treatment ( $20 \mu \mathrm{g}$ /mouse), the LPS-induced inflammatory processes reached maximum levels. Therefore, these time points were selected to investigate whether oral administration of PARP-1 inhibitors might suppress early development of the inflammatory response as well as reduce its intensity.

\section{MPO-analysis}

MPO activity in the dose and time finding study was measured in homogenates 
using a MPO activity assay kit (Cytostore, Calgary, Canada) according to the manufacturer's instruction. Briefly, snap-frozen lung tissue was homogenized in hexadecyltri-methylammonium bromide (HTAB)-buffer. Approximately $50 \mu \mathrm{l}$ HTAB-buffer was added to $1 \mathrm{mg}$ of lung tissue. After centrifugation (10000xg, $2 \mathrm{~min}, 4^{\circ} \mathrm{C}$ ), lung homogenates were kept on ice and MPO-activity was determined according to the manufacturer's protocol during 5 minutes at $450 \mathrm{~nm}$. However, to exclude any interference of the applied compounds with the activity measurements, MPO protein levels were further determined quantitatively using a mouse MPO ELISA kit (HBT, Uden, The Netherlands) according to the manufacturer's instruction. Prior to this analysis, snap-frozen lung tissue was ground to a powder in a stainless steel mortar under liquid nitrogen and homogenized in a lysis buffer containing $200 \mathrm{mM} \mathrm{NaCl}, 5 \mathrm{mM}$ EDTA, $10 \mathrm{mM}$ tris, $10 \%$ glycine, $1 \mathrm{mM}$ PMSF, $1 \mu \mathrm{g} / \mathrm{ml}$ leupeptide and $28 \mu \mathrm{g} / \mathrm{ml}$ aprotinine $(\mathrm{pH}$ 7.4). Approximately $20 \mu \mathrm{l}$ lysisbuffer was added to $1 \mathrm{mg}$ tissue. After centrifugation $\left(10000 x g, 15 \mathrm{~min}, 4^{\circ} \mathrm{C}\right)$, lung homogenates were stored at $-80^{\circ} \mathrm{C}$. Myeloperoxidase protein levels in lung tissue homogenate were quantitatively determined using the ELISA kit. The protein concentration was determined according to the BCA method (Pierce, Rockford, IL, USA). The amount of MPO was expressed as ng MPO/mg protein. Measurement of MPO-activity in the dose and time finding study revealed that in addition to increased MPO-protein levels, MPO-activity was also increased after LPS-treatment (data not shown).

\section{Gene transcription analysis by quantitative PCR}

Snap-frozen lung tissue was ground to a powder in a stainless steel mortar under liquid nitrogen and homogenized in Trizol Reagent (Invitrogen, Carlsbad, CA, USA). Total RNA isolation was performed according to the manufacturer's instructions. Concentration of the isolated total RNA was determined spectrophotometrically at 260 and $280 \mathrm{~nm}$. Reverse transcription reaction was performed using $1 \mu \mathrm{g}$ of total RNA and reverse-transcribed into cDNA using iScript $^{\mathrm{TM}}$ cDNA Synthesis Kit (Biorad Laboratories, Hercules, CA, USA). Subsequently, real time PCR was performed with a MyiQ Single Colour real time PCR detection system (BioRad) using SYBR $\odot$ Green Supermix (Biorad), $5 \mu \mathrm{l}$ diluted (10x) CDNA, and $0.3 \mu \mathrm{M}$ primers in a total volume of $25 \mu \mathrm{l}$. PCR was conducted as follows: denaturing at $95^{\circ} \mathrm{C}$ for $3 \mathrm{~min}$, followed by 40 cycles of $95^{\circ} \mathrm{C}$ for 15 seconds and $60^{\circ} \mathrm{C}$ for 45 seconds. After the PCR procedure, a melt curve $\left(60-95^{\circ} \mathrm{C}\right)$ was produced for product identification and control of purity. $\beta$-Actin was included as an internal control gene, since the various treatments did not influence its gene-expression. rtPCR primers were designed using Primer express software (Applied Biosystems). Primer sequences used were as follows:

TNF- $\alpha$ 5'-GACCCTCACACTCAGATCATCTTCT (forward) and 5'-CCACTTGGT GGTTTGCTACGA (reverse), IL-6 5'-ACAAGTCGGAGGCTTAATTACACAT 
(forward) and 5'-AATCAGAATTGCCATTGCACAA (reverse), MIP-2 5'-GAACAT CCAGAGCTTGAGTGTGA (forward) and 5'-CTTGAGAGTGGCTATGACTTCTG TC (reverse), MIP-1 $\alpha$ 5'-ACTATTTTGAAACCAGCAGCCTTT (forward) and 5'GATCTGCCGGTTTCTCTTAGTCA (reverse), I $\mathrm{k} \alpha$ 5'-CGGAGGACGGAGACTC GTT (forward) and 5'-TTCACCTGACCAATGACTTCCA (reverse), IL-1 $\beta$ 5'AATCTATACCTGTCCTGTGTAATGAAAGAC (forward) and 5'-TGGGTATTGCT TGGGATCCA (reverse), heme oxygenase (HO)-1 5'-CCGCCTTCCTGCTCAAC AT (forward) and 5'-CATCTGTGAGGGACTCTGGTCTT (reverse), superoxide dismutase (SOD)2 5'-AGGCTATCAAGCGTGACTTTGG (forward) and 5'TGAACCTTGGACTCCCACAGA (reverse), $\beta$-Actin 5'-CGTGAAAAGATGACCC AGATCA (forward) and 5'-CACAGCCTGGATGGCTACGT (reverse). Data were analysed using the MyiQ Software system (BioRad) and were expressed as relative gene expression (fold increase) using the $2^{-\Delta \Delta_{\mathrm{Ct}}}$ method [129].

\section{Immunohistochemical staining of poly ADP-ribose (PAR)-polymers}

The presence of PAR-polymers was determined using immunohistochemical staining. Briefly, paraffin sections were deparaffinized and rehydrated. Endogenous peroxidase was quenched with $0.3 \%$ hydrogen peroxidase. For antigen retrieval, sections were incubated with trypsin for $10 \mathrm{~min}$ at $37^{\circ} \mathrm{C}$. After blocking the sections with $10 \%$ non fat dry milk for $10 \mathrm{~min}$ and $10 \%$ goat serum for $15 \mathrm{~min}$, sections were incubated overnight with the primary polyclonal antibody to PAR (96-10-04, Alexis, Lausen, Switserland). Next, sections were incubated with a biotinylated goat anti-rabbit immunoglobulin (Dako, Glostrup, Denmark), followed by incubation with avidin-peroxidase (ABC-kit, Vectastain) for $30 \mathrm{~min}$ and 3,3'diaminobenzidine for $10 \mathrm{~min}$. Sections were counterstained with hematoxylin, dehydrated and mounted with Entellan (Merck). Slides containing the stained lung section were encoded and at least 200 epithelial cells were evaluated for the presence of PAR-polymers in their nuclei.

\section{Mice plasma serum amyloid $\mathbf{p}$ component and IL-6 analysis}

Plasma serum amyloid $p$ component (SAP) levels were determined using a quantitative ELISA-based test kit (Gentaur, Brussels, Belgium). Plasma IL-6 levels were determined using a Mouse IL-6 Immunoassay kit (R\&D Systems, Minneapolis, USA).

\section{Statistical Analysis}

Results are reported as mean \pm SEM. Statistical analyses were carried out using SPSS 14.0. Data appeared not normally distributed and were therefore evaluated with non-parametric tests. The data of the LPS-treated mice at $4 \mathrm{~h}$ and $24 \mathrm{~h}$ after IT LPS-treatment compared to the $\mathrm{NaCl}$-treated mice were evaluated using Mann-Whitney test. Furthermore, the effect of treatment with the flavonoids 
flavone, fisetin and tricetin or dexamethasone on the LPS-induced changes of inflammatory markers and the efficiency between fisetin and dexamethasone was evaluated using Kruskal-Wallis test followed by posthoc test of Siegel and Castellan [145]. Differences were considered to be statistically significant at P $<0.05$.

\section{RESULTS}

\section{Neutrophil infiltration in lungs}

The amount of MPO protein in lung tissue homogenates was determined as a measure for influx of neutrophils (Figure 1). At $4 \mathrm{~h}$ after LPS-stimulation, slightly but not significantly increased levels of MPO were observed. Intratracheal instillation of mice with LPS significantly increased lung MPO-levels at $24 \mathrm{~h}$ after LPS-treatment. Previous oral administration of flavone, fisetin and tricetin significantly reduced MPO-levels in lungs at $24 \mathrm{~h}$ after LPS-treatment. Pretreatment of the mice with dexamethasone also significantly attenuated lung MPOlevels at $24 \mathrm{~h}$ after IT LPS treatment. Fisetin pretreatment had a significantly stronger reducing effect on MPO-levels than dexamethasone pretreatment.

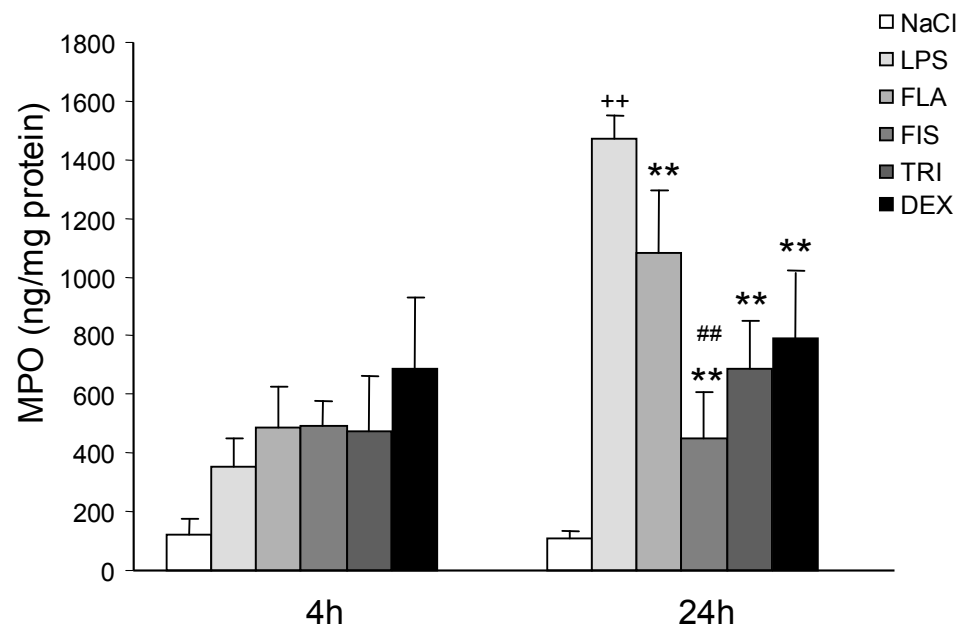

Figure 1. MPO-protein levels in lungs after IT LPS instillation of C57BL/6 mice. Mice orally received flavone (FLA), fisetin (FIS), tricetin (TRI) and dexamethasone (DEX) for 4 consecutive days prior to the LPS-challenge. MPO-levels were determined at $4 \mathrm{~h}$ and $24 \mathrm{~h}$ after LPS-treatment. MPO levels are expressed as ng MPO/mg protein and are mean \pm SEM of 6 mice.

$++P<0.05$ vs $24 \mathrm{~h} \mathrm{NaCl}$-treated mice

** $P<0.05$ vs $24 \mathrm{~h}$ LPS-treated mice without flavonoids or DEX

$\# \# P<0.05$ vs $24 \mathrm{~h}$ LPS+DEX-treated mice 


\section{Gene-expression in lung tissue}

Chemokine and cytokine expression in lung tissue

Since PARP-1 is involved in both the NF- $\mathrm{KB}$ and activator protein-1 (AP-1) pathways [11, 15, 82], the effect of oral administration of PARP-1 inhibiting flavonoids on these pathways was evaluated by measuring transcription of $\mathrm{IkB} \alpha, \mathrm{IL}-1 \beta, \mathrm{IL}-6$ and TNF- $\alpha$ and also of the chemokines MIP- $1 \alpha$ and MIP-2 (Figure 2).
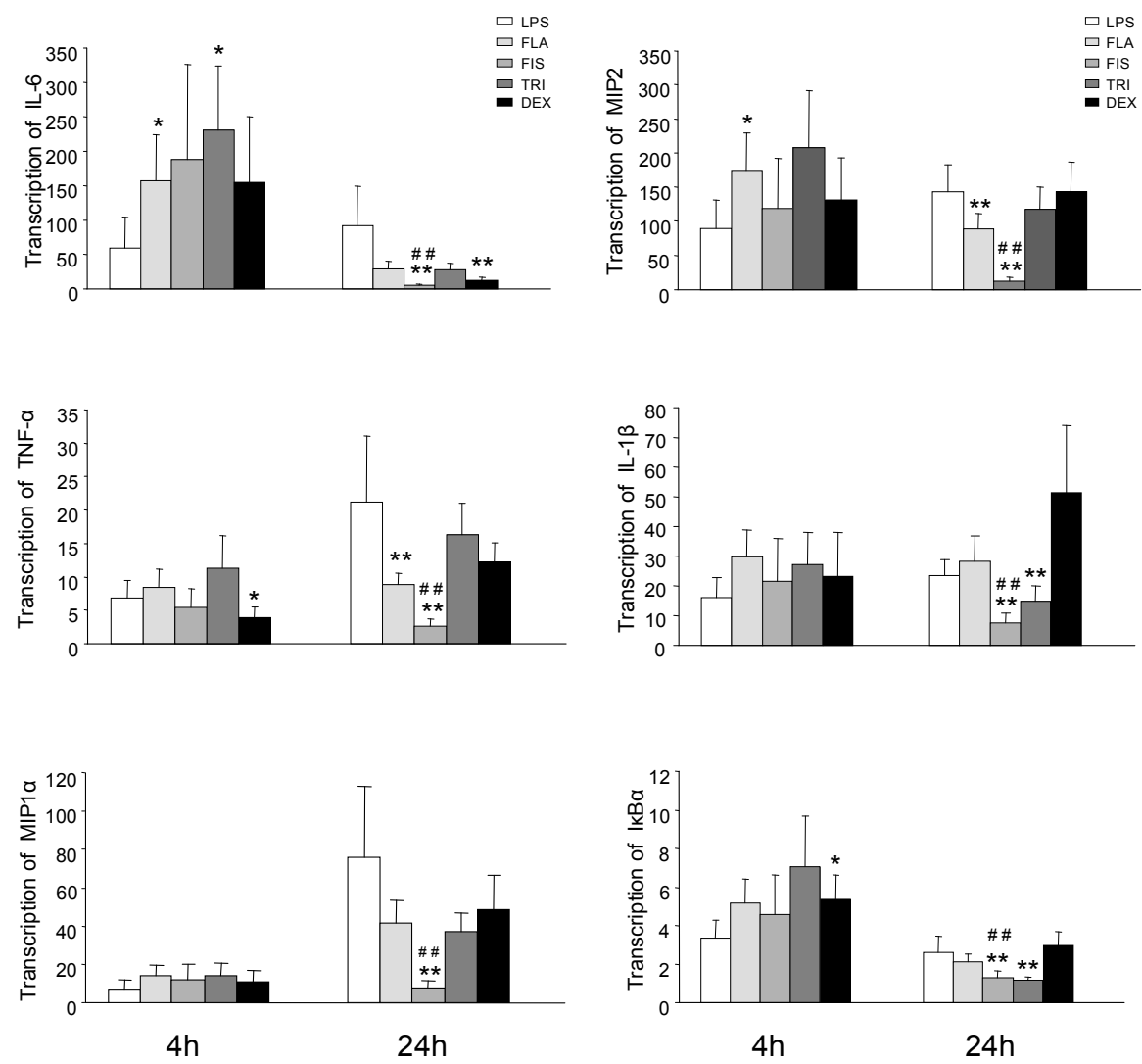

Figure 2. Transcription of the chemokines and cytokines IL-6, TNF- $\alpha$, MIP- $1 \alpha$, MIP-2, IL-1 $\beta$, I $\mathrm{B} \alpha$ in lungs of IT LPS-treated C57BL/6 mice. Mice orally received flavone (FLA), fisetin (FIS), tricetin (TRI) and dexamethasone (DEX) for 4 consecutive days prior to the LPS-challenge. Gene expression was determined $4 \mathrm{~h}$ and $24 \mathrm{~h}$ after LPS-challenge and was analysed using quantitative PCR and expressed as fold increase over control treatment $(=\mathrm{NaCl})$ and are mean \pm SEM of 6 mice.

$* P<0.05$ vs 4 h LPS-treated mice without flavonoids or DEX

** $P<0.05$ vs $24 \mathrm{~h}$ LPS-treated mice without flavonoids or DEX $\# \# P<0.05$ vs $24 \mathrm{~h}$ LPS+DEX-treated mice 
IT LPS-treatment increased gene-expression of IL-6, TNF- $\alpha$, IL-1 $\beta$ and I $\mathrm{KB} \alpha$, MIP-1 $\alpha$ and MIP-2 both at $4 \mathrm{~h}$ and $24 \mathrm{~h}$. A 4-day oral administration of fisetin significantly reduced transcription of IL- 6 , TNF- $\alpha$, MIP- $1 \alpha$, MIP-2, IL-1 $\beta$, IкB $\alpha$ at $24 \mathrm{~h}$ after IT LPS. Oral administration of mice with flavone and tricetin significantly increased gene transcription of IL- 6 at $4 \mathrm{~h}$ after LPS treatment, whereas $\mathrm{TNF}-\alpha$ gene transcription was reduced at $24 \mathrm{~h}$ after LPS treatment in mice receiving flavone. Flavone pretreatment also reduced MIP-2 gene-transcription at $24 \mathrm{~h}$ after LPS treatment, but at $4 \mathrm{~h}$ after LPS-treatment an increased transcription was observed. Tricetin reduced transcription of IL-1 $\beta$ and I $\mathrm{KB} \alpha$ at $24 \mathrm{~h}$ after LPS treatment. Dexamethasone treatment reduced the transcription of the IL-6 gene at $24 \mathrm{~h}$ and of TNF- $\alpha$ at $4 \mathrm{~h}$ after LPS-treatment. An increased $I_{\kappa} \mathrm{B} \alpha$ genetranscription was observed at $4 \mathrm{~h}$ after LPS treatment in the dexamethasone pretreated mice.

Antioxidant expression in lung tissue

Since the administered flavonoids fisetin and tricetin are known to have antioxidant effects, transcription of the redox-regulated HO-1 and the antioxidant SOD2 genes was also investigated. Both genes were significantly upregulated following LPS-treatment (Figure 3). HO-1 gene transcription was significantly reduced in fisetin pretreated mice at $4 \mathrm{~h}$ and $24 \mathrm{~h}$ and in flavone pretreated mice at $24 \mathrm{~h}$ after LPS-treatment. Dexamethasone pretreatment significantly increased $\mathrm{HO}-1$ gene transcription at both time points, indicating increased oxidative stress. SOD2 gene transcription was significantly reduced in mice receiving fisetin ( $4 \mathrm{~h}$ and $24 \mathrm{~h}$ ), flavone (24h), tricetin (24h). At $4 \mathrm{~h}$ after LPS-treatment, flavone as well as dexamethasone administration increased gene transcription of SOD2. 

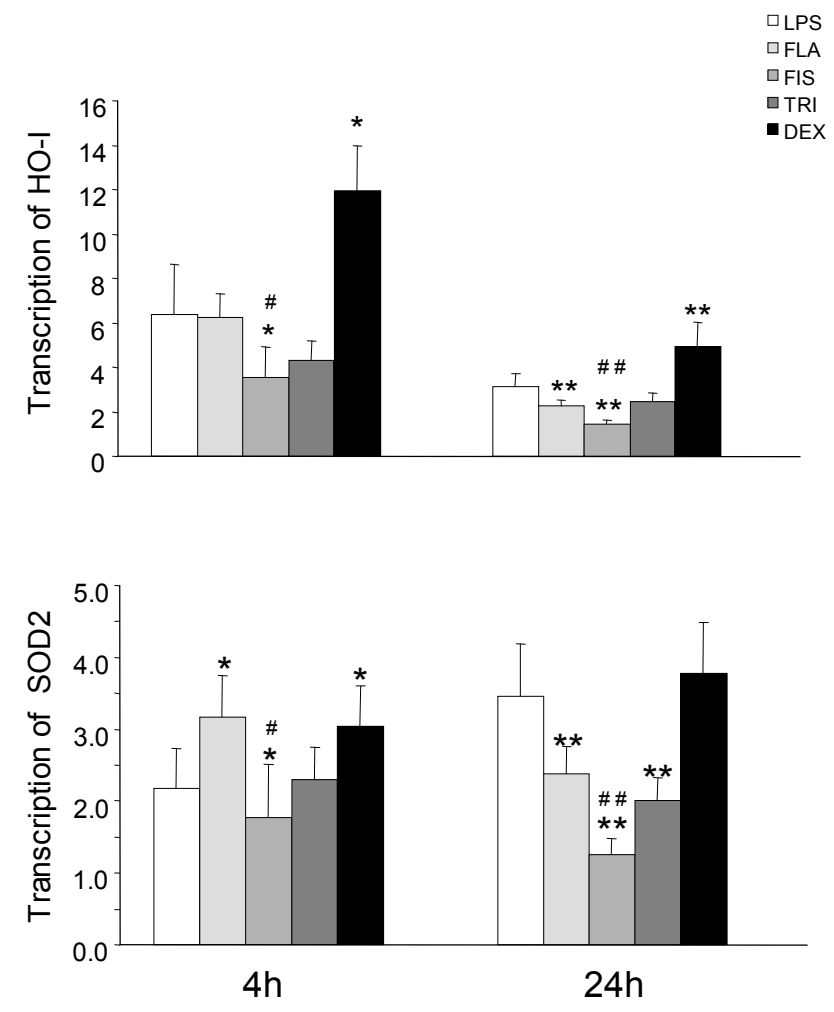

Figure 3. Transcription of HO-1 and SOD2 in lungs of IT LPS-treated C57BL/6 mice. Mice orally received flavone (FLA), fisetin (FIS), tricetin (TRI) and dexamethasone (DEX) for 4 consecutive days prior to the LPS-challenge. Gene expression was determined $4 \mathrm{~h}$ and $24 \mathrm{~h}$ after LPS-challenge and was analysed using quantitative PCR and expressed as fold increase over control treatment $(=\mathrm{NaCl})$ and are mean \pm SEM of 6 mice.

$* P<0.05$ vs 4 h LPS-treated mice without flavonoids or DEX

** $P<0.05$ vs $24 \mathrm{~h}$ LPS-treated mice without flavonoids or DEX

$\# P<0.05$ vs 4 h LPS+DEX-treated mice

$\# \#>0.05$ vs $24 \mathrm{~h}$ LPS+DEX-treated mice

\section{PAR-polymer formation in LPS-exposed lungs}

The extent of PARP-1 activation in LPS-exposed lungs was determined by evaluating the presence of PAR-polymers in the nuclei of pulmonary epithelial cells. It was observed that intratracheal treatment of mice with LPS induced PARP-1 activation, as was indicated by the presence of PAR-polymers in the epithelial cells. This was most apparent at $24 \mathrm{~h}$ after LPS-exposure. At $4 \mathrm{~h}$ after LPS-exposure, a small number of epithelial cells showed PAR-polymers in the nuclei (data not shown). Furthermore, at 24h after LPS-exposure it was observed that lungs of LPS-exposed mice contained infiltrated leukocytes, of which most were also positive for the presence of PAR-polymers (Figure 4). 
$\mathrm{NaCl}$

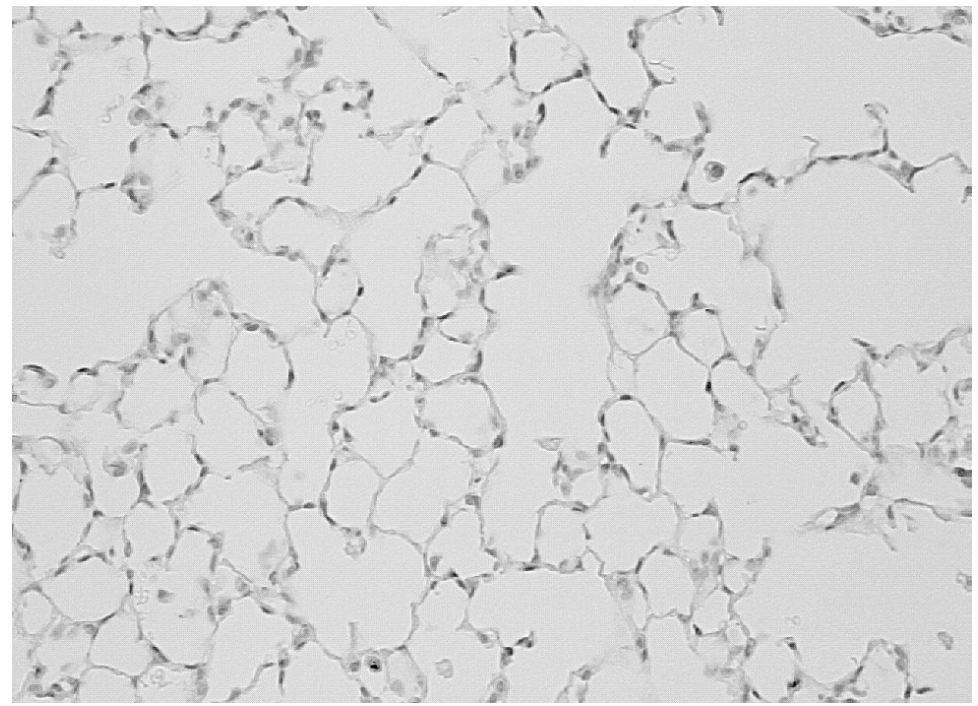

LPS

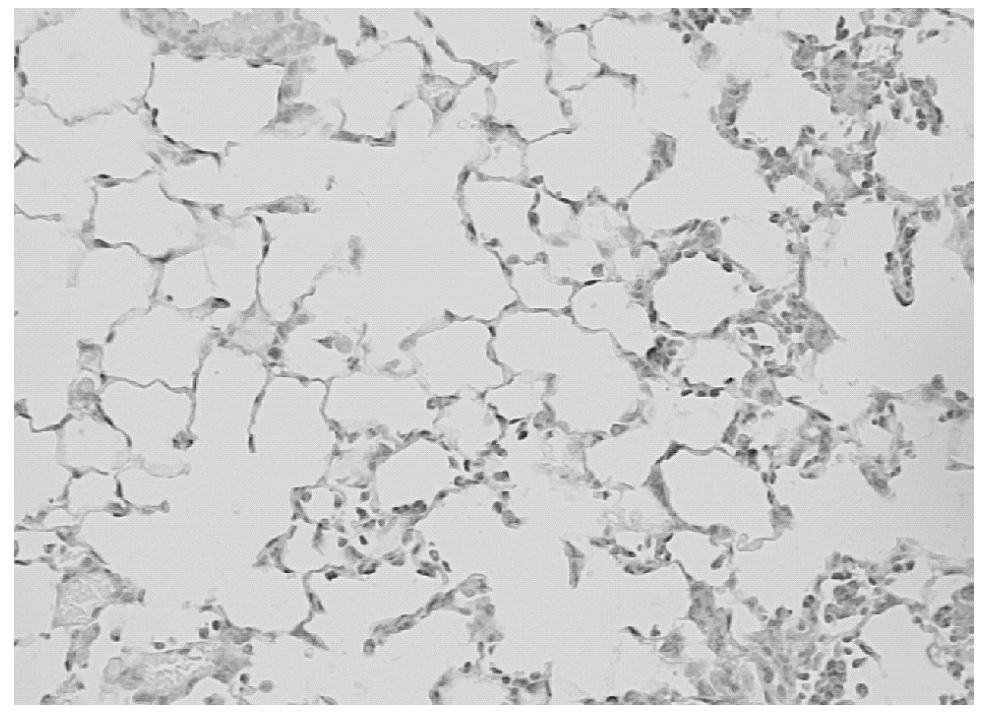

Figure 4. PAR-polymer formation in lungs of IT LPS-treated C57BL/6 mice. PARP-1 activation was determined immunohistochemically $24 \mathrm{~h}$ after LPS exposure. Magnification 400x.

Since most consistent anti-inflammatory effects were observed for fisetin, the effect of this flavonoid on PARP-1 activation in pulmonary epithelial cells was studied. LPS treatment induced a significant increase in the frequency of PARpolymer positive nuclei after $24 \mathrm{~h}$ which was attenuated in mice that orally received fisetin and dexamethasone (Figure 5). For fisetin a reduction of $67.2 \%$ 
$\pm 16.2 \%$ and for dexamethasone a reduction of $39.4 \% \pm 31 \%$ was found. Since a high variability was found between mice these differences were not statistically significant.

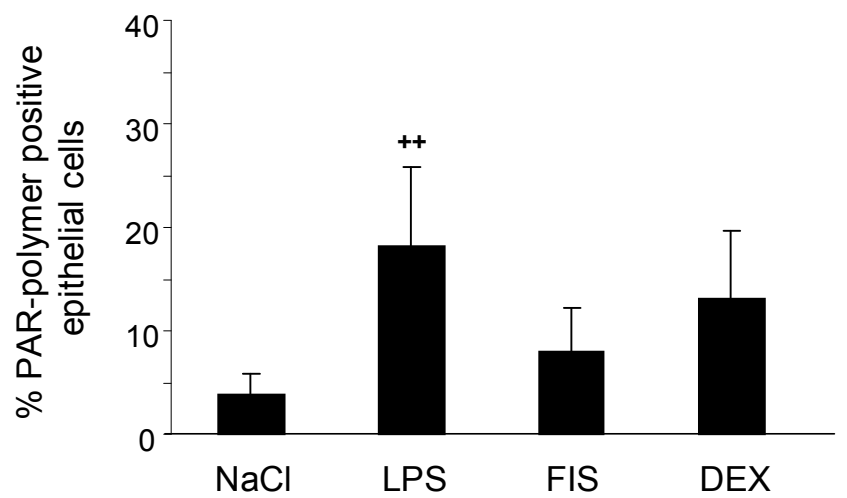

Figure 5. Percentage PAR-polymer positive epithelial cells in lungs of IT LPS-treated C57BL/6 mice $24 \mathrm{~h}$ after LPS-exposure. Mice orally received fisetin (FIS) and dexamethasone (DEX) for 4 consecutive days prior to the LPS-challenge. Data shown are mean \pm SEM of 4-6 mice per group and are based on at least 200 cells per animal.

$++\mathrm{P}<0.05$ vs $24 \mathrm{~h} \mathrm{NaCl}$-treated mice

\section{Plasma SAP and IL-6 levels}

Plasma levels of the acute phase reactant SAP and cytokine IL-6 were measured to investigate whether treatment of the LPS-exposed mice with the putative anti-inflammatory flavonoids fisetin, tricetin and flavone or the antiinflammatory glucocorticoid dexamethasone also reduced the systemic inflammatory response.

Plasma SAP-levels were significantly increased at $24 \mathrm{~h}$ after IT treatment with LPS. However, no significant changes were observed for mice receiving the flavonoids flavone, fisetin or tricetin, nor for mice pre-treated with the antiinflammatory drug dexamethasone (Figure 6). 


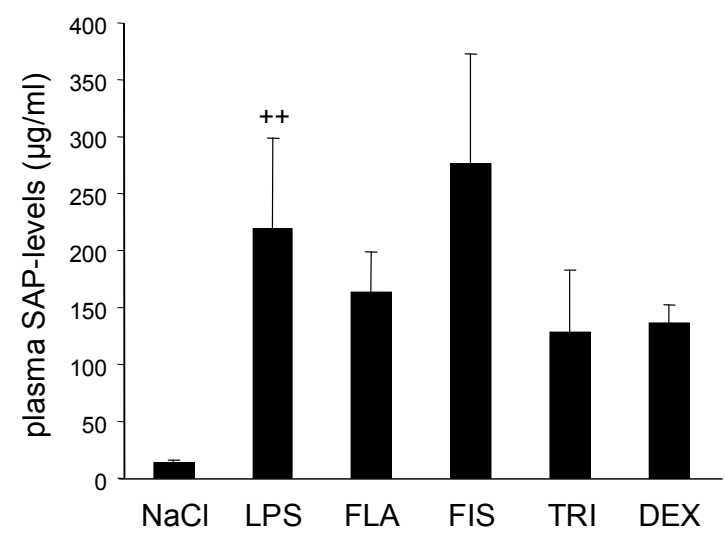

Figure 6. Plasma SAP levels of IT LPS-treated C57BL/6 mice. Mice orally received flavone (FLA), fisetin (FIS), tricetin (TRI) and dexamethasone (DEX) for 4 consecutive days prior to the LPSchallenge. Plasma SAP-levels are measured $24 \mathrm{~h}$ after LPS-exposure and expressed as $\mu \mathrm{g} / \mathrm{ml}$ and are mean \pm SEM of 6 mice.

$++P<0.05$ vs $24 \mathrm{~h} \mathrm{NaCl}$-treated mice

Increased plasma IL-6 levels were observed at $4 \mathrm{~h}$ and $24 \mathrm{~h}$ after LPS-treatment. In mice that received flavone and fisetin significantly further increased plasma IL-6 levels were observed at $4 \mathrm{~h}$ after IT LPS-treatment. At $24 \mathrm{~h}$ after IT LPStreatment, tricetin and dexamethasone administration to mice significantly reduced plasma IL-6 levels. Dexamethasone pre-treatment showed a stronger reducing effect on LPS-induced plasma IL-6 release (Figure 7).

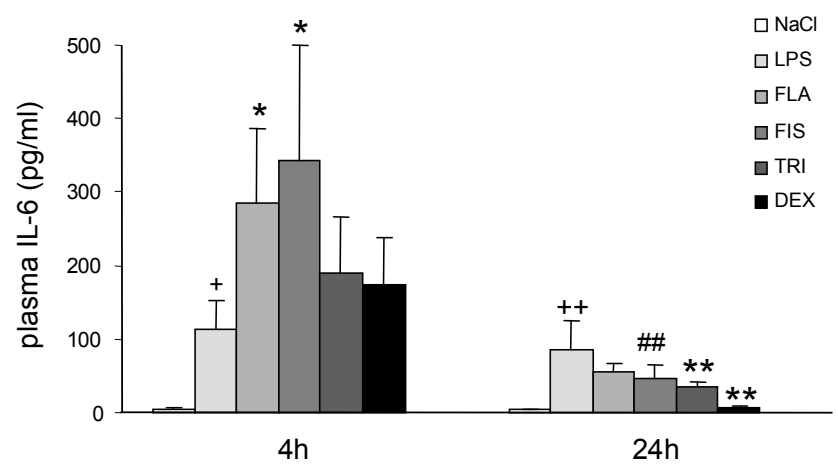

Figure 7. Plasma IL-6 levels of IT LPS-treated C57BL/6 mice. Mice orally received flavone (FLA), fisetin (FIS), tricetin (TRI) and dexamethasone (DEX) for 4 consecutive days prior to the LPSchallenge. Plasma IL- 6 levels are measured $4 \mathrm{~h}$ and $24 \mathrm{~h}$ after LPS-exposure and are expressed as $\mathrm{pg} / \mathrm{ml}$ and are mean \pm SEM of 6 mice.

$+P<0.05$ vs $4 \mathrm{~h} \mathrm{NaCl}$-treated mice

$++P<0.05$ vs $24 \mathrm{~h} \mathrm{NaCl}$-treated mice

$* P<0.05$ vs 4 h LPS-treated mice without flavonoids or DEX

** $P<0.05$ vs $24 \mathrm{~h}$ LPS-treated mice without flavonoids or DEX $\# \# P<0.05$ vs $24 \mathrm{~h}$ LPS+DEX-treated mice 


\section{DISCUSSION}

In this study the orally administered PARP-1 inhibiting flavonoids flavone, fisetin and tricetin appeared to differ to a great extent with respect to their efficacy. Most consistent anti-inflammatory effects were found for fisetin, specifically in the lungs. The anti-inflammatory effects of fisetin in the lungs were more pronounced then the effects of the anti-inflammatory glucocorticoid dexamethasone.

Oral administration of flavonoids in IT LPS-induced acute pulmonary inflammation was used to evaluate the potential application of these compounds as nutraceuticals or as ingredients of functional foods for patients with pulmonary diseases. The flavonoids which were evaluated in the present study can be found in apples, onions, grapes and strawberries (fisetin), Ginkgo Biloba (tricetin), dill weeds and oats (flavone) [121].

In the present study, flavone, fisetin and tricetin were all administered to the mice as their aglycone. In plants and foods, flavonoids are mainly present as glycosides, and initially it was thought that the aglycones were the only form that was able to be taken up in the gastro-intestinal tract [53]. However, currently it is considered that also flavonoid glycosides can be absorbed without preceding hydrolysis [54, 55]. After absorption, flavonoids are extensively metabolized in various organs such as small intestine and liver, resulting in the formation of sulfated, glucuronidated and methylated compounds [56]. The tissue distribution of specific flavonoids has been recently evaluated in various studies. The tissue distribution of quercetin and quercetin metabolites was assessed in rats fed a quercetin-rich diet for 11 weeks [146]. High quercetin levels were found in rat lung tissue. In the present study, plasma or tissue levels of the various flavonoids and metabolites were not determined. However, clear effects were observed in fisetin pretreated mice, implying that fisetin or its metabolites are absorbed from the gastrointestinal tract and distributed throughout the body. Whether fisetin or its metabolites also accumulate in the lungs of mice, as has been reported for quercetin in rat lungs, remains to be investigated.

Recently, the mechanism of the in vitro anti-inflammatory effects of fisetin was extensively investigated [147]. Fisetin was found to suppress activation of NF$\kappa \mathrm{B}$ by inhibiting activation of I $\mathrm{\kappa B} \alpha$ kinase (IKK). Fisetin was reported to block phosphorylation and degradation of $\mathrm{I} \mathrm{K} \mathrm{B} \alpha$ and subsequently induce suppression of the nuclear translocation of p65 subunit [147]. In a study by Chen et al. (2004) [114], the anti-inflammatory effects of various flavonoids were investigated in respiratory epithelial cells. It was found that the flavones luteolin and apigenin inhibited IKK activity, I $\mid \kappa B \alpha$ degradation and NF-KB DNA-protein binding [114]. In the present study, pretreatment of mice with the flavonoid fisetin significantly suppressed the LPS-induced acute pulmonary inflammation. 
At $4 \mathrm{~h}$ after LPS-treatment, fisetin pretreatment did not significantly modulate any of the tested NF- $\mathrm{kB}$ dependent genes. However, at $24 \mathrm{~h}$ after LPS-treatment, fisetin reduced transcription of the cytokines IL-1 $\beta$, IL- 6 and TNF- $\alpha$ and also of the chemokines MIP- $1 \alpha$ and MIP-2, suggesting that at this time point NF-KB dependent transcription was attenuated. In addition, fisetin reduced transcription of the NF- $\kappa B$ inhibitor protein $I \kappa B \alpha$ at $24 \mathrm{~h}$ after LPS-treatment, which appears to imply that at this time point the LPS-induced activation of NF- $\kappa B$ was no longer enhanced. Flavone and tricetin also showed attenuation of inflammatory markers, but appeared to have lower efficacy than fisetin.

In this study, significant increases in IL-6 levels in plasma and IL-6 transcription in lung tissue were observed at $4 \mathrm{~h}$ after IT LPS-treatment in the flavone (plasma and lung), fisetin (plasma) and tricetin (lung) pretreated mice. Xing et al (1998) [148] postulated that in mouse models of LPS-induced acute pulmonary inflammation and endotoxaemia, the cytokine IL-6 plays an anti-inflammatory role in acute inflammatory responses, as an upstream signal leading to a downregulation of proinflammatory cytokines [148]. The elevated IL-6 levels at $4 \mathrm{~h}$ in these mice might therefore indicate that increased production of IL- 6 in the earlier phase may lead to a enhanced downregulation of the inflammatory response. Particularly for fisetin, this might be an explanation for the potent anti-inflammatory effects at $24 \mathrm{~h}$ after LPS-treatment in lungs as well as in blood.

Transcription of HO-1 and SOD2 genes was determined in this study as a marker for oxidative stress. HO-1 expression is upregulated in response to agents that generate ROS, and induction of $\mathrm{HO}-1$ is generally regarded as a protective mechanism against oxidative tissue injury [149]. In the present study, both HO-1 and SOD2 transcription were elevated at $4 \mathrm{~h}$ as well as $24 \mathrm{~h}$ after IT LPS-treatment. Pretreatment with fisetin significantly reduced HO-1 and SOD2 transcription at these time points and after pretreatment with tricetin a reduced HO-1 and SOD2 transcription was observed at 24h after LPS treatment. Flavone also reduced HO-1 and SOD2 transcription at 24h after LPS treatment, although it has no antioxidant activity. In contrast, the anti-inflammatory glucocorticoid dexamethasone significantly increased HO-1 and SOD2 transcriptional activities. Despite the fact that a much cited explanation for the anti-inflammatory effects of flavonoids is their antioxidant effect, results of the present study imply that other mechanisms are more likely to underlie the antiinflammatory effects described in the present study.

Pretreatment of the LPS-exposed mice with the anti-inflammatory glucocorticoid dexamethasone $(2 \mathrm{mg} / \mathrm{kg}$ bodyweight) did not affect the expression of the anti-inflammatory genes in the lungs. Lung MPO-levels and plasma IL-6 levels at $24 \mathrm{~h}$ after LPS exposure were significantly reduced in the dexamethasone treated group. In comparison to the flavonoids, dexamethasone was applied at a much lower concentration, which has been applied before in mouse models. 
The potential inhibiting effects of fisetin on PARP-1 in the lungs were determined by immunohistochemical staining of the PAR-polymer in the pulmonary epithelial cells. Increased PAR-polymer formation was observed at 24h after LPS-exposure, which was also consistent with the results of Liaudet et al. (2002) [29]. Both fisetin as well as dexamethasone tended to attenuate the number of PAR-polymer positive pulmonary epithelial cells.

Altogether, the evaluated flavonoids and specifically fisetin exerted potent antiinflammatory effects in an in vivo model of LPS-induced acute pulmonary inflammation. The anti-inflammatory effects were not only observed in the lungs but also systemic effects were found. The flavonoids flavone and tricetin also showed attenuation of inflammatory markers, but appeared to be less potent than fisetin; the order of potency was fisetin $>$ tricetin $>$ flavone. Furthermore, fisetin was found to have a higher efficacy in reducing pulmonary inflammation as compared to the well-established anti-inflammatory glucocorticoid dexamethasone. Since long-term intake of corticosteroids is known to be accompanied with serious side-effects, and no effective treatment for chronic inflammatory diseases such as COPD has been developed yet, alternative treatments are needed. The results obtained indicate that functionals foods or nutraceuticals containing fisetin may be promising candidates for the application in the treatment of inflammatory pulmonary diseases. 


\section{CHAPTER 6}

\section{The caffeine metabolite 1,7-dimethylxanthine inhibits the lipopolysaccharide-induced inflammatory response in mouse lungs and ex vivo in blood of COPD patients}

Liesbeth Geraets

Astrid Haegens Antje R Weseler Karen Brauers Juanita HJ Vernooy Emiel FM Wouters Aalt Bast

Geja J Hageman 


\section{ABSTRACT}

The nuclear enzyme poly(ADP-ribose) polymerse-1 (PARP-1) has previously been reported to play an important role in lipopolysaccharide (LPS)-induced pulmonary inflammation. Therefore, PARP-1 inhibitors are considered to have a potential application in the treatment of inflammatory lung diseases such as chronic obstructive pulmonary disease (COPD).

In the present study, the anti-inflammatory effects of a previously identified PARP-1 inhibiting caffeine metabolite, 1,7-dimethylxanthine, were evaluated using two different models. First, orally administered 1,7-dimethylxanthine was tested in vivo in a mouse model of LPS-induced acute pulmonary inflammation. 1,7-Dimethylxanthine significantly attenuated the LPS-induced increased lung myeloperoxidase (MPO)-levels and gene-transcription of interleukin (IL)-6, tumor necrosis factor (TNF)- $\alpha$, macrophage inflammatory protein (MIP)- $1 \alpha$ and MIP-2. Reduced systemic levels of both serum amyloid P component (SAP) as well as IL-6 were observed in plasma of 1,7-dimethylxanthine treated mice. Furthermore, 1,7-dimethylxanthine tended to attenuate the LPS-induced PARpolymer formation. In addition, the anti-inflammatory effects at $24 \mathrm{~h}$ were more pronounced when compared to the synthetic PARP-1 inhibitor 3-aminobenzamide. In the second model, blood of COPD patients and healthy controls was stimulated ex vivo with LPS in the presence or absence of 1,7-dimethylxanthine at a physiological concentration. In this model, 1,7-dimethylxanthine significantly suppressed the LPS-induced production of the cytokines IL- 6 and TNF- $\alpha$.

Since no effective treatment for chronic inflammatory diseases such as COPD has been developed yet, there is an urgent need for novel therapeutic strategies. These results suggest that the PARP-1 inhibitor 1,7-dimethylxanthine may be applied as anti-inflammatory treatment in inflammatory diseases such as COPD. 


\section{INTRODUCTION}

Exposure of the respiratory system to airborne particles from cigarette smoke and air pollution is a major etiologic factor in the development of chronic pulmonary diseases [150-152]. The bacterial cell wall component lipopolysaccharide (LPS), present as contaminant in cigarette smoke or organic dusts, has been shown to induce acute and chronic lung inflammation [153].

Previously, activation of the nuclear enzyme poly(ADP-ribose) polymerase-1 (PARP-1) has been demonstrated to play a central role in LPS-induced acute pulmonary inflammation [29]. PARP-1 is activated during oxidative stress [85] and is involved in regulation of transcription and stress response via the transcription factors nuclear factor kappa B (NF- $\mathrm{kB}$ ) and activator protein-1 (AP1) $[21,24,81]$. PARP-1 appears to be not only involved in acute inflammatory responses, but also in chronic inflammatory conditions [23, 29, 30, 83, 84, 154]. Consequently, the therapeutic potential of PARP-1 has extended to alleviation of chronic inflammatory conditions as well. Previously, increased activity of PARP-1 has been observed in peripheral blood mononuclear cells in patients with chronic obstructive pulmonary disease (COPD) [30]. COPD is not only characterized by pulmonary inflammation and airflow limitation, but also by systemic inflammation as is evident from an increased number of circulating lymphocytes and increased serum levels of the cytokines tumor necrosis factoralpha (TNF- $\alpha$ ), interleukin (IL)- 6 and IL-8 as well as from increased markers of oxidative stress $[155,156]$. Current therapies for COPD are aimed at improving airflow limitation and reducing exacerbations, while no effective treatment for the pulmonary nor for the systemic inflammatory manifestations of COPD has been established yet.

Previously, we observed that several methylxanthines, among which the caffeine metabolite 1,7-dimethylxanthine (paraxanthine) and to a lesser extent theophylline, which is still used in the treatment of COPD, have PARP-1 inhibiting effects in vitro in pulmonary epithelial cells. Furthermore, it was suggested that these compounds may offer potential therapeutic application in reducing pulmonary and systemic inflammation [89, 107].

The aim of the present study, therefore, was to investigate the effect of oral administration of the PARP-1 inhibitor 1,7-dimethylxanthine in a mouse model with LPS-induced acute pulmonary and systemic inflammation. The antiinflammatory effects of 1,7-dimethylxanthine were compared to the orally administered synthetic PARP-1 inhibitor 3-aminobenzamide. Furthermore, we investigated the effect of 1,7-dimethylxanthine on cytokine release in ex vivo LPS-stimulated whole blood of COPD patients and healthy controls. 


\section{MATERIAL AND METHODS}

\section{LPS-induced pulmonary inflammation in mice}

\section{Animals}

Male C57BL/6 mice (12 weeks) were obtained from Charles River (Maastricht, The Netherlands). Animals were housed individually in standard laboratory cages and allowed food and water ad libitum during the experiments. The experiments were approved by the Ethics Committee for Animal Experiments of Maastricht University (Maastricht, The Netherlands).

\section{Experimental protocol}

On 4 consecutive days, mice ( $n=6 /$ group) received the PARP- 1 inhibitors via oral gavage (18 mg 1,7-dimethylxanthine or $13.6 \mathrm{mg}$ 3-aminobenzamide/kg bodyweight/day). The daily administered doses of 1,7-dimethylxanthine and the PARP-1 inhibitor 3-aminobenzamide were equal to $100 \mu \mathrm{mol} / \mathrm{kg}$ bodyweight. In a previous in vitro study, we found that 1,7-dimethylxanthine showed a similar PARP-1 inhibiting activity as compared to the synthetic PARP1 inhibitor 3-aminobenzamide [107]. Prior to administration, each compound was freshly suspended in soy oil, which was also used as vehicle control $(5 \mathrm{ml}$ soy oil/kg bodyweight). At day 4, one hour after the final oral administration mice received LPS intratracheally. Intratracheal (IT) instillation technique was performed via a non-surgical procedure according to Vernooy et al [144]. Mice were anesthesized by subcutaneous injection with ketamin hydrochloride (Nimatek; Eurovet, Bladel, The Netherlands) and xylazine hydrochloride (Xylaject; Dopharma, Raamsdonksveer, The Netherlands). LPS (O55:B5, Sigma, Darmstadt, Germany), dissolved in $50 \mu \mathrm{L}$ sterile $0.9 \% \mathrm{NaCl}$, was instilled intratracheally $(20 \mu \mathrm{g} / \mathrm{mouse})$ via a canule and syringe $(2 \times 25 \mu \mathrm{l})$, followed by $100 \mu \mathrm{l}$ air. Sham-treated mice were instilled intratracheally with $50 \mu \mathrm{L}$ sterile $0.9 \% \mathrm{NaCl}$. After IT treatment, mice were kept in an upright position for 10 minutes to allow the fluid to spread throughout the lungs. Mice were killed $4 \mathrm{~h}$ and $24 \mathrm{~h}$ after IT treatment while under pentobarbital (Nembutal, Ceva Sante Animale, Naaldwijck, The Netherlands) anesthesia. Blood was collected via heart puncture in EDTA-containing tubes, immediately centrifuged (2000xg, 10 $\min , 4^{\circ} \mathrm{C}$ ) and plasma was stored at $-80^{\circ} \mathrm{C}$. Lungs were removed and lung tissue was snap-frozen for RNA-isolation and MPO analysis. For immunohistochemical analyses, lung tissue was inflated with $10 \%$ phosphate-buffered formalin ( $\mathrm{pH}$ 7.4) through the trachea and subsequently fixed in formalin for $24 \mathrm{~h}$ after which it was further processed for immunohistochemical staining.

\section{Dose and time finding study}

Initial data were obtained using various time points (2-4-6-8-12-24-48-72-96h) 
as well as various LPS concentrations (0-10-20-40 $\mu \mathrm{g}$ LPS), with MPO-activity in lung homogenates as primary parameter. These data revealed that the inflammatory response was starting to develop at $4 \mathrm{~h}$ after LPS-treatment. At $24 \mathrm{~h}$ after LPS-treatment $(20 \mu \mathrm{g}$ /mouse), the LPS-induced inflammatory processes reached maximum levels. Therefore, these time points were selected to investigate whether oral administration of PARP- 1 inhibitors might suppress early development of the inflammatory response as well as reduce its intensity.

\section{Myeloperoxidase (MPO)-analysis}

MPO activity in the dose and time finding study was measured in homogenates using a MPO activity assay kit (Cytostore, Calgary, Canada) according to the manufacturer's instruction. Briefly, lung tissue was homogenized in hexadecyltri-methylammonium bromide (HTAB)-buffer. Approximately $50 \mu \mathrm{l} \mathrm{HTAB}$ buffer was added to $1 \mathrm{mg}$ of lung tissue. After centrifugation (10000xg, $2 \mathrm{~min}$, $4^{\circ} \mathrm{C}$ ), lung homogenates were kept on ice and MPO-activity was determined according to the manufacturer's protocol during 5 minutes at $450 \mathrm{~nm}$. However, to exclude any interference of the applied compounds with the activity measurements, MPO protein levels were further determined quantitatively using a mouse MPO ELISA kit (HBT, Uden, The Netherlands) according to the manufacturer's instruction. Prior to this analysis, snap-frozen lung tissue was ground to a powder in a stainless steel mortar under liquid nitrogen and homogenized in a lysis buffer containing $200 \mathrm{mM} \mathrm{NaCl}, 5 \mathrm{mM}$ EDTA, $10 \mathrm{mM}$ tris, $10 \%$ glycine, $1 \mathrm{mM}$ PMSF, $1 \mu \mathrm{g} / \mathrm{ml}$ leupeptide and $28 \mu \mathrm{g} / \mathrm{ml}$ aprotinine $(\mathrm{pH}$ 7.4). Approximately $20 \mu \mathrm{l}$ lysisbuffer was added to $1 \mathrm{mg}$ tissue. After centrifugation $\left(10000 x g, 15 \mathrm{~min}, 4^{\circ} \mathrm{C}\right)$, lung homogenates were stored at $-80^{\circ} \mathrm{C}$. Myeloperoxidase protein levels in lung tissue homogenate were quantitatively determined using the ELISA kit. The protein concentration was determined according to the BCA method (Pierce, Rockford, IL, USA). The amount of MPO was expressed as ng MPO/mg protein. Measurement of MPO-activity in the dose and time finding study revealed that in addition to increased MPO-protein levels, MPO-activity was also increased after LPS-treatment (data not shown).

\section{Gene transcription analysis by quantitative PCR}

Snap-frozen lung tissue was ground to a powder in a stainless steel mortar under liquid nitrogen and homogenized in Trizol Reagent (Invitrogen, Carlsbad, CA, USA). Total RNA isolation was performed according to the manufacturer's instructions. Concentration of the isolated total RNA was determined spectrophotometrically at 260 and $280 \mathrm{~nm}$. Reverse transcription reaction was performed using $1 \mu \mathrm{g}$ of total RNA and reverse-transcribed into cDNA using iScript $^{\mathrm{TM}}$ CDNA Synthesis Kit (Biorad Laboratories, Hercules, CA, USA). Subsequently, real time PCR was performed with a MyiQ Single Colour real time PCR detection system (BioRad) using SYBR@ Green Supermix (Biorad), $5 \mu \mathrm{l}$ 
diluted (10x) cDNA, and $0.3 \mu \mathrm{M}$ primers in a total volume of $25 \mu \mathrm{l}$. PCR was conducted as follows: denaturing at $95^{\circ} \mathrm{C}$ for $3 \mathrm{~min}$, followed by 40 cycles of $95^{\circ} \mathrm{C}$ for 15 seconds and $60^{\circ} \mathrm{C}$ for 45 seconds. After the PCR procedure, a melt curve $\left(60-95^{\circ} \mathrm{C}\right)$ was produced for product identification and control of purity. $\beta$-Actin was included as an internal control gene, since the various treatments did not influence its gene-expression. rtPCR primers were designed using Primer express software (Applied Biosystems). Primer sequences used were as follows:

TNF- $\alpha$ 5'-GACCCTCACACTCAGATCATCTTCT (forward) and 5'-CCACTTGGT GGTTTGCTACGA (reverse), IL-6 5'-ACAAGTCGGAGGCTTAATTACACAT (forward) and 5'-AATCAGAATTGCCATTGCACAA (reverse), MIP-2 5'-GAACAT CCAGAGCTTGAGTGTGA (forward) and 5'-CTTGAGAGTGGCTATGACTTCTG TC (reverse), MIP-1 $\alpha$ 5'-ACTATTTTGAAACCAGCAGCCTTT (forward) and 5'GATCTGCCGGTTTCTCTTAGTCA (reverse), I $1 \kappa B \alpha 5^{\prime}$-CGGAGGACGGAGACTC GTT (forward) and 5'-TTCACCTGACCAATGACTTCCA (reverse), IL-1 $\beta$ 5'-AAT CTATACCTGTCCTGTGTAATGAAAGAC (forward) and 5'-TGGGTATTGCTTG GGATCCA (reverse), $\beta$-Actin 5'-CGTGAAAAGATGACCCAGATCA (forward) and 5'-CACAGCCTGGATGGCTACGT (reverse).

Data were analyzed using the MyiQ Software system (BioRad) and were expressed as relative gene expression (fold increase) using the $2^{-\Delta \Delta_{C t}}$ method [129].

\section{Immunohistochemical staining}

The presence of PAR-polymers was determined using immunohistochemical staining. Briefly, paraffin sections were deparaffinized and rehydrated. Endogenous peroxidase was quenched with $0.3 \%$ hydrogen peroxidase. For antigen retrieval, sections were incubated with trypsin for $10 \mathrm{~min}$ at $37^{\circ} \mathrm{C}$. After blocking the sections with $10 \%$ non fat dry milk for $10 \mathrm{~min}$ and $10 \%$ goat serum for $15 \mathrm{~min}$, sections were incubated overnight with the primary polyclonal antibody to PAR (96-10-04, Alexis, Lausen, Switserland). Next, sections were incubated with a biotinylated goat anti-rabbit immunoglobulin (Dako, Glostrup, Denmark), followed by incubation with avidin-peroxidase (ABC-kit, Vectastain) for $30 \mathrm{~min}$ and 3,3'diaminobenzidine for $10 \mathrm{~min}$. Sections were counterstained with hematoxylin, dehydrated and mounted with Entellan (Merck). Slides containing the stained lung section were encoded and at least 200 epithelial cells were evaluated for the presence of PAR-polymers in their nuclei.

\section{Plasma serum amyloid $p$ component (SAP) and IL-6 analysis}

Plasma SAP levels were determined using a quantitative ELISA-based test kit (Gentaur, Brussels, Belgium). Plasma IL-6 levels were determined using a Mouse IL-6 Immunoassay kit (R\&D Systems, Minneapolis, USA). 


\section{Statistical analysis}

Results are reported as mean \pm SEM. Statistical analyses were carried out using SPSS 14.0. Data appeared not normally distributed and were therefore evaluated with non-parametric tests. The data of the LPS-treated mice at $4 \mathrm{~h}$ and $24 \mathrm{~h}$ after IT LPS-treatment compared to the $\mathrm{NaCl}$-treated mice were evaluated using Mann-Whitney test. Furthermore, the effect of treatment with 1,7-dimethylxanthine or 3-aminobenzamide on the LPS-induced changes of inflammatory markers and the efficiency between 1,7-dimethylxanthine and 3-aminobenzamide was evaluated using Kruskal-Wallis test followed by posthoc test of Siegel and Castellan [145]. Differences were considered to be statistically significant at $\mathrm{P}<0.05$.

\section{Ex vivo LPS-stimulated human whole blood}

\section{Human whole blood assay}

The study protocol was approved by the Medical Ethics Committee for Clinical Experiments of Maastricht University (Maastricht, The Netherlands). Informed consent was obtained from all participants prior to inclusion. $\mathrm{N}=10$ healthy volunteers and $\mathrm{n}=10$ COPD patients were included in this study.

COPD patients (GOLD stage: II-IV, FEV 1 : 43.8 $\pm 3.8 \%$, FVC: $83.2 \pm 4.8 \%$, number of pack years: $22.9 \pm 4.8$ y) were recruited from the Astmacenter Hornerheide in Haelen, The Netherlands, between August 2006 and December 2006. The bronchodilatory medication of the COPD patients was restricted to the use of anticholinergics and beta-2 sympathomimetics. The use of theophylline as well as inhaled corticosteroids was to be avoided for at least one week prior to the blood collection scheduled.

Blood was collected after an overnight fast in heparin-containing vacutainer tubes and was kept on ice until further processing. Whole blood was aliquoted into 24-well sterile plates and diluted 1:4 with RPMI 1640 (supplemented with L-glutamine, Invitrogen). To induce cytokine production, LPS (O26:B6, Sigma) was added to the diluted whole blood at $1 \mathrm{ng} / \mathrm{ml}$ and thereafter the plates were incubated at $5 \% \mathrm{CO}_{2}$ at $37^{\circ} \mathrm{C}$ for $16 \mathrm{~h}$. A pilot study in which whole blood was incubated with LPS for various time points $(8 \mathrm{~h}-24 \mathrm{~h})$, indicated that TNF- $\alpha$ release reached maximal levels at $16 \mathrm{~h}$. Cell-free supernatants were collected after centrifugation $\left(19000 \mathrm{xg}, 5 \mathrm{~min}\right.$ ) and stored at $-20^{\circ} \mathrm{C}$ until cytokine analyses. 1,7-Dimethylxanthine (Sigma) was added to the blood at a concentration of $10 \mu \mathrm{M}, 30 \mathrm{~min}$ before stimulation with LPS. All incubations were performed in triplicate.

\section{Human cytokine analysis}

TNF- $\alpha$, IL- 8 and IL- 6 were quantified by means of PeliKine Compact human ELISA kits (CLB/Sanquin, The Netherlands). Assays were performed as de- 
scribed in the manufacturer's instructions. The sensitivities for TNF- $\alpha$, IL- 8 and IL-6 were $1 \mathrm{pg} / \mathrm{ml}, 1 \mathrm{pg} / \mathrm{ml}$ and $0.2 \mathrm{pg} / \mathrm{ml}$, respectively.

\section{Statistical Analysis}

Results are reported as mean \pm SEM. Statistical analyses were carried out using SPSS 14.0. Data were not normally distributed and were therefore evaluated with non-parametric tests. To compare the baseline characteristics and the sensitivity in response to LPS between the COPD patients and healthy controls, the Mann-Whitney $U$ test was used. The effect of 1,7-dimethylxanthine on the LPS-induced cytokine production was determined using Wilcoxon signed rank test. Two-tailed $\mathrm{P}$ values of 0.05 or less were considered statistically significant.

\section{RESULTS}

\section{LPS-induced pulmonary inflammation in mice}

\section{MPO-levels in lung tissue}

The amount of MPO protein in lung tissue homogenates was determined as a measure of neutrophil influx. At $4 \mathrm{~h}$ after LPS-stimulation, no significantly increased amount of MPO was observed. MPO-levels were significantly increased at $24 \mathrm{~h}$ after IT LPS-treatment. Treatment of the mice with 1,7dimethylxanthine significantly reduced MPO-levels at 24h. Significant reductions in MPO-levels at 24h after LPS-stimulation were also observed in mice pretreated with 3-aminobenzamide (Figure 1).

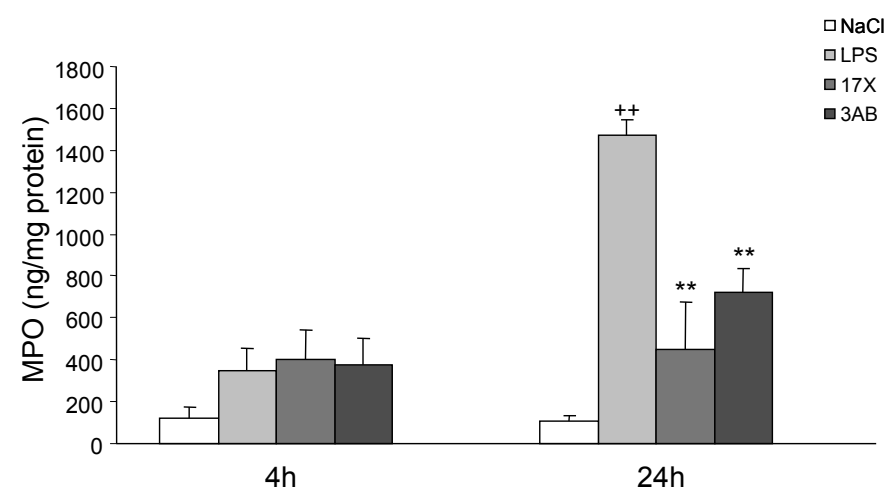

Figure 1. MPO-levels in lungs of IT LPS-treated C57BL/6 mice. Mice orally received 1,7dimethylxanthine $(17 \mathrm{X})$ and 3 -aminobenzamide $(3 \mathrm{AB})$ for 4 consecutive days prior to the LPSchallenge. MPO-levels were determined at $4 \mathrm{~h}$ and $24 \mathrm{~h}$ after LPS-treatment. MPO levels are expressed as ng MPO/mg protein and are mean \pm SEM of 6 mice.

$++\mathrm{P}<0.05$ vs $24 \mathrm{~h} \mathrm{NaCl}$-treated mice

** $\mathrm{P}<0.05$ vs $24 \mathrm{~h}$ LPS-treated mice without $17 \mathrm{X}$ or $3 \mathrm{AB}$ 


\section{Gene-transcription analysis in lung tissue}

Using qPCR, transcription of various inflammatory genes was evaluated. Since PARP-1 is involved in mediating the NF- $\kappa B$ and AP-1 regulated genes $[11,15$, 82], the effect of oral administration of 1,7-dimethylxanthine on these genes was evaluated by measuring transcription of $\mathrm{I} \kappa \mathrm{B} \alpha, \mathrm{IL}-1 \beta, \mathrm{IL}-6$ and TNF- $\alpha$. Gene transcription of the chemokines MIP-1 $\alpha$ and MIP-2, that are produced by activated macrophages and that are also reported to be NF- $\kappa \mathrm{B}$ dependent, was also determined. IT LPS-treatment increased gene-expression of IL-6, TNF- $\alpha$, IL$1 \beta$ and $I_{\kappa B} \alpha$, as well as of MIP- $1 \alpha$ and MIP-2, at $4 \mathrm{~h}$ and $24 \mathrm{~h}$ (Figure 2).
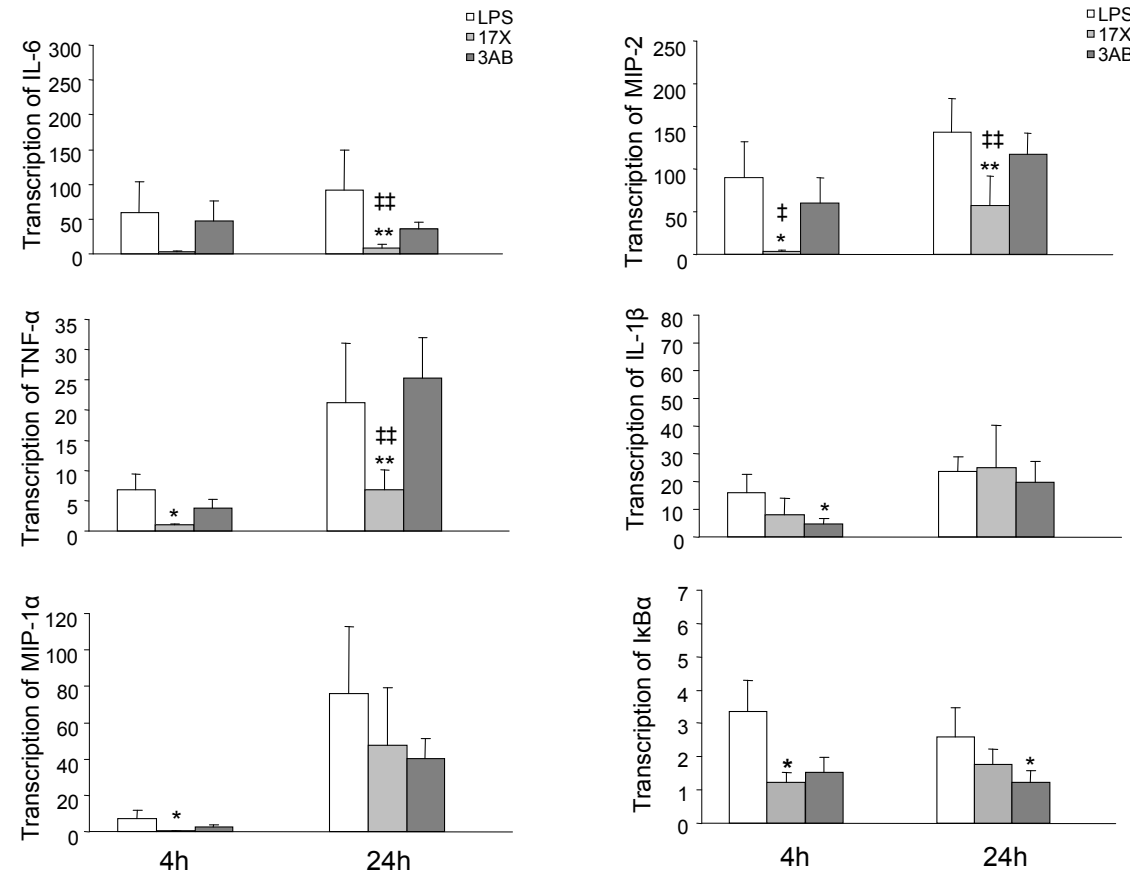

Figure 2. Gene-transcription of IL-6, TNF- $\alpha$, MIP- $1 \alpha$, MIP-2, IL- $1 \beta$ and I $\kappa B \alpha$ in lungs of IT LPS treated $\mathrm{C} 57 \mathrm{BL} / 6$ mice. Mice orally received 1,7-dimethylxanthine (17X) or 3-aminobenzamide $(3 \mathrm{AB})$ for 4 consecutive days prior to the LPS-challenge. Gene expression was determined $4 \mathrm{~h}$ and $24 \mathrm{~h}$ after LPS-challenge and was analysed using qPCR and expressed as fold increase over control treatment (intratracheal instillation of $\mathrm{NaCl}$ ) and are mean \pm SEM of 6 mice.

$* \mathrm{P}<0.05$ vs $4 \mathrm{~h}$ LPS-treated mice without $17 \mathrm{X}$ or $3 \mathrm{AB}$

$* * \mathrm{P}<0.05$ vs $24 \mathrm{~h}$ LPS-treated mice without $17 \mathrm{X}$ or $3 \mathrm{AB}$

$\neq \mathrm{P}<0.05$ vs $4 \mathrm{~h}$ LPS+3AB-treated mice

¥¥ $\mathrm{P}<0.05$ vs $24 \mathrm{~h}$ LPS $+3 \mathrm{AB}$-treated mice

In mice treated with 1,7-dimethylxanthine TNF- $\alpha$ gene-transcription was significantly reduced at both $4 \mathrm{~h}$ as well as $24 \mathrm{~h}$ after IT LPS-treatment and IL-6 gene transcription was significantly reduced at $24 \mathrm{~h}$ after IT LPS treatment. In 
the 1,7-dimethylxanthine treated mice, transcription of MIP-1 $\alpha$ and MIP-2 was significantly reduced at $4 \mathrm{~h}$ after LPS treatment. MIP-2 gene transcription was also reduced at $24 \mathrm{~h}$ after LPS treatment in these mice. No effect of 1,7dimethylxanthine treatment on LPS-induced IL-1 $\beta$ transcription was observed. In the 3 -aminobenzamide treated mice, IL-1 $\beta$ transcription was attenuated at $4 \mathrm{~h}$ after LPS-treatment.

Finally, transcription of IאB $\alpha$ was significantly reduced by 1,7-dimethylxanthine treatment at $4 \mathrm{~h}$ after LPS-instillation and by 3 -aminobenzamide treatment at $24 \mathrm{~h}$ after IT LPS-treatment.

\section{PAR-polymer formation in lung tissue}

To investigate whether intratracheal LPS-exposure resulted in pulmonary PARP1 activation, and whether oral administration of the PARP-1 inhibitor 1,7dimethylxanthine had a reducing effect on PAR-polymer formation, pulmonary epithelial cells were immunohistochemically evaluated for the presence of PAR-polymers in their nuclei. Intratracheal instillation of mice with LPS resulted in PARP-1 activation, as can be shown by formation of PAR-polymers in the epithelial cells.

$\mathrm{NaCl}$

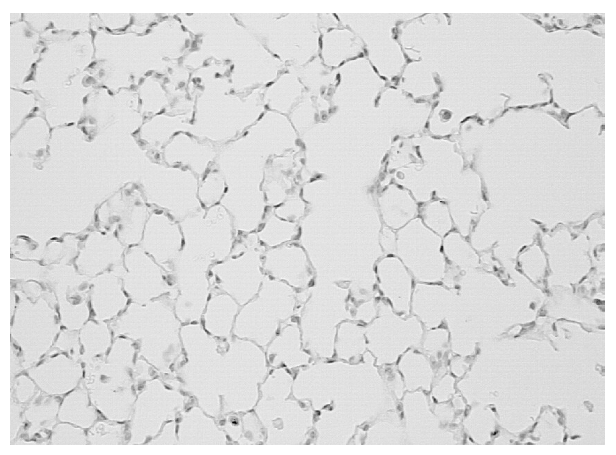

LPS

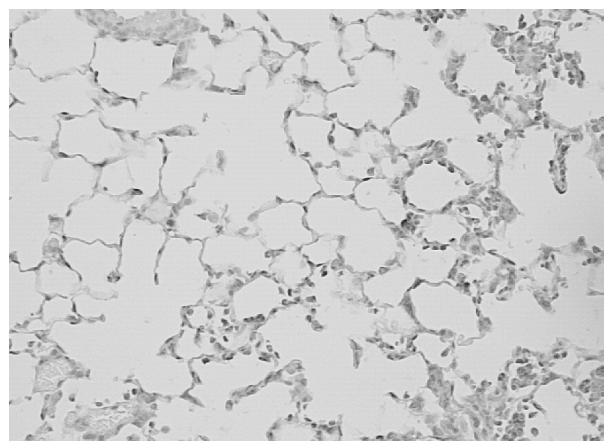

Figure 3. PAR-polymer formation in lungs of IT LPS-exposed C57BL/6 mice. PARP-1 activation was determined immunohistochemically $24 \mathrm{~h}$ after LPS exposure. Magnification 400x. 
At $4 \mathrm{~h}$ after LPS-exposure, a small number of epithelial cells showed PARpolymers in the nuclei (data not shown). However, at 24h after LPS-exposure PARP-1 activation was apparent (Figure 3). A significant increase in the frequency of PAR-positive nuclei was observed at 24h after LPS treatment. Furthermore, at 24h after LPS-exposure it was observed that lungs of LPSexposed mice contained infiltrated leukocytes, of which most were positive for the presence of PAR-polymers. Oral administration of 1,7-dimethylxanthine attenuated the frequency of PAR-polymer positive pulmonary epithelial cells at $24 \mathrm{~h}$ after LPS treatment, which was not observed for 3-aminobenzamide (Figure 4). Since the lungs of only 4 mice could be analysed, the effect of 1,7dimethylxanthine was not statistically significant.

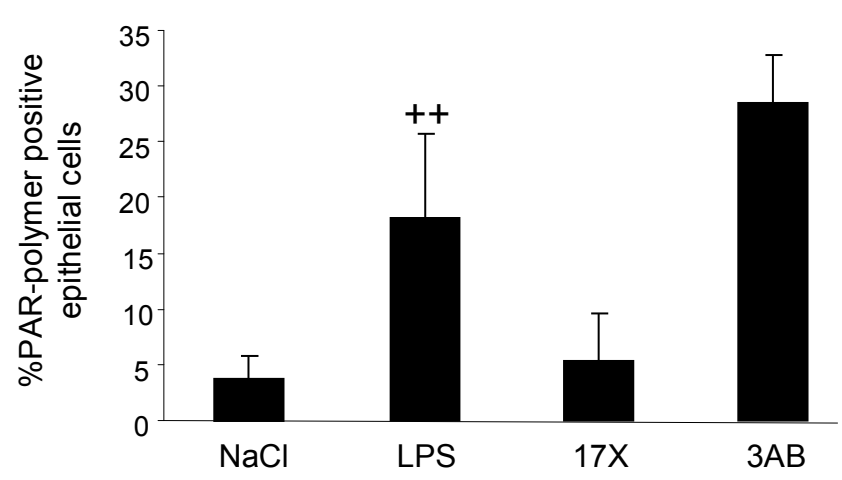

Figure 4. Percentage PAR-polymer positive epithelial cells in lungs of IT LPS-treated C57BL/6 mice. Mice orally received 1,7-dimethylxanthine (17X) or 3-aminobenzamide (3AB) for 4 consecutive days prior to LPS-challenge. Data shown are mean \pm SEM of 4-6 mice per group and are based on at least 200 cells per animal.

$++\mathrm{P}<0.05$ vs $24 \mathrm{~h} \mathrm{NaCl}$-treated mice

\section{Plasma SAP and IL-6 levels}

To investigate whether 1,7-dimethylxanthine treatment also reduced the systemic inflammatory response, plasma levels of the acute phase reactant SAP and cytokine IL-6 were measured. Plasma SAP levels were not increased at $4 \mathrm{~h}$ after LPS-treatment, but at $24 \mathrm{~h}$ after LPS-treatment, significantly increased SAPlevels were observed. Treatment of the mice with 1,7-dimethylxanthine significantly reduced plasma SAP-levels (Figure 5). 3-Aminobenzamide treatment did not significantly reduce plasma SAP-levels.

Intratracheal instillation of mice with LPS significantly increased plasma IL-6 levels both at $4 \mathrm{~h}$ and $24 \mathrm{~h}$ after treatment. At $24 \mathrm{~h}$, IL-6 levels were significantly attenuated following 1,7-dimethylxanthine treatment. Administration of 3aminobenzamide did not result in a significant change in plasma IL-6 levels (Figure 6). 


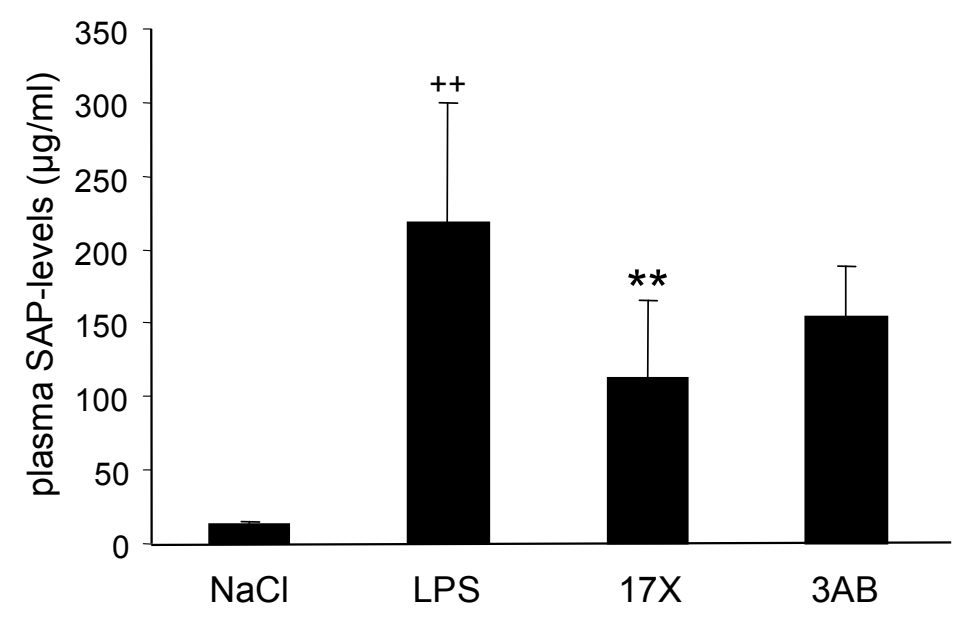

Figure 5. SAP levels in plasma of IT LPS-treated C57BL/6 mice. Mice orally received 1,7dimethylxanthine $(17 \mathrm{X})$ or 3 -aminobenzamide $(3 \mathrm{AB})$ for 4 consecutive days prior to the LPSchallenge. Plasma SAP-levels are determined $24 \mathrm{~h}$ after LPS-challenge and are expressed as $\mu \mathrm{g} / \mathrm{ml}$ and are mean \pm SEM of 6 mice.

$++\mathrm{P}<0.05$ vs $24 \mathrm{~h} \mathrm{NaCl}$-treated mice

** $\mathrm{P}<0.05$ vs $24 \mathrm{~h}$ LPS-treated mice without $17 \mathrm{X}$ or $3 \mathrm{AB}$

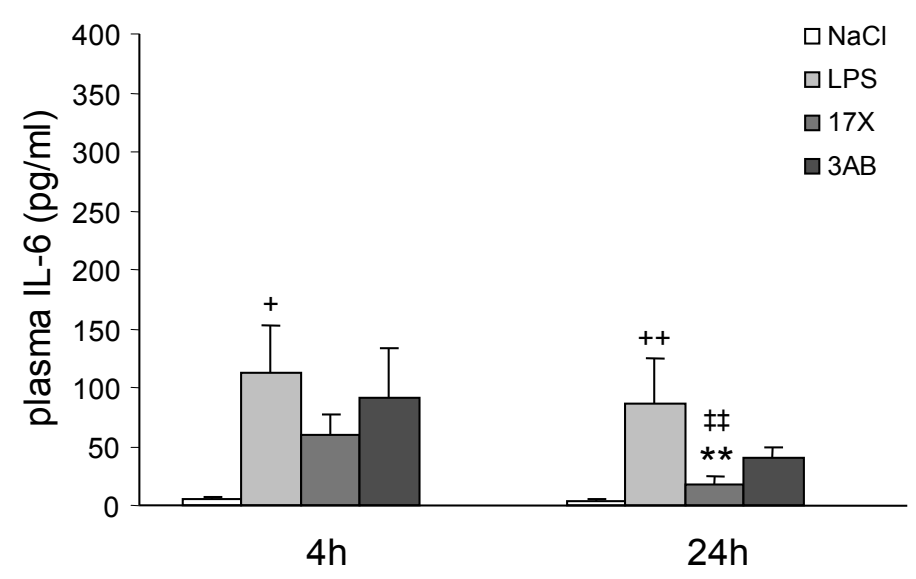

Figure 6. Plasma IL- 6 levels $4 \mathrm{~h}$ and $24 \mathrm{~h}$ after IT LPS-treatment of C57BL/6 mice. Mice orally received 1,7-dimethylxanthine $(17 \mathrm{X})$ or 3 -aminobenzamide $(3 \mathrm{AB})$ for 4 consecutive days prior to the LPS-challenge. Plasma IL-6 levels are expressed as $\mathrm{pg} / \mathrm{ml}$ and are mean \pm SEM of 6 mice.

$+\mathrm{P}<0.05$ vs $4 \mathrm{~h} \mathrm{NaCl}$-treated mice

$++\mathrm{P}<0.05$ vs $24 \mathrm{~h} \mathrm{NaCl}$-treated mice

** $\mathrm{P}<0.05$ vs $24 \mathrm{~h}$ LPS-treated mice without $17 \mathrm{X}$ or $3 \mathrm{AB}$

¥¥ $\mathrm{P}<0.05$ vs $24 \mathrm{~h}$ LPS+3AB-treated mice 


\section{Ex vivo LPS-stimulated human whole blood}

\section{Cytokine levels}

Characteristics and baseline blood parameters of both COPD patients as well as healthy controls are summarized in Table 1. Significant differences in the numbers of leukocytes and monocytes were observed between COPD patients and healthy controls, indicating the presence of systemic inflammation in COPD.

\section{Table 1 Subjects' characteristics}

\begin{tabular}{lll}
\hline & Controls & COPD \\
\hline $\mathrm{N}$ & 10 & 10 \\
Gender & 10 males & 10 males \\
Age $(\mathrm{yrs})$ & $65.3 \pm 1.5$ & $64.7 \pm 2.5$ \\
Body weight $(\mathrm{kg})$ & $75.6 \pm 1.6$ & $74.3 \pm 5.8$ \\
Height $(\mathrm{m})$ & $1.72 \pm 0.02$ & $1.72 \pm 0.02$ \\
BMI $\left(\mathrm{kg} / \mathrm{m}^{2}\right)$ & $25.6 \pm 0.8$ & $25.0 \pm 1.7$ \\
Leukocytes $\left(10^{9} / \mathrm{l}\right)$ & $5.67 \pm 0.43$ & $9.12 \pm 1.16^{*}$ \\
Lymphocytes $\left(10^{9} / \mathrm{l}\right)$ & $1.85 \pm 0.15$ & $2.26 \pm 0.28$ \\
Monocytes $\left(10^{9} / \mathrm{l}\right)$ & $0.47 \pm 0.06$ & $0.9 \pm 0.13 *$ \\
\hline
\end{tabular}

$* \mathrm{p}<0.05$ compared to controls

Stimulation of whole blood of both COPD patients and healthy controls with LPS significantly increased cytokine and chemokine levels. The LPS-induced increase in TNF- $\alpha$, IL- 6 and IL-8 levels was significantly higher in COPD patients as compared to healthy controls (Figure 7A). The differences in IL-6 and IL-8 levels between COPD patients and healthy controls disappeared after adjusting for the number of leukocytes and monocytes. However, after adjusting for the number of leukocytes TNF- $\alpha$ levels produced by blood cells of COPD patients were still higher than those of healthy controls (data not shown). In blood of COPD patients, 1,7-dimethylxanthine significantly reduced the LPS-induced TNF- $\alpha$ levels, whereas in blood of healthy subjects LPSinduced IL- 6 levels but not TNF- $\alpha$ levels were significantly reduced by $1,7-$ dimethylxanthine (Figure 7B). 


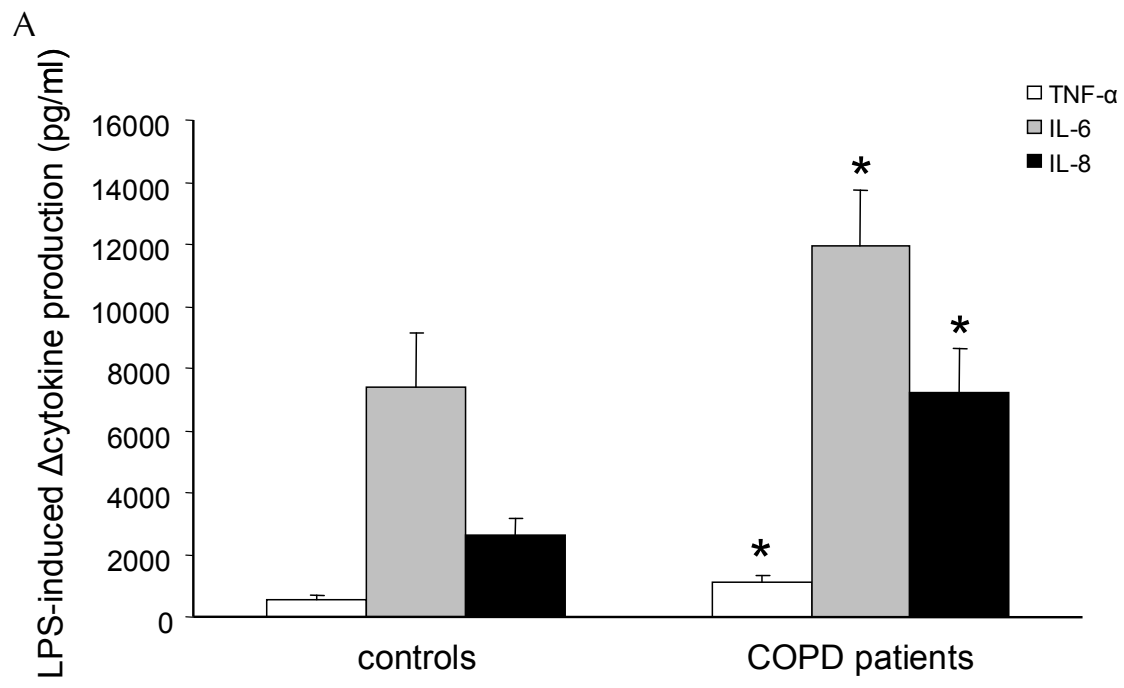

B

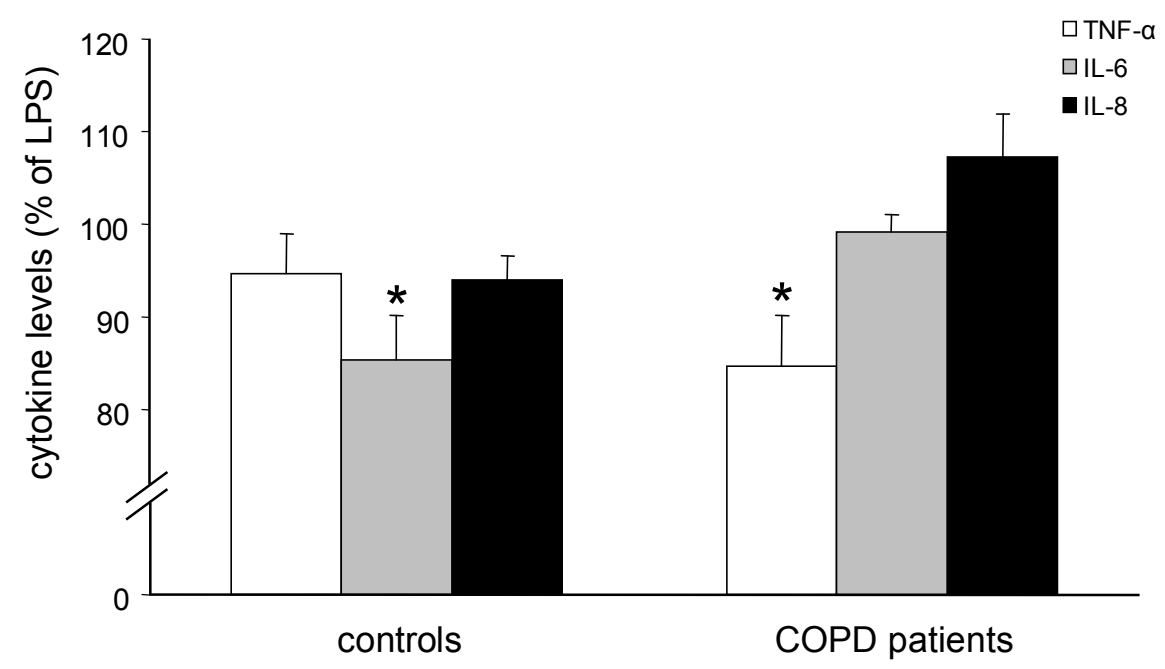

Figure 7

A. LPS-induced increases in TNF- $\alpha$, IL-6 and IL-8 levels in blood of COPD patients $(n=10)$ and healthy controls $(n=10)$. Plasma cytokine levels are expressed as $\mathrm{pg} / \mathrm{ml}$ and are expressed as mean \pm SEM of $\mathrm{n}=10$ subjects.

$* \mathrm{P}<0.05$ vs control subjects

B. Effect of 1,7-dimethylxanthine on LPS-induced TNF- $\alpha$, IL-6 and IL-8 levels production in blood of COPD patients $(n=10)$ and healthy controls $(n=10)$. Results are expressed as percentage, with $100 \%$ representing cytokine levels of LPS-stimulated blood, and are expressed as mean \pm SEM of $n=10$ subjects.

$* \mathrm{P}<0.05$ vs LPS-stimulated blood 


\section{DISCUSSION}

\section{Anti-inflammatory effects of 1,7-dimethylxanthine on LPS-induced inflam- mation}

In the present study, oral administration of the PARP-1 inhibiting methylxanthine 1,7-dimethylxanthine reduced markers of local and systemic inflammation in a mouse model of LPS-induced acute pulmonary inflammation. Furthermore, 1,7-dimethylxanthine reduced the ex vivo LPS-stimulated TNF- $\alpha$ release in whole blood of COPD patients and IL-6 release in whole blood of healthy controls.

Previously, it was demonstrated that the LPS-induced acute pulmonary inflammation was significantly attenuated in PARP-1 knock-out mice [29]. In addition, it was also observed that the pharmaceutical PARP-1 inhibitor PJ34 reduced levels of the cytokines TNF- $\alpha$, MIP- $1 \alpha$ and IL- 6 and diminished MPO activity in broncheoalveolar lavage (BAL) fluid in LPS-challenged wild-type mice [29]. In various animal models of endotoxic shock, PARP-1 inhibition with 3-aminobenzamide was found to suppress pulmonary leukocyte recruitment, expression of adhesion molecules such as ICAM-1 and pulmonary iNOS gene- and protein-expression [82, 157].

In the present study, IT LPS treatment significantly increased lung MPO-levels at $24 \mathrm{~h}$ after treatment, which were significantly reduced in mice that received 1,7-dimethylxanthine. MPO is abundantly present in intracellular granules of neutrophils and is released upon activation of neutrophils [158]. Therefore, pulmonary MPO-levels are considered to be an indication of neutrophil influx in the lungs. The observed reduction in levels of MPO indicated that 1,7dimethylxanthine decreased the neutrophil influx at $24 \mathrm{~h}$ after IT LPS-treatment. Furthermore, 1,7-dimethylxanthine significantly reduced transcription of MIP$1 \alpha$ and $I \kappa B \alpha(4 \mathrm{~h}), \mathrm{IL}-6$ (24h) and TNF- $\alpha$ and MIP-2 (4h and 24h) after LPStreatment. From these data it can be concluded that administration of 1,7dimethylxanthine attenuated the NF- $\mathrm{\kappa B}$ mediated gene-transcription during the early phase of the inflammatory response. At $24 \mathrm{~h}$ after LPS treatment major reductions were still observed for both $\mathrm{NF}-\mathrm{KB}$ and $\mathrm{AP}-1$ mediated genes. In addition, the LPS-induced systemic inflammatory response was reduced by 1,7dimethylxanthine treatment, as indicated by reduced levels of the acute phase reactant SAP and the cytokine IL-6 at 24h after LPS-treatment.

\section{Anti-inflammatory efficacy of 1,7-dimethylxanthine as compared with 3- aminobenzamide}

In this study, the effect of 1,7-dimethylxanthine on LPS-induced pulmonary inflammation was compared with the effects of the synthetic PARP-1 inhibitor 3-aminobenzamide. 1,7-Dimethylxanthine and 3-aminobenzamide were administered at doses equal to $100 \mu \mathrm{mol} / \mathrm{kg}$ bodyweight for 4 consecutive days. 
3-Aminobenzamide attenuated the LPS-induced increase in pulmonary MPOlevels and gene transcription of I $\mathrm{\kappa B} \alpha$ and slightly reduced plasma IL-6 levels. It was observed that the anti-inflammatory effects of 1,7-dimethylxanthine were more pronounced when compared to the effects of 3-aminobenzamide, especially at $24 \mathrm{~h}$ after LPS treatment.

However, it should be noted that diverse mechanisms are likely to be responsible for the observed anti-inflammatory effects of the various compounds. In addition to the PARP-1 inhibiting effects which is the main characteristic of 3aminobenzamide, 1,7-dimethylxanthine has been reported to exert antiinflammatory effects via adenosine receptor antagonism and inhibition of phosphodiesterase 4 (PDE4) [159, 160].

The potential inhibiting effects of 1,7-dimethylxanthine on PARP-1 in the lungs were determined by immunohistochemical staining of the PAR-polymer in the pulmonary epithelial cells. Increased PAR-polymer formation was observed at $24 \mathrm{~h}$ after LPS-exposure, which was also consistent with the results of Liaudet et al. (2002) [29]. In addition, in the lungs of the LPS-exposed mice, many infiltrating leukocytes were also positive for the presence of PAR-polymers. In contrast to 1,7-dimethylxanthine which tended to attenuate the frequency of PAR-polymer positive cells at $24 \mathrm{~h}$, the PARP-1 inhibitor 3 -aminobenzamide did not affect the PAR-polymer formation in lung epithelial cells.

In the present study, 3-aminobenzamide was orally administered at a dose of $13.6 \mathrm{mg} / \mathrm{kg}$ bodyweight for 4 consecutive days. In other studies similar or even lower concentrations of 3-aminobenzamide have been applied intravenously or intraperitoneally and clear effects were observed such as reduced airway inflammation in ovalbumin-sensitized mice, suppressed pulmonary leukocyte recruitment, expression of ICAM-1 and reduced pulmonary iNOS gene- and protein-expression in LPS-induced endotoxic shock in rabbits, or reduced neutrophil accumulation in zymosan-induced peritonitis in mice [26, 80, 82, 161]. In most of these studies, anti-inflammatory effects were measured at a short period (2-6h) after exposure to the inflammatory stimulus, in contrast to the time point of $24 \mathrm{~h}$ after LPS-exposure in the present study. Furthermore, 3aminobenzamide was administered intravenously or intraperitoneally in those studies. Since, the half life of 3-aminobenzamide was reported to be $90 \mathrm{~min}$ [162], the absence of clear PARP-inhibiting effects of 3-aminobenzamide at $24 \mathrm{~h}$ in the present study may be explained by a low oral availability and rapidly decreasing tissue concentrations.

\section{The ex vivo anti-inflammatory effects of 1,7-dimethylxanthine}

In the ex vivo model, whole blood of COPD patients and healthy controls was stimulated with LPS after pretreatment with 1,7-dimethylxanthine. Differences in sensitivity in response to LPS were observed between the COPD patients and healthy controls. The observed higher numbers of leukocytes and monocytes in 
COPD patients very likely explained the higher response to LPS. However, differences in TNF- $\alpha$ levels between COPD patients and healthy controls were still observed after adjusting for the number of leukocytes (data not shown). For 1,7-dimethylxanthine a clear attenuating effect on the ex vivo LPS-stimulated production of TNF- $\alpha$ was found for COPD patients and not for healthy controls, indicating that 1,7 dimethylxanthine may especially be effective under conditions of systemic inflammation. The cytokine TNF- $\alpha$ is considered to contribute importantly to the pathogenesis of COPD. A study by Keatings et al. showed that the levels of TNF- $\alpha$ in sputum were significantly higher in patients with COPD compared with both smokers and nonsmokers, suggesting that increased levels of TNF- $\alpha$ were related to COPD [163]. Although synthetic TNF- $\alpha$ blockers, such as infliximab, were proven to be efficient therapeutic agents in various inflammatory diseases such as rheumatoid arthritis [164, 165], it was recently shown that subjects with moderate to severe COPD did not benefit from treatment with infliximab $[49,50]$. Therefore the need for more effective antiinflammatory treatments still exists. Moreover, it should be noted that PARP-1 inhibitors act via different mechanisms than synthetic TNF- $\alpha$ blockers such as infliximab that bind with high affinity to TNF- $\alpha$ and block its biological activity. PARP-1 has been reported to modulate the transcriptional level of TNF- $\alpha$ and other inflammatory mediators $[11,20]$.

\section{Differences between human and murine caffeine metabolism}

In this study, the caffeine metabolite 1,7-dimethylxanthine was applied in both an in vivo and an ex vivo model of LPS-induced inflammation. In humans, caffeine is readily absorbed and metabolized in the liver by the hepatic enzyme cytochrome P4501A2 (CYP1A2) to its major metabolites 1,7-dimethylxanthine (paraxanthine), theophylline (1,3-dimethylxanthine) and theobromine (3,7dimethylxanthine). $\mathrm{N}-3$ demethylation is the major pathway in humans resulting in the predominant formation of 1,7-dimethylxanthine. Lelo et al (1986) reported that 1,7-dimethylxanthine accounts for $67.3 \%$ of total dimethylxanthines in plasma after oral caffeine intake, while theobromine and theophylline account for $24.4 \%$ and $8.3 \%$ respectively [166]. Plasma 1,7-dimethylxanthine levels of $20 \mu \mathrm{M}$ have been reported after the intake of coffee, which indicates that the concentrations used in the present study were physiologically relevant levels [66]. Also in mice, caffeine clearance depends largely on activity of CYP1A2 [167]. However, 1,7-dimethylxanthine is not the major metabolite of caffeine found in blood of mice, since the $\mathrm{N}-1, \mathrm{~N}-3$ and $\mathrm{N}-7$ demethylation pathways are equally important for metabolizing caffeine in mice, resulting in the formation of equivalent amounts of theobromine, 1,7-dimethylxanthine and theophylline in mice [168]. Altogether, it is therefore considered likely that administration of caffeine to humans is able to exert anti-inflammatory effects via its metabolites. 


\section{Conclusion}

Based on the results of the present study it can be concluded that oral administration of PARP-1 inhibiting methylxanthines such as 1,7-dimethylxanthine is efficacious in reducing local and systemic inflammation in a mouse model of LPS-induced acute pulmonary inflammation. Furthermore, 1,7-dimethylxanthine efficiently reduced the ex vivo LPS-induced TNF- $\alpha$ production in blood of COPD patients at a physiological relevant concentration. The results of this study indicate that the application of the PARP-1 inhibiting caffeine metabolite 1,7-dimethylxanthine might be a promising extension to the currently available therapeutics in the treatment of inflammatory diseases such as COPD. 


\section{CHAPTER 7}

General Discussion 


\section{GENERAL DISCUSSION}

The hypothesis of the $\mathrm{PhD}$ research described in this thesis was that dietary mild PARP-1 inhibitors are able to attenuate NF- $\mathrm{kB}$ mediated gene-expression and therefore may be applied as anti-inflammatory treatment in inflammatory diseases such as COPD. These inhibitors can be potential ingredients for medicinal foods and nutraceuticals. The screening process of identifying dietary inhibitors of the nuclear enzyme PARP-1 was an important part of this project and is described in chapter 2, 3 and $\mathbf{4}$. Furthermore, the potential application of these compounds as anti-inflammatory agents was also evaluated and described in chapters $\mathbf{5}$ and $\mathbf{6}$ of this thesis.

In this final chapter a general discussion is presented:

- $\quad$ the main findings will be summarized and discussed

- $\quad$ a benefit risk evaluation of food-derived PARP-1 inhibitors will be presented together with potential implications and suggestions for further evaluation

- $\quad$ the conclusions of the study described in this thesis will be presented

\section{MAIN FINDINGS}

\section{Identification of PARP-1 inhibiting dietary compounds}

In order to identify potential dietary mild PARP-1 inhibitors, we started screening various compounds for their PARP-1 inhibiting activity with an enzymebased ELISA method using the purified human recombinant PARP-1 enzyme. With this assay, we could relatively easy and efficiently test various compounds, but also compare them to the classical PARP-1 inhibitor 3-aminobenzamide. In a next step, the PARP-1 inhibiting compounds were further evaluated in cultured lung epithelial and vascular endothelial cells exposed to hydrogen peroxide $\left(\mathrm{H}_{2} \mathrm{O}_{2}\right)$ or $\mathrm{N}$-methyl- $\mathrm{N}^{\prime}$-nitro- $\mathrm{N}$-nitroso-guanidine (MNNG), as inducers of DNA strand breaks and PARP-1 over-activation. PARP-activation was measured as a decrease in intracellular $\mathrm{NAD}^{+}$levels and as PAR-polymer formation. Although PAR-polymers are known to be very rapidly degraded, measurement of the PAR-polymer formation after a short incubation period of 5-10 min can be used to indicate PARP-1 activation. In combination with the determination of intracellular $\mathrm{NAD}^{+}$levels, this provides a reliable assessment of the extent of PARP-1 activation or inhibition.

After an initial screening of a variety of compounds including chlorogenic acid, resveratrol and folic acid, two groups of dietary compounds were selected for further in vitro screening processes: 1) methylxanthines and 2) flavonoids. 


\section{Methylxanthines as PARP-1 inhibitors}

In chapter 2, we described the research on the PARP-1 inhibiting activity of methylxanthines. 1,7-Dimethylxanthine (the major metabolite of caffeine in humans) was found to inhibit the purified PARP-1 enzyme with high efficacy. Also other methylxanthines such as theophylline, theobromine, 1-methylxanthine and 3-methylxanthine were found to inhibit PARP-1. Furthermore, it was observed that oxidative stress-induced depletion of intracellular NAD ${ }^{+}$ levels and PAR-polymer formation in cultured pulmonary epithelial cells as well as vascular endothelial cells was most efficiently prevented by 1,7dimethylxanthine. Since PARP-1 has been implicated in necrotic cell death [86], the effect of PARP-1 inhibitors on oxidative-stress induced necrosis was subsequently investigated. Since cell death processes may influence the cellular energy levels in a specific way, variations in the ADP:ATP ratio are used to distinguish between the different modes of cell death. ADP:ATP ratios for cells undergoing apoptosis are expected to be higher than control values but below 1, while values above 1 characterize necrotic cells [95]. By measuring this ratio, it was found that oxidative stress-induced necrotic cell death was reduced and shifted to apoptotic cell-death processes in presence of 1,7-dimethylxanthine in pulmonary epithelial and vascular endothelial cells respectively.

\section{Flavonoids: PARP-1 inhibiting and anti-inflammatory activity}

In chapter 3 we described the screening of flavonoids for their potential PARP1 inhibiting activity. Especially, the flavonoids fisetin, tricetin and quercetin were found to inhibit the purified enzyme as well as to prevent the MNNGinduced depletion of intracellular NAD+-levels and formation of PAR-polymers in pulmonary epithelial cells. In a final series of in vitro experiments described in this chapter, the influence of PARP-1 inhibition on the NF- $\kappa B$ mediated gene expression was evaluated. Since PARP-1 acts as a co-activator of NF- $\kappa B$ and the poly(ADP-ribosyl)ation process promotes the accessibility of genes for the transcription machinery and increases gene-transcription [14, 17], the potential anti-inflammatory effect of dietary PARP-1 inhibiting compounds was investigated. We used an in vitro model in which the production and genetranscription of the cytokine IL-8 was determined in LPS-stimulated cultured pulmonary epithelial cells pretreated with the various PARP-1 inhibiting compounds. Although IL-8 is considered to be an important cytokine in inflammatory diseases such as COPD, also other cytokines are involved. These cytokines were measured in the ex vivo assay as described in chapter $\mathbf{6}$ and in an ex vivo study in which the anti-inflammatory effects of flavonoids were investigated [169].

At present, there is still much controversy about the exact role of PARP-1 in NF$\kappa \mathrm{B}$ mediated gene-expression. It has been suggested that solely the PARP-1 protein and not its activity is important in facilitating the acetylation of the p65 
subunit of NF-kB, which is required for full activation of NF-kB [16, 18]. Conversely, others reported that the synthesis of PAR-polymers facilitated the transcriptional activation properties of $\mathrm{NF}-\mathrm{kB}$, probably via chromatin relaxation and recruitment of other proteins of the transcription complex [14, 19]. Nonetheless, several studies indicated the attenuating activity of various synthetic PARP-1 inhibitors on the NF-KB mediated gene-expression [20, 21]. In the study presented in chapter 3, the LPS-induced NF-kB mediated production of IL-8 in pulmonary epithelial cells was found to be reduced by the flavonoids fisetin, tricetin and quercetin. Furthermore, the synthetic PARP-1 inhibitor PJ34 showed a comparable anti-inflammatory activity.

The in vitro anti-inflammatory effects of the PARP-1 inhibiting flavonoid flavone were described in chapter 4. Flavone inhibited the purified PARP-1 enzyme and also prevented the MNNG-induced depletion of intracellular NAD+-levels and formation of the PAR-polymers. Furthermore, flavone was found to attenuate the LPS-induced production and transcription of the NF- $\mathrm{KB}$ mediated cytokine IL-8. Also, a significant increased gene transcription of $І \kappa B \alpha$, the inhibiting protein of NF- $\mathrm{\kappa B}$, was observed in the flavone-pretreated cells after LPS-stimulation. This may indicate an enhancement of feed-back pathways, leading to a resolution of the inflammatory response. Finally, flavone did not show any relevant radical scavenging activity, as determined with ESR spectroscopy and the TEAC assay. This implies that the observed anti-inflammatory effects of flavone could not be explained by antioxidant properties.

In the LPS-stimulated pulmonary epithelial cells no nuclear translocation of NF$\kappa \mathrm{B}$ could be detected, which made it difficult to elucidate the potential involvement of NF-kB-related mechanisms in the observed reduction in IL-8 gene-expression after treatment with flavone. The AP-1 pathway could also be involved, though the possible anti-inflammatory effect of PARP- 1 inhibitors on this pathway, for instance by inhibition of MAPK activity was not further tested. It was decided to focus on potential effects of PARP-1 inhibitors on the NF- $\mathrm{kB}$ mediated gene-expression. Recently, the mechanism of the anti-inflammatory effects of the flavonoid fisetin was extensively investigated using various cell lines such as human lung adenocarcinoma cells and human fibroblasts. Fisetin was found to suppress NF-KB activation. By inhibiting activation of IKK, fisetin blocked the phosphorylation and degradation of $\mathrm{I} K \mathrm{~B}$ and subsequently induced suppression of the nuclear translocation of p65 subunit [147]. However, since no nuclear translocation of NF-KB could be detected in our in vitro model, we were unable to evaluate the contribution of this potential mechanism in pulmonary epithelial cells.

\section{Structure-activity requirements of PARP-1 inhibiting flavonoids}

This distinctive flavonoid compound flavone was identified as PARP-1 inhibitor and anti-inflammatory compound, which was rather unexpected since flavone 
has a flavonoid structure without any hydroxyl groups. For flavonoids in general, it was previously shown that their antioxidant effects and various enzyme inhibiting effects are largely dependent on their hydroxylation pattern [58, 59, 170]. As mentioned in chapter 3, general structural characteristics of competitive synthetic PARP-1 inhibitors include a carboxamide-group attached to an aromatic ring or the carbamoyl group built in a polyaromatic heterocyclic skeleton. However, this is not characteristic of flavone or flavonoids in general. This implies that flavonoids and/or flavone may be considered to reflect a group of compounds with structural characteristics that enable them to interact with the catalytic site of PARP-1. Since a mix of competitive and noncompetitive inhibition of the PARP-1 enzyme was observed, interaction of flavonoids with other sites of the PARP- 1 enzyme that may affect its catalytic activity, such as the automodification site, cannot be excluded.

Many different structures were screened for their PARP-1 inhibiting activity. Nevertheless, based on our results no specific statement about a possible structure-activity relationship for PARP1 inhibiting activity of flavonoids can be given.

\section{Evaluation of PARP-1 inhibition in vivo}

Based on the results of our in vitro studies described in chapters 2, 3 and 4, four compounds were selected for further in vivo mouse and ex vivo human evaluation: the flavonoids 1) flavone, 2) fisetin and 3) tricetin and the methylxanthine 4) 1,7-dimethylxanthine.

In chapter $\mathbf{5}$ the in vivo application of the flavonoids flavone, fisetin and tricetin in a mouse model of LPS-induced acute pulmonary inflammation was described. Based on MPO-analysis in a dose- and time-finding study, 2 time points after LPS-exposure, $4 \mathrm{~h}$ and $24 \mathrm{~h}$, were chosen to investigate whether oral administration of PARP-1 inhibitors might suppress early development of the inflammatory response as well as reduce its intensity. The flavonoid fisetin significantly reduced lung MPO-levels and gene-expression of inflammatory mediators such as IL- 6 , TNF- $\alpha$, IL-1 $\beta$, MIP- $1 \alpha$ and MIP-2 at $24 \mathrm{~h}$ after LPSstimulation. The LPS-induced gene transcription of the HO-1 and SOD2 genes was also significantly reduced by fisetin, indicating less oxidative stress was induced in mice that received fisetin. Flavone and tricetin also showed attenuation of inflammatory markers, although most consistent effects were observed for fisetin. Furthermore, fisetin was found to have a higher efficacy in reducing pulmonary inflammation as compared to the well-established antiinflammatory glucocorticoid dexamethasone. Dexamethasone was able to efficiently reduce systemic but not pulmonary inflammation in this in vivo mouse model. Finally, oral administration of fisetin as well as dexamethasone was found to attenuate the number of PAR-polymer positive pulmonary epithelial cells. 
In chapter $\mathbf{6}$ we described the results of the in vivo application of the PARP-1 inhibitor 1,7-dimethylxanthine in a mouse model of LPS-induced acute pulmonary inflammation. 1,7-Dimethylxanthine significantly attenuated both pulmonary as well as systemic inflammation which was indicated by reduced pulmonary MPO-levels, attenuated gene transcription of the pro-inflammatory cytokines IL- 6 , TNF- $\alpha$, MIP- $1 \alpha$ and MIP-2 in lungs and reduced plasma levels of SAP and IL-6 at $24 \mathrm{~h}$. The anti-inflammatory effects of 1,7-dimethylxanthine were more pronounced when compared to the synthetic PARP-1 inhibitor 3aminobenzamide. 3-Aminobenzamide also failed to attenuate the LPS-induced increase in the number of PAR-polymer positive pulmonary epithelial cells. The reported short half-life of 3-aminobenzamide [162] and a poor oral availability are probably responsible for the lack of clear effects at $24 \mathrm{~h}$ after LPS treatment. The ex vivo anti-inflammatory effects of 1,7-dimethylxanthine in LPS-stimulated blood of COPD patients and healthy controls were also assessed and described in chapter 6. In this ex vivo model, 1,7-dimethylxanthine significantly suppressed the LPS-induced production of the cytokines IL- 6 and TNF- $\alpha$ at physiologically relevant levels that can be reached after consumption of 2 cups of coffee.

Finally, it should be noted that inhibition of PARP-1 is probably not the sole mechanism responsible for the observed anti-inflammatory effects of the various compounds. In addition to the PARP-1 inhibiting effects which is the main characteristic of 3-aminobenzamide, 1,7-dimethylxanthine has been reported to exert anti-inflammatory effects via adenosine receptor antagonism and inhibition of phosphodiesterase 4 (PDE4) [159, 160]. Flavonoids, such as fisetin, have been reported to modulate signal transduction pathways, including MAPK [60]. Moreover, dexamethasone is not acting via PARP-inhibition, but by binding to the cytoplasmatic glucocorticoid receptor. Subsequent nuclear localization of this complex controls transcription of multiple inflammatory genes encoding cytokines, chemokines, adhesion molecules and inflammatory enzymes such as iNOS [171]. So, various mechanisms are likely to be responsible for the observed anti-inflammatory effects.

\section{DISCUSSION}

Several aspects of the potential application of food-derived PARP-1 inhibiting flavonoids and methylxanthines as described in the current thesis require further discussion. Therefore, the following issues will be discussed in more detail in this paragraph:

- $\quad$ Possible adverse effects of PARP-1 inhibition in general

- $\quad$ Benefit risk considerations of flavonoids and methylxanthines 


\section{Possible adverse effects of the use of PARP-1 inhibitors}

As indicated in chapter 1, PARP-1 has a facilitating role in DNA repair and it has been suggested that PARP-1 inhibition might interfere with this repairfacilitating function. However, the importance of the DNA-repair facilitating function of PARP-1 in normal cellular physiology is still not clear. The suggestions that PARP-1 inhibition has some important side-effects on DNA-repair were based mainly on studies with PARP-1 knockout cells and mice [5, 172]. PARP-1 knockout mice were found to be hypersensitive to alkylating agents or ionising radiation $[5,172]$. Using these knockout models, no difference can be made between the physical absence of the enzyme and a reduced catalytic activity. Recently, evidence was presented that PARP-1 has probably a relatively minor role in DNA repair pathways in animals with functional PARP-1 under conditions of increased oxidative stress. This was supported by a study of Hauser et al (2006) in which the potent PARP-1 inhibitor INO-1001 was applied in a porcine model of thoracic aortic cross-clamping. No increased DNA damage or adverse effect on DNA repair was observed after treatment with INO-1001 [120]. PARP-1 has also been reported to be involved in telomere stability, and maintenance of telomere length. In humans, telomere length is considered an indicator of the biological age, and telomere attrition is associated with a shorter life expectancy in population groups with a high risk for cardiovascular diseases [173]. PARP-1 knock-out mice were found to have shorter telomeres than wild-type mice [174]. The importance of PARP-1 in maintaining genomic integrity, which is required for functional cells and organs, is also indicated by the positive correlation between cellular poly(ADPribosyl)ation capacity and mammalian lifespan [175]. However, the exact consequences of PARP-1 inhibition for telomere stability need to be determined.

\section{Benefit risk considerations of flavonoids}

The effects of flavonoids observed on LPS-induced inflammatory response in the studies described in the current thesis are most likely the result of combination of several effects such as PARP-1 inhibition, antioxidant and antiinflammatory effects. Since flavonoids are extensively metabolized in intestine and liver in vivo, resulting in conjugation with glucuronides, sulfates and in methylation, the PARP-1 inhibiting activity of these metabolites should also be evaluated.

Besides the positive health effects of flavonoids such as reduced risk for cardiovascular and chronic inflammatory diseases as mentioned in chapter 1 $[51,57]$, some toxic effects of flavonoids have also been reported. As a consequence of their antioxidant activities, flavonoids become oxidized into different oxidation products, which can react with cellular constituents such as proteins, DNA and lipids. Flavonoids have been identified to antagonize DNA topoi- 
somerases, which can lead to mutagenesis and chromosomal aberrations [176178].

No studies are available to date, however, that evaluate the potential health effects of long-term use of dietary supplements or functional foods with high concentrations of flavonoids. Whether long-term supplementation of the flavonoids fisetin, tricetin and flavone, in people suffering a chronic inflammatory disease is associated with a high risk for serious side-effects, needs to be carefully evaluated.

\section{Benefit risk considerations of methylxanthines}

Coffee is nowadays the most important source of methylxanthines, such as caffeine. Coffee is a complex chemical mixture containing more than a thousand different chemicals, including carbohydrates, lipids, nitrogenous compounds, vitamins, minerals, phenolic compounds, and alkaloids such as the methylxanthine caffeine. Various studies have been conducted to evaluate health effects of long-term intake of coffee. Based on observational, epidemiological studies, coffee intake in humans has been associated with various health effects, both beneficial as well as adverse effects [179]. In the past, concerns about potential health risks of coffee and caffeine intake were likely to be influenced by associations between high coffee intake and unhealthy behaviour such as cigarette smoking and physical inactivity. More recently, coffee consumption and caffeine intake has been associated with a reduced risk for various chronic metabolic disorders, such as type 2 diabetes mellitus and liver cirrhosis, but also neurological disorders such as Parkinson's disease [103, 180, 181]. Although coffee consumption is associated with increases in risk factors for cardiovascular diseases including blood pressure and plasma homocysteine levels, most studies have not found coffee consumption to be associated with significantly increased cardiovascular risk [182]. According to the World Cancer Research Fund, it is not expected that coffee has any significant effect on the risk of pancreatic or kidney cancer [183]. This would suggest that chronic use of beverages with a high concentration PARP-1 inhibitor is not associated with a high cancer risk. Previously, emphasis was put on the teratogenic effect of caffeine in rodents. Based on epidemiological studies it was subsequently concluded that caffeine does not present any teratogenic risk in humans [184]. However, a recent published study showed a positive correlation between high doses of caffeine intake during pregnancy and the risk of a miscarriage [185]. Chronic caffeine intake to increase levels of 1,7dimethylxanthine should therefore be discouraged for specific groups like pregnant women, but it might have beneficial effects in patients with chronic inflammatory diseases such as COPD. 


\section{IMPLICATIONS AND SUGGESTIONS}

The research described in this thesis indicates that both in vivo administration of, as well as in vitro and ex vivo incubation with, dietary PARP- 1 inhibitors such as fisetin and 1,7-dimethylxanthine exert anti-inflammatory effects. This needs to be further evaluated in an intervention study with humans suffering from an inflammatory disease such as COPD. The mouse model for acute LPSinduced pulmonary inflammation allowed us not only to evaluate local pulmonary effects, but also systemic anti-inflammatory effects of orally administered PARP-1 inhibitors under standardized conditions. Although the applied in vivo mouse model was a model of acute inflammation, the relevance for more chronic situations might therefore be debatable. The combined results of the in vivo animal study and of the ex vivo study of blood of COPD patients and healthy controls however suggest that these compounds might have potential anti-inflammatory effects in COPD patients. It should be noted here that in addition to the ex vivo evaluation of 1,7-dimethylxantine as described in chapter 6, the anti-inflammatory effects of the flavonoids fisetin, tricetin and flavone were also ex vivo evaluated. Both fisetin and tricetin significantly decreased the LPS-induced production of TNF- $\alpha$ in blood of COPD patients [169].

To confirm our results and to investigate the potential beneficial effects on clinical parameters and quality of life of COPD patients, supplementation with these compounds as nutraceuticals or with medicinal foods needs to be evaluated in this patient group. For flavonoids, it should be noted that the dietary matrix in which these compounds are administered can significantly influence the expected results. In the in vivo animal study, the flavonoids were suspended in soy oil, which is known to increase the bioavailability of these compounds [143]. For the flavonoid tricetin it was found that this compound is not stabile in aqueous medium, since it is degraded into oxidation products within $45 \mathrm{~min}$ (unpublished data). Furthermore, the form of flavonoids (aglycone or flavonoid glycosides) can have an important effect on the bioavailability of these compounds. In addition, in order to achieve relatively higher plasma flavonoid levels, it is necessary to use food enriched with flavonoids, since these cannot be reached with a normal diet.

Another issue which requires to be discussed is that in order to improve health status of patients suffering a chronic inflammatory disease such as COPD, long term use of supplements is needed. There are no data available about chronic use of flavonoids such as fisetin in patients suffering a chronic disease such as COPD. The long term effects of these compounds should also be examined to evaluate the safety of chronic supplementation in this patient group. 


\section{CONCLUSIONS}

Based on the results presented in this thesis, it can be concluded that dietary PARP-1 inhibitors such as 1,7-dimethylxanthine and fisetin are able to attenuate NF-kB mediated gene-expression and exert anti-inflammatory effects, both in vitro as well as in vivo in the mouse and ex vivo in human blood. Based on these effects, they are considered potential candidates for nutraceutical treatment of inflammatory diseases such as COPD.

Up to now, no successful treatment for COPD, in particular treatment for the local and systemic inflammation in COPD, has been developed yet. Dietary mild PARP-1 inhibitors such as 1,7-dimethylxanthine or fisetin might be applied as supplements, in order to reduce both pulmonary as well as systemic inflammation and improve quality of life of COPD patients. 
REFERENCES 


\section{REFERENCES}

[1] Jagtap P, Szabo C. Poly(ADP-ribose) polymerase and the therapeutic effects of its inhibitors. Nat Rev Drug Discov 2005;4:421-40.

[2] Virag L, Szabo C. The therapeutic potential of poly(ADP-ribose) polymerase inhibitors. Pharmacol Rev 2002;54:375-429.

[3] Ame JC, Spenlehauer C, de Murcia G. The PARP superfamily. Bioessays 2004;26:882-93.

[4] Muiras ML. Mammalian longevity under the protection of PARP-1's multi-facets. Ageing Res Rev 2003;2:129-48.

[5] de Murcia JM, Niedergang C, Trucco C, Ricoul M, Dutrillaux B, Mark M, et al. Requirement of poly(ADP-ribose) polymerase in recovery from DNA damage in mice and in cells. Proc Natl Acad Sci U S A 1997;94:7303-7.

[6] Dantzer F, de La Rubia G, Menissier-De Murcia J, Hostomsky Z, de Murcia G, Schreiber V. Base excision repair is impaired in mammalian cells lacking Poly(ADP-ribose) polymerase-1. Biochemistry 2000;39:7559-69.

[7] Masson M, Niedergang C, Schreiber V, Muller S, Menissier-de Murcia J, de Murcia G. XRCC1 is specifically associated with poly(ADP-ribose) polymerase and negatively regulates its activity following DNA damage. Mol Cell Biol 1998;18:3563-71.

[8] Schreiber V, Ame JC, Dolle P, Schultz I, Rinaldi B, Fraulob V, et al. Poly(ADP-ribose) polymerase-2 (PARP-2) is required for efficient base excision DNA repair in association with PARP-1 and XRCC1. J Biol Chem 2002;277:23028-36.

[9] Poirier GG, de Murcia G, Jongstra-Bilen J, Niedergang C, Mandel P. Poly(ADP-ribosyl)ation of polynucleosomes causes relaxation of chromatin structure. Proc Natl Acad Sci U S A 1982;79:3423-7.

[10] Schreiber V, Dantzer F, Ame JC, de Murcia G. Poly(ADP-ribose): novel functions for an old molecule. Nat Rev Mol Cell Biol 2006;7:517-28.

[11] Oliver FJ, Menissier-de Murcia J, Nacci C, Decker P, Andriantsitohaina R, Muller S, et al. Resistance to endotoxic shock as a consequence of defective NF-kappaB activation in poly (ADP-ribose) polymerase-1 deficient mice. Embo J 1999;18:4446-54.

[12] Lazebnik YA, Kaufmann SH, Desnoyers S, Poirier GG, Earnshaw WC. Cleavage of poly(ADPribose) polymerase by a proteinase with properties like ICE. Nature 1994;371:346-7.

[13] van Wijk SJ, Hageman GJ. Poly(ADP-ribose) polymerase-1 mediated caspase-independent cell death after ischemia/reperfusion. Free Radic Biol Med 2005;39:81-90.

[14] Chiarugi A. Poly(ADP-ribose) polymerase: killer or conspirator? The 'suicide hypothesis' revisited. Trends Pharmacol Sci 2002;23:122-9.

[15] Hassa PO, Hottiger MO. A role of poly (ADP-ribose) polymerase in NF-kappaB transcriptional activation. Biol Chem 1999;380:953-9.

[16] Hassa PO, Covic M, Hasan S, Imhof R, Hottiger MO. The enzymatic and DNA binding activity of PARP-1 are not required for NF-kappa B coactivator function. J Biol Chem 2001;276:45588-97.

[17] Hassa PO, Buerki C, Lombardi C, Imhof R, Hottiger MO. Transcriptional coactivation of nuclear factor-kappaB-dependent gene expression by $\mathrm{p} 300$ is regulated by poly(ADP)-ribose polymerase-1. J Biol Chem 2003;278:45145-53.

[18] Hassa PO, Haenni SS, Buerki C, Meier NI, Lane WS, Owen H, et al. Acetylation of poly(ADPribose) polymerase- 1 by $\mathrm{p} 300 / \mathrm{CREB}-$ binding protein regulates coactivation of NF-kappaBdependent transcription. J Biol Chem 2005;280:40450-64.

[19] Chang WJ, Alvarez-Gonzalez R. The sequence-specific DNA binding of NF-kappa B is reversibly regulated by the automodification reaction of poly (ADP-ribose) polymerase $1 . \mathrm{J}$ Biol Chem 2001;276:47664-70.

[20] Chiarugi A, Moskowitz MA. Poly(ADP-ribose) polymerase-1 activity promotes NF-kappaBdriven transcription and microglial activation: implication for neurodegenerative disorders. J Neurochem 2003;85:306-17. 
[21] Chiarugi A. Inhibitors of poly(ADP-ribose) polymerase-1 suppress transcriptional activation in lymphocytes and ameliorate autoimmune encephalomyelitis in rats. $\mathrm{Br} J$ Pharmacol 2002;137:761-70.

[22] Andreone TL, O'Connor M, Denenberg A, Hake PW, Zingarelli B. Poly(ADP-ribose) polymerase-1 regulates activation of activator protein-1 in murine fibroblasts. J Immunol 2003;170:2113-20.

[23] Zingarelli B, Hake PW, O'Connor M, Denenberg A, Wong HR, Kong S, et al. Differential regulation of activator protein-1 and heat shock factor-1 in myocardial ischemia and reperfusion injury: role of poly(ADP-ribose) polymerase-1. Am J Physiol Heart Circ Physiol 2004;286:H1408-15.

[24] Veres B, Radnai B, Gallyas F, Jr., Varbiro G, Berente Z, Osz E, et al. Regulation of kinase cascades and transcription factors by a poly(ADP-ribose) polymerase-1 inhibitor, 4hydroxyquinazoline, in lipopolysaccharide-induced inflammation in mice. J Pharmacol Exp Ther 2004;310:247-55.

[25] Ha HC. Defective transcription factor activation for proinflammatory gene expression in poly(ADP-ribose) polymerase 1-deficient glia. Proc Natl Acad Sci U S A 2004;101:5087-92.

[26] Boulares AH, Zoltoski AJ, Sherif ZA, Jolly P, Massaro D, Smulson ME. Gene knockout or pharmacological inhibition of poly(ADP-ribose) polymerase-1 prevents lung inflammation in a murine model of asthma. Am J Respir Cell Mol Biol 2003;28:322-9.

[27] Soriano FG, Pacher P, Mabley J, Liaudet L, Szabo C. Rapid reversal of the diabetic endothelial dysfunction by pharmacological inhibition of poly(ADP-ribose) polymerase. Circ Res 2001;89:684-91.

[28] Kaplan J, O'Connor M, Hake PW, Zingarelli B. Inhibitors of poly (ADP-ribose) polymerase ameliorate myocardial reperfusion injury by modulation of activator protein-1 and neutrophil infiltration. Shock 2005;23:233-8.

[29] Liaudet L, Pacher P, Mabley JG, Virag L, Soriano FG, Hasko G, et al. Activation of poly(ADPRibose) polymerase- 1 is a central mechanism of lipopolysaccharide-induced acute lung inflammation. Am J Respir Crit Care Med 2002;165:372-7.

[30] Hageman GJ, Larik I, Pennings HJ, Haenen GR, Wouters EF, Bast A. Systemic poly(ADPribose) polymerase- 1 activation, chronic inflammation, and oxidative stress in COPD patients. Free Radic Biol Med 2003;35:140-8.

[31] Abdelkarim GE, Gertz K, Harms C, Katchanov J, Dirnagl U, Szabo C, et al. Protective effects of PJ34, a novel, potent inhibitor of poly(ADP-ribose) polymerase (PARP) in in vitro and in vivo models of stroke. Int J Mol Med 2001;7:255-60.

[32] Thomas HD, Calabrese CR, Batey MA, Canan S, Hostomsky Z, Kyle S, et al. Preclinical selection of a novel poly(ADP-ribose) polymerase inhibitor for clinical trial. Mol Cancer Ther 2007;6:945-56.

[33] Mabley JG, Jagtap P, Perretti M, Getting SJ, Salzman AL, Virag L, et al. Anti-inflammatory effects of a novel, potent inhibitor of poly (ADP-ribose) polymerase. Inflamm Res 2001;50:561-9.

[34] Jagtap P, Soriano FG, Virag L, Liaudet L, Mabley J, Szabo E, et al. Novel phenanthridinone inhibitors of poly (adenosine 5'-diphosphate-ribose) synthetase: potent cytoprotective and antishock agents. Crit Care Med 2002;30:1071-82.

[35] Tikhe JG, Webber SE, Hostomsky Z, Maegley KA, Ekkers A, Li J, et al. Design, synthesis, and evaluation of 3,4-dihydro-2H-[1,4]diazepino[6,7,1-hi]indol-1-ones as inhibitors of poly(ADPribose) polymerase. J Med Chem 2004;47:5467-81.

[36] Alano CC, Kauppinen TM, Valls AV, Swanson RA. Minocycline inhibits poly(ADP-ribose) polymerase-1 at nanomolar concentrations. Proc Natl Acad Sci U S A 2006;103:9685-90.

[37] Thiemermann C, Bowes J, Myint FP, Vane JR. Inhibition of the activity of poly(ADP ribose) synthetase reduces ischemia-reperfusion injury in the heart and skeletal muscle. Proc Natl Acad Sci U S A 1997;94:679-83.

[38] Roesner JP, Vagts DA, Iber T, Eipel C, Vollmar B, Noldge-Schomburg GF. Protective effects of PARP inhibition on liver microcirculation and function after haemorrhagic shock and resusci- 
tation in male rats. Intensive Care Med 2006;32:1649-57.

[39] Sharma S, Stutzman JD, Kelloff GJ, Steele VE. Screening of potential chemopreventive agents using biochemical markers of carcinogenesis. Cancer Res 1994;54:5848-55.

[40] Rankin PW, Jacobson EL, Benjamin RC, Moss J, Jacobson MK. Quantitative studies of inhibitors of ADP-ribosylation in vitro and in vivo. J Biol Chem 1989;264:4312-7.

[41] Rabe KF, Hurd S, Anzueto A, Barnes PJ, Buist SA, Calverley P, et al. Global strategy for the diagnosis, management, and prevention of chronic obstructive pulmonary disease: GOLD executive summary. Am J Respir Crit Care Med 2007;176:532-55.

[42] Lopez AD, Murray CC. The global burden of disease, 1990-2020. Nat Med 1998;4:1241-3.

[43] Lopez AD, Shibuya K, Rao C, Mathers CD, Hansell AL, Held LS, et al. Chronic obstructive pulmonary disease: current burden and future projections. Eur Respir J 2006;27:397-412.

[44] Agusti AG, Noguera A, Sauleda J, Sala E, Pons J, Busquets X. Systemic effects of chronic obstructive pulmonary disease. Eur Respir J 2003;21:347-60.

[45] Celli BR, Halbert RJ, Nordyke RJ, Schau B. Airway obstruction in never smokers: results from the Third National Health and Nutrition Examination Survey. Am J Med 2005;118:1364-72.

[46] Behrendt CE. Mild and moderate-to-severe COPD in nonsmokers: distinct demographic profiles. Chest 2005;128:1239-44.

[47] Stoller JK, Aboussouan LS. Alpha1-antitrypsin deficiency. Lancet 2005;365:2225-36.

[48] Silva GE, Sherrill DL, Guerra S, Barbee RA. Asthma as a risk factor for COPD in a longitudinal study. Chest 2004;126:59-65.

[49] van der Vaart H, Koeter GH, Postma DS, Kauffman HF, ten Hacken NH. First study of infliximab treatment in patients with chronic obstructive pulmonary disease. Am J Respir Crit Care Med 2005;172:465-9.

[50] Rennard SI, Fogarty C, Kelsen S, Long W, Ramsdell J, Allison J, et al. The safety and efficacy of infliximab in moderate to severe chronic obstructive pulmonary disease. Am J Respir Crit Care Med 2007;175:926-34.

[51] Hertog MG, Feskens EJ, Hollman PC, Katan MB, Kromhout D. Dietary antioxidant flavonoids and risk of coronary heart disease: the Zutphen Elderly Study. Lancet 1993;342:1007-11.

[52] de Vries JH, Janssen PL, Hollman PC, van Staveren WA, Katan MB. Consumption of quercetin and kaempferol in free-living subjects eating a variety of diets. Cancer Lett 1997;114:141-4.

[53] Kuhnau J. The flavonoids. A class of semi-essential food components: their role in human nutrition. World Rev Nutr Diet 1976;24:117-91.

[54] Hollman PC, de Vries JH, van Leeuwen SD, Mengelers MJ, Katan MB. Absorption of dietary quercetin glycosides and quercetin in healthy ileostomy volunteers. Am J Clin Nutr 1995;62:1276-82.

[55] Hollman PC, van Trijp JM, Buysman MN, van der Gaag MS, Mengelers MJ, de Vries JH, et al. Relative bioavailability of the antioxidant flavonoid quercetin from various foods in man. FEBS Lett 1997;418:152-6.

[56] Hollman PC, Katan MB. Absorption, metabolism and health effects of dietary flavonoids in man. Biomed Pharmacother 1997;51:305-10.

[57] Nijveldt RJ, van Nood E, van Hoorn DE, Boelens PG, van Norren K, van Leeuwen PA. Flavonoids: a review of probable mechanisms of action and potential applications. Am J Clin Nutr 2001;74:418-25.

[58] Rice-Evans CA, Miller NJ, Paganga G. Structure-antioxidant activity relationships of flavonoids and phenolic acids. Free Radic Biol Med 1996;20:933-56.

[59] Middleton EJ, Kandaswami C. The impact of plant flavonoids on mammalian biology: implications for immunity, inflammation and cancer, in. The flavonoids: Advances in research since 1986 1993:619-52.

[60] Williams RJ, Spencer JP, Rice-Evans C. Flavonoids: antioxidants or signalling molecules? Free Radic Biol Med 2004;36:838-49.

[61] Spencer JP, Abd-el-Mohsen MM, Rice-Evans C. Cellular uptake and metabolism of flavonoids and their metabolites: implications for their bioactivity. Arch Biochem Biophys 2004;423:148-61. 
[62] Knekt P, Kumpulainen J, Jarvinen R, Rissanen H, Heliovaara M, Reunanen A, et al. Flavonoid intake and risk of chronic diseases. Am J Clin Nutr 2002;76:560-8.

[63] Tabak C, Arts IC, Smit HA, Heederik D, Kromhout D. Chronic obstructive pulmonary disease and intake of catechins, flavonols, and flavones: the MORGEN Study. Am J Respir Crit Care Med 2001;164:61-4.

[64] Funaguchi N, Ohno Y, La BL, Asai T, Yuhgetsu H, Sawada M, et al. Narirutin inhibits airway inflammation in an allergic mouse model. Clin Exp Pharmacol Physiol 2007;34:766-70.

[65] Das M, Ram A, Ghosh B. Luteolin alleviates bronchoconstriction and airway hyperreactivity in ovalbumin sensitized mice. Inflamm Res 2003;52:101-6.

[66] Tang-Liu DD, Williams RL, Riegelman S. Disposition of caffeine and its metabolites in man. J Pharmacol Exp Ther 1983;224:180-5.

[67] Kalow W, Tang BK. The use of caffeine for enzyme assays: a critical appraisal. Clin Pharmacol Ther 1993;53:503-14.

[68] Rabe KF, Magnussen H, Dent G. Theophylline and selective PDE inhibitors as bronchodilators and smooth muscle relaxants. Eur Respir J 1995;8:637-42.

[69] Ito K, Lim S, Caramori G, Cosio B, Chung KF, Adcock IM, et al. A molecular mechanism of action of theophylline: Induction of histone deacetylase activity to decrease inflammatory gene expression. Proc Natl Acad Sci U S A 2002;99:8921-6.

[70] Horrigan LA, Kelly JP, Connor TJ. Immunomodulatory effects of caffeine: friend or foe? Pharmacol Ther 2006;111:877-92.

[71] Gamble E, Grootendorst DC, Brightling CE, Troy S, Qiu Y, Zhu J, et al. Antiinflammatory effects of the phosphodiesterase-4 inhibitor cilomilast (Ariflo) in chronic obstructive pulmonary disease. Am J Respir Crit Care Med 2003;168:976-82.

[72] Soto FJ, Hanania NA. Selective phosphodiesterase-4 inhibitors in chronic obstructive lung disease. Curr Opin Pulm Med 2005;11:129-34.

[73] Rutgers SR, Timens W, Tzanakis N, Kauffman HF, van der Mark TW, Koeter GH, et al. Airway inflammation and hyperresponsiveness to adenosine 5'-monophosphate in chronic obstructive pulmonary disease. Clin Exp Allergy 2000;30:657-62.

[74] van den Berge M, Hylkema MN, Versluis M, Postma DS. Role of adenosine receptors in the treatment of asthma and chronic obstructive pulmonary disease: recent developments. Drugs R D 2007;8:13-23.

[75] Cosio BG, Tsaprouni L, Ito K, Jazrawi E, Adcock IM, Barnes PJ. Theophylline restores histone deacetylase activity and steroid responses in COPD macrophages. J Exp Med 2004;200:68995.

[76] Kirsten DK, Wegner RE, Jorres RA, Magnussen H. Effects of theophylline withdrawal in severe chronic obstructive pulmonary disease. Chest 1993;104:1101-7.

[77] Baba K, Sakakibara A, Yagi T, Niwa S, Hattori T, Koishikawa I, et al. Effects of theophylline withdrawal in well-controlled asthmatics treated with inhaled corticosteroid. J Asthma 2001;38:615-24.

[78] Kidney J, Dominguez M, Taylor PM, Rose M, Chung KF, Barnes PJ. Immunomodulation by theophylline in asthma. Demonstration by withdrawal of therapy. Am J Respir Crit Care Med 1995;151:1907-14.

[79] Hassa PO, Hottiger MO. The functional role of poly(ADP-ribose)polymerase 1 as novel coactivator of NF-kappaB in inflammatory disorders. Cell Mol Life Sci 2002;59:1534-53.

[80] Szabo C, Lim LH, Cuzzocrea S, Getting SJ, Zingarelli B, Flower RJ, et al. Inhibition of poly (ADP-ribose) synthetase attenuates neutrophil recruitment and exerts antiinflammatory effects. J Exp Med 1997; 186:1041-9.

[81] Ha HC, Hester LD, Snyder SH. Poly(ADP-ribose) polymerase-1 dependence of stress-induced transcription factors and associated gene expression in glia. Proc Natl Acad Sci U S A 2002;99:3270-5.

[82] Kiefmann R, Heckel K, Doerger M, Schenkat S, Kupatt C, Stoeckelhuber M, et al. Role of PARP on iNOS pathway during endotoxin-induced acute lung injury. Intensive Care Med 2004;30:1421-31. 
[83] Garcia Soriano F, Virag L, Jagtap P, Szabo E, Mabley JG, Liaudet L, et al. Diabetic endothelial dysfunction: the role of poly(ADP-ribose) polymerase activation. Nat Med 2001;7:108-13.

[84] Goto S, Xue R, Sugo N, Sawada M, Blizzard KK, Poitras MF, et al. Poly(ADP-ribose) polymerase impairs early and long-term experimental stroke recovery. Stroke 2002;33:11016.

[85] Schraufstatter IU, Hinshaw DB, Hyslop PA, Spragg RG, Cochrane CG. Oxidant injury of cells. DNA strand-breaks activate polyadenosine diphosphate-ribose polymerase and lead to depletion of nicotinamide adenine dinucleotide. J Clin Invest 1986;77:1312-20.

[86] Ha HC, Snyder SH. Poly(ADP-ribose) polymerase is a mediator of necrotic cell death by ATP depletion. Proc Natl Acad Sci U S A 1999;96:13978-82.

[87] Suto MJ, Turner WR, Arundel-Suto CM, Werbel LM, Sebolt-Leopold JS. Dihydroisoquinolinones: the design and synthesis of a new series of potent inhibitors of poly(ADP-ribose) polymerase. Anticancer Drug Des 1991;6:107-17.

[88] Banasik M, Komura H, Shimoyama M, Ueda K. Specific inhibitors of poly(ADP-ribose) synthetase and mono(ADP-ribosyl)transferase. J Biol Chem 1992;267:1569-75.

[89] Moonen HJJ, Geraets L, Vaarhorst A, Wouters EFM, Bast A, Hageman GJ. Theophylline prevents NAD+ depletion via PARP-1 inhibition in human pulmonary epithelial cells. Biochem Biophys Res Commun 2005;338:1805-10.

[90] Decker P, Miranda EA, de Murcia G, Muller S. An improved nonisotopic test to screen a large series of new inhibitor molecules of poly(ADP-ribose) polymerase activity for therapeutic applications. Clin Cancer Res 1999;5:1169-72.

[91] Brown JA, Marala RB. Development of a high-throughput screening-amenable assay for human poly(ADP-ribose) polymerase inhibitors. J Pharmacol Toxicol Methods 2002;47:13741.

[92] Aposhian HV, Kornberg A. Enzymatic synthesis of deoxyribonucleic acid. IX. The polymerase formed after T2 bacteriophage infection of Escherichia coli: a new enzyme. J Biol Chem 1962;237:519-25.

[93] Zatman LJ, Kaplan NO, Colowick SP, Ciotti MM. Effect of isonicotinic acid hydrazide on diphosphopyridine nucleotidases. J Biol Chem 1954;209:453-66.

[94] Jacobson EL, Jacobson MK. Tissue NAD as a biochemical measure of niacin status in humans. Methods Enzymol 1997;280:221-30.

[95] Bradbury DA, Simmons TD, Slater KJ, Crouch SP. Measurement of the ADP:ATP ratio in human leukaemic cell lines can be used as an indicator of cell viability, necrosis and apoptosis. J Immunol Methods 2000;240:79-92.

[96] Claycomb WC. Poly(adenosine diphosphate ribose) polymerase activity and nicotinamide adenine dinucleotide in differentiating cardiac muscle. Biochem J 1976;154:387-93.

[97] Kroger H, Ehrlich W, Klewer M, Gratz R, Dietrich A, Miesel R. The influence of antagonists of poly(ADP-ribose) metabolism on acetaminophen hepatotoxicity. Gen Pharmacol 1996;27:167-70.

[98] Zingarelli B, Salzman AL, Szabo C. Genetic disruption of poly (ADP-ribose) synthetase inhibits the expression of P-selectin and intercellular adhesion molecule-1 in myocardial ischemia/reperfusion injury. Circ Res 1998;83:85-94.

[99] Trucco C, Oliver FJ, de Murcia G, Menissier-de Murcia J. DNA repair defect in poly(ADPribose) polymerase-deficient cell lines. Nucleic Acids Res 1998;26:2644-9.

[100] Schultz N, Lopez E, Saleh-Gohari N, Helleday T. Poly(ADP-ribose) polymerase (PARP-1) has a controlling role in homologous recombination. Nucleic Acids Res 2003;31:4959-64.

[101] Burkart V, Wang ZQ, Radons J, Heller B, Herceg Z, Stingl L, et al. Mice lacking the poly(ADP-ribose) polymerase gene are resistant to pancreatic beta-cell destruction and diabetes development induced by streptozocin. Nat Med 1999;5:314-9.

[102] van Dam RM, Feskens EJ. Coffee consumption and risk of type 2 diabetes mellitus. Lancet 2002;360:1477-8.

[103] Salazar-Martinez E, Willett WC, Ascherio A, Manson JE, Leitzmann MF, Stampfer MJ, et al. Coffee consumption and risk for type 2 diabetes mellitus. Ann Intern Med 2004;140:1-8. 
[104] The Diabetes Control and Complications Trial Research Group. The effect of intensive treatment of diabetes on the development and progression of long-term complications in insulin-dependent diabetes mellitus. N Engl J Med 1993;329:977-86.

[105] Pickup JC. Inflammation and activated innate immunity in the pathogenesis of type 2 diabetes. Diabetes Care 2004;27:813-23.

[106] D'Amours D, Desnoyers S, D'Silva I, Poirier GG. Poly(ADP-ribosyl)ation reactions in the regulation of nuclear functions. Biochem J 1999;342 ( Pt 2):249-68.

[107] Geraets L, Moonen HJ, Wouters EF, Bast A, Hageman GJ. Caffeine metabolites are inhibitors of the nuclear enzyme poly(ADP-ribose)polymerase- 1 at physiological concentrations. Biochem Pharmacol 2006;72:902-10.

[108] Mitchell DB, Santone KS, Acosta D. Evaluation of cytotoxicity in cultured cells by enzyme leakage. J Tiss Cult Meth 1980;6:113-6.

[109] Mukaida N, Okamoto S, Ishikawa Y, Matsushima K. Molecular mechanism of interleukin-8 gene expression. J Leukoc Biol 1994;56:554-8.

[110] Rahman I. Oxidative stress, transcription factors and chromatin remodelling in lung inflammation. Biochem Pharmacol 2002;64:935-42.

[111] MacNee W. Oxidative stress and lung inflammation in airways disease. Eur J Pharmacol 2001;429:195-207.

[112] Thannickal VJ, Fanburg BL. Reactive oxygen species in cell signaling. Am J Physiol Lung Cell Mol Physiol 2000;279:L1005-28.

[113] Comalada M, Ballester I, Bailon E, Sierra S, Xaus J, Galvez J, et al. Inhibition of proinflammatory markers in primary bone marrow-derived mouse macrophages by naturally occurring flavonoids: analysis of the structure-activity relationship. Biochem Pharmacol 2006;72:1010-21.

[114] Chen CC, Chow MP, Huang WC, Lin YC, Chang YJ. Flavonoids inhibit tumor necrosis factoralpha-induced up-regulation of intercellular adhesion molecule-1 (ICAM-1) in respiratory epithelial cells through activator protein-1 and nuclear factor-kappaB: structure-activity relationships. Mol Pharmacol 2004;66:683-93.

[115] Nair MP, Mahajan S, Reynolds JL, Aalinkeel R, Nair H, Schwartz SA, et al. The flavonoid quercetin inhibits proinflammatory cytokine (tumor necrosis factor alpha) gene expression in normal peripheral blood mononuclear cells via modulation of the NF-kappa beta system. Clin Vaccine Immunol 2006;13:319-28.

[116] Erdelyi K, Kiss A, Bakondi E, Bai P, Szabo C, Gergely P, et al. Gallotannin inhibits the expression of chemokines and inflammatory cytokines in A549 cells. Mol Pharmacol 2005;68:895-904.

[117] Day AJ, Mellon F, Barron D, Sarrazin G, Morgan MR, Williamson G. Human metabolism of dietary flavonoids: identification of plasma metabolites of quercetin. Free Radic Res 2001;35:941-52.

[118] Arts MJ, Haenen GR, Voss HP, Bast A. Masking of antioxidant capacity by the interaction of flavonoids with protein. Food Chem Toxicol 2001;39:787-91.

[119] Spencer CM, Cai Y, Martin R, Gaffney SH, Goulding PN, Magnolato D, et al. Polyphenol complexation- some thoughts and observations. Phytochemistry 1988;27:2397-409.

[120] Hauser B, Groger M, Ehrmann U, Albicini M, Bruckner UB, Schelzig H, et al. The parp-1 inhibitor ino-1001 facilitates hemodynamic stabilization without affecting DNA repair in porcine thoracic aortic cross-clamping-induced ischemia/reperfusion. Shock 2006;25:633-40.

[121] Andersen OM, Markman KR, editors. Flavonoids. Chemistry, biochemistry and applications. CRC Press 2006; Boca Raton, Florida, USA.

[122] Sampson L, Rimm E, Hollman PC, de Vries JH, Katan MB. Flavonol and flavone intakes in US health professionals. J Am Diet Assoc 2002;102:1414-20.

[123] Hertog MG, Hollman PC, Katan MB, Kromhout D. Intake of potentially anticarcinogenic flavonoids and their determinants in adults in The Netherlands. Nutr Cancer 1993;20:21-9.

[124] Hollman PC, vd Gaag M, Mengelers MJ, van Trijp JM, de Vries JH, Katan MB. Absorption and disposition kinetics of the dietary antioxidant quercetin in man. Free Radic Biol Med 
1996;21:703-7.

[125] Conquer JA, Maiani G, Azzini E, Raguzzini A, Holub BJ. Supplementation with quercetin markedly increases plasma quercetin concentration without effect on selected risk factors for heart disease in healthy subjects. J Nutr 1998;128:593-7.

[126] Milo GE, Kurian P, Kirsten E, Kun E. Inhibition of carcinogen-induced cellular transformation of human fibroblasts by drugs that interact with the poly(ADP-ribose) polymerase system. Initial evidence for the development of transformation resistance. FEBS Lett 1985;179:332-6.

[127] Wenzel U, Kuntz S, Brendel MD, Daniel H. Dietary flavone is a potent apoptosis inducer in human colon carcinoma cells. Cancer Res 2000;60:3823-31.

[128] Hofmann MA, Schiekofer S, Isermann B, Kanitz M, Henkels M, Joswig M, et al. Peripheral blood mononuclear cells isolated from patients with diabetic nephropathy show increased activation of the oxidative-stress sensitive transcription factor NF-kappaB. Diabetologia 1999;42:222-32.

[129] Livak KJ, Schmittgen TD. Analysis of relative gene expression data using real-time quantitative PCR and the 2(-Delta Delta C(T)) Method. Methods 2001;25:402-8.

[130] Fischer MA, Gransier TJ, Beckers LM, Bekers O, Bast A, Haenen GR. Determination of the antioxidant capacity in blood. Clin Chem Lab Med 2005;43:735-40.

[131] Szabo C, Zanchi A, Komjati K, Pacher P, Krolewski AS, Quist WC, et al. Poly(ADP-Ribose) polymerase is activated in subjects at risk of developing type 2 diabetes and is associated with impaired vascular reactivity. Circulation 2002;106:2680-6.

[132] Christman JW, Sadikot RT, Blackwell TS. The role of nuclear factor-kappa B in pulmonary diseases. Chest 2000;117:1482-7.

[133] Fakler CR, Wu B, McMicken HW, Geske RS, Welty SE. Molecular mechanisms of lipopolysaccharide induced ICAM-1 expression in A549 cells. Inflamm Res 2000;49:63-72.

[134] Huber AR, Kunkel SL, Todd RF, 3rd, Weiss SJ. Regulation of transendothelial neutrophil migration by endogenous interleukin-8. Science 1991;254:99-102.

[135] Pesci A, Balbi B, Majori M, Cacciani G, Bertacco S, Alciato P, et al. Inflammatory cells and mediators in bronchial lavage of patients with chronic obstructive pulmonary disease. Eur Respir J 1998;12:380-6.

[136] Norzila MZ, Fakes K, Henry RL, Simpson J, Gibson PG. Interleukin-8 secretion and neutrophil recruitment accompanies induced sputum eosinophil activation in children with acute asthma. Am J Respir Crit Care Med 2000;161:769-74.

[137] Rutgers SR, Timens W, Kaufmann HF, van der Mark TW, Koeter GH, Postma DS. Comparison of induced sputum with bronchial wash, bronchoalveolar lavage and bronchial biopsies in COPD. Eur Respir J 2000;15:109-15.

[138] Perez P, Lira SA, Bravo R. Overexpression of RelA in transgenic mouse thymocytes: specific increase in levels of the inhibitor protein I kappa B alpha. Mol Cell Biol 1995;15:3523-30.

[139] Geraets L, Moonen HJ, Brauers K, Wouters EF, Bast A, Hageman GJ. Dietary Flavones and Flavonoles Are Inhibitors of Poly(ADP-ribose)polymerase-1 in Pulmonary Epithelial Cells. J Nutr 2007;137:2190-5.

[140] Geraets L, Moonen HJ, Brauers K, Gottschalk RW, Wouters EF, Bast A, et al. Flavone as PARP-1 inhibitor: Its effect on lipopolysaccharide induced gene-expression. Eur J Pharmacol 2007;573:241-8.

[141] Puljic R, Benediktus E, Plater-Zyberk C, Baeuerle PA, Szelenyi S, Brune K, et al. Lipopolysaccharide-induced lung inflammation is inhibited by neutralization of GM-CSF. Eur J Pharmacol 2007;557:230-5.

[142] Deng YM, Xie QM, Tang HF, Sun JG, Deng JF, Chen JQ, et al. Effects of ciclamilast, a new PDE 4 PDE4 inhibitor, on airway hyperresponsiveness, PDE4D expression and airway inflammation in a murine model of asthma. Eur J Pharmacol 2006;547:125-35.

[143] Azumo K, Ippoushi K, Ito H, Horie H, Terao J. Enhancing effect of lipids and emulsifiers on the accumulation of quercetin metabolites in blood plasma after the short-term ingestion of onions in rats. Biosci Biotechnol Biochem 2003;67:2548-55.

[144] Vernooy JH, Dentener MA, van Suylen RJ, Buurman WA, Wouters EF. Intratracheal instilla- 
tion of lipopolysaccharide in mice induces apoptosis in bronchial epithelial cells: no role for tumor necrosis factor-alpha and infiltrating neutrophils. Am J Respir Cell Mol Biol 2001;24:569-76.

[145] Siegel S, Castellan NJ. Nonparametric statistics for the behavioral sciences. McGraw-Hill Book Co, Inc, New York 1988.

[146] de Boer VC, Dihal AA, van der Woude H, Arts IC, Wolffram S, Alink GM, et al. Tissue distribution of quercetin in rats and pigs. J Nutr 2005;135:1718-25.

[147] Sung B, Pandey MK, Aggarwal BB. Fisetin, an inhibitor of cyclin-dependent kinase 6, downregulates nuclear factor-kappaB-regulated cell proliferation, antiapoptotic and metastatic gene products through the suppression of TAK-1 and receptor-interacting protein-regulated IkappaBalpha kinase activation. Mol Pharmacol 2007;71:1703-14.

[148] Xing Z, Gauldie J, Cox G, Baumann H, Jordana M, Lei XF, et al. IL-6 is an antiinflammatory cytokine required for controlling local or systemic acute inflammatory responses. J Clin Invest 1998;101:311-20.

[149] Ryter SW, Choi AM. Heme oxygenase-1: redox regulation of a stress protein in lung and cell culture models. Antioxid Redox Signal 2005;7:80-91.

[150] Michel O, Kips J, Duchateau J, Vertongen F, Robert L, Collet H, et al. Severity of asthma is related to endotoxin in house dust. Am J Respir Crit Care Med 1996;154:1641-6.

[151] Smid T, Heederik D, Houba R, Quanjer PH. Dust- and endotoxin-related acute lung function changes and work-related symptoms in workers in the animal feed industry. Am J Ind Med 1994 25:877-88.

[152] Schwartz DA, Thorne PS, Yagla SJ, Burmeister LF, Olenchock SA, Watt JL, et al. The role of endotoxin in grain dust-induced lung disease. Am J Respir Crit Care Med 1995;152:603-8.

[153] Hasday JD, Bascom R, Costa JJ, Fitzgerald T, Dubin W. Bacterial endotoxin is an active component of cigarette smoke. Chest 1999;115:829-35.

[154]Jijon HB, Churchill T, Malfair D, Wessler A, Jewell LD, Parsons HG, et al. Inhibition of poly(ADP-ribose) polymerase attenuates inflammation in a model of chronic colitis. Am J Physiol Gastrointest Liver Physiol 2000;279:G641-51.

[155] Boots AW, Haenen GR, Bast A. Oxidant metabolism in chronic obstructive pulmonary disease. Eur Respir J 2003;46:14s-27s.

[156] van Helvoort HA, Heijdra YF, Dekhuijzen PN. Systemic immunological response to exercise in patients with chronic obstructive pulmonary disease: what does it mean? Respiration 2006;73:255-64.

[157] Kiefmann R, Heckel K, Dorger M, Schenkat S, Stoeckelhuber M, Wesierska-Gadek J, et al. Role of poly(ADP-ribose) synthetase in pulmonary leukocyte recruitment. Am J Physiol Lung Cell Mol Physiol 2003;285:L996-L1005.

[158] Klebanoff SJ. Myeloperoxidase. Proc Assoc Am Physicians 1999;111:383-9.

[159] Fredholm B. Are methylxanthine effects due to antagonism of endogenous adenosine? . Trends Pharmacol Sci 1979-1980;1:129-32.

[160] Daly JW. Caffeine analogs: biomedical impact. Cell Mol Life Sci 2007;64:2153-69.

[161] Szabo C, Cuzzocrea S, Zingarelli B, O'Connor M, Salzman AL. Endothelial dysfunction in a rat model of endotoxic shock. Importance of the activation of poly (ADP-ribose) synthetase by peroxynitrite. J Clin Invest 1997;100:723-35.

[162] Uchida K, Takahashi S, Fujiwara K, Ueda K, Nakae D, Emi Y, et al. Preventive effect of 3aminobenzamide on the reduction of NAD levels in rat liver following administration of diethylnitrosamine. Jpn J Cancer Res 1988;79:1094-100.

[163] Keatings VM, Collins PD, Scott DM, Barnes PJ. Differences in interleukin-8 and tumor necrosis factor-alpha in induced sputum from patients with chronic obstructive pulmonary disease or asthma. Am J Respir Crit Care Med 1996;153:530-4.

[164] Atzeni F, Sarzi-Puttini P, Doria A, laccarino L, Capsoni F. Potential off-label use of infliximab in autoimmune and non-autoimmune diseases: a review. Autoimmun Rev 2005;4:144-52.

[165] Reimold AM. New indications for treatment of chronic inflammation by TNF-alpha blockade. Am J Med Sci 2003;325:75-92. 
[166] Lelo A, Miners JO, Robson R, Birkett DJ. Assessment of caffeine exposure: caffeine content of beverages, caffeine intake, and plasma concentrations of methylxanthines. Clin Pharmacol Ther 1986;39:54-9.

[167] Buters JT, Tang BK, Pineau T, Gelboin HV, Kimura S, Gonzalez FJ. Role of CYP1A2 in caffeine pharmacokinetics and metabolism: studies using mice deficient in CYP1A2. Pharmacogenetics 1996;6:291-6.

[168] Berthou F, Guillois B, Riche C, Dreano Y, Jacqz-Aigrain E, Beaune PH. Interspecies variations in caffeine metabolism related to cytochrome P4501A enzymes. Xenobiotica 1992;22:67180.

[169] Weseler AR, Moonen HJJ, Geraets L, Manders R, Van Loon LJC, Pennings HJ, et al. Flavonoids significantly attenuate cytokine release in blood from patients with chronic obstructive pulmonary disease and diabetes mellitus type II. Submitted 2008.

[170] Heijnen CGM, Haenen GRRM, Vekemans JAJM, Bast A. Peroxynitrite scavenging of flavonoids: Structure activity relationship. Environmental Toxicology and Pharmacology 2001;10:199-206.

[171] Barnes PJ. Anti-inflammatory actions of glucocorticoids: molecular mechanisms. Clin Sci (Lond) 1998;94:557-72.

[172] Masutani M, Suzuki H, Kamada N, Watanabe M, Ueda O, Nozaki T, et al. Poly(ADP-ribose) polymerase gene disruption conferred mice resistant to streptozotocin-induced diabetes. Proc Natl Acad Sci U S A 1999;96:2301-4.

[173] Houben JM, Moonen HJ, van Schooten FJ, Hageman GJ. Telomere length assessment: biomarker of chronic oxidative stress? Free Radic Biol Med 2008;44:235-46.

[174] d'Adda di Fagagna F, Hande MP, Tong WM, Lansdorp PM, Wang ZQ, Jackson SP. Functions of poly(ADP-ribose) polymerase in controlling telomere length and chromosomal stability. Nat Genet 1999;23:76-80.

[175] Grube K, Burkle A. Poly(ADP-ribose) polymerase activity in mononuclear leukocytes of 13 mammalian species correlates with species-specific life span. Proc Natl Acad Sci U S A 1992;89:11759-63.

[176] Constantinou A, Mehta R, Runyan C, Rao K, Vaughan A, Moon R. Flavonoids as DNA topoisomerase antagonists and poisons: structure-activity relationships. J Nat Prod 1995;58:217-25.

[177] van Waalwijk van Doorn-Khosrovani SB, Janssen J, Maas LM, Godschalk RW, Nijhuis JG, van Schooten FJ. Dietary flavonoids induce MLL translocations in primary human CD34+ cells. Carcinogenesis 2007;28:1703-9.

[178] Ferguson LR, Baguley BC. Topoisomerase II enzymes and mutagenicity. Environ Mol Mutagen 1994;24:245-61.

[179] Ranheim T, Halvorsen B. Coffee consumption and human health--beneficial or detrimental?-Mechanisms for effects of coffee consumption on different risk factors for cardiovascular disease and type 2 diabetes mellitus. Mol Nutr Food Res 2005;49:274-84.

[180] Hernan MA, Takkouche B, Caamano-Isorna F, Gestal-Otero JJ. A meta-analysis of coffee drinking, cigarette smoking, and the risk of Parkinson's disease. Ann Neurol 2002;52:276-84.

[181] Tverdal A, Skurtveit S. Coffee intake and mortality from liver cirrhosis. Ann Epidemiol 2003;13:419-23.

[182] Lopez-Garcia E, van Dam RM, Willett WC, Rimm EB, Manson JE, Stampfer MJ, et al. Coffee consumption and coronary heart disease in men and women: a prospective cohort study. Circulation 2006;113:2045-53.

[183] World Cancer Research Fund (WCRF)/ American Institute for Cancer Research (AICR) Expert Report. Food, Nutrition, Physical Activity and the Prevention of Cancer: a Global Perspective. 2008.

[184] Browne ML. Maternal exposure to caffeine and risk of congenital anomalies: a systematic review. Epidemiology 2006;17:324-31.

[185] Weng X, Odouli R, Li DK. Maternal caffeine consumption during pregnancy and the risk of miscarriage: a prospective cohort study. Am J Obstet Gynecol 2008;198:279 e1-8. 
SAMENVATTING 


\section{SAMENVATTING}

Dit proefschrift beschrijft de in vitro identificatie, de in vitro en ex vivo evaluatie en de in vivo toepassing van voedingscomponenten met een milde remmende activiteit van het enzym poly(ADP-ribose) polymerase-1 (PARP-1).

De hypothese van het in dit proefschrift beschreven onderzoek is dat milde PARP-1 remmers afkomstig uit de voeding gunstige effecten kunnen hebben bij inflammatoire aandoeningen zoals chronisch obstructief longlijden (COPD). Het onderliggende mechanisme is gebaseerd op het remmen van genexpressie die gemedieerd wordt door de transcriptiefactor NF-kB. Hierbij speelt PARP-1 een rol als co-activator. Door deze co-activatie te verminderen zou de inflammatoire respons geremd worden. Deze voedingscomponenten zouden mogelijk toegepast kunnen worden als ingrediënten van functional foods of nutraceuticals voor patiënten met inflammatoire aandoeningen.

$\overline{\text { Alvorens de belangrijkste bevindingen te beschrijven dienen een aantal begrippen en processen }}$ nader uitgelegd te worden:

- $\quad$ Genexpressie is het proces waarbij de erfelijke informatie van een gen dat in het DNA opgesloten is vertaald wordt in een genproduct. Dit product kan een eiwit zoals een cytokine (signaalstof) zijn.

- Een transcriptiefactor is een eiwit dat bindt aan specifieke delen van het DNA en onderdeel uitmaakt van het genexpressie-syteem dat het aflezen van de erfelijke informatie van het DNA controleert. NF- $k B$ is zo' $n$ transcriptiefactor en medieert de expressie van vele genen zoals de cytokines TNF- $\alpha$ of IL-8.

- Een co-activator is een eiwit dat de genexpressie verhoogd door interactie met een transcriptiefactor.

- $\quad$ Chronisch obstructief longlijden of COPD (de verzamelnaam voor chronische bronchitis en longemfyseem) is een aandoening aan de luchtwegen en longen, die zich vaak pas op latere leeftijd openbaart. Hierbij worden de luchtwegen vernauwd door een langdurige ontsteking (longinflammatie) en de longen beschadigd waardoor een grotendeels onomkeerbare verslechtering van de longfunctie ontstaat. Roken wordt gezien als de belangrijkste risicofactor voor het ontstaan van COPD. Naast een steeds verdergaande verminderde longfunctie wordt deze aandoening ook gekenmerkt door extrapulmonale effecten, ook wel systemische effecten genoemd (effecten in de weefsels en organen buiten de longen). Deze systemische effecten dragen bij aan de ernst van het ziektebeeld en kunnen de kwaliteit van leven ernstig schaden.

- $\quad$ Poly(ADP-ribose) polymerase-1 (PARP-1) is een enzym dat aanvankelijk bekend was vanwege de facilitaire rol in herstel van DNA schade. Momenteel wordt steeds duidelijker dat PARP-1 beschouwd kan worden als een belangrijke co-activator van de transcriptie

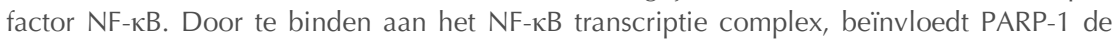
$\mathrm{NF}-\mathrm{kB}$ gemedieerde genexpressie. Remming van PARP-1 zou mogelijk deze genexpressie kunnen verminderen waardoor inflammatieprocessen gereduceerd kunnen worden. Recent is bij COPD patiënten naast longinflammatie en systemische inflammatie, een verhoogde systemische PARP-1 activiteit aangetoond in witte bloedcellen. Mogelijk zou milde PARP-1 remming middels voedingscomponenten een positieve bijdrage kunnen leveren aan het verminderen van de inflammatoire respons bij COPD patiënten. 
De in vitro studies (hoofdstukken 2, 3 en 4) laten zien dat diverse voedingscomponenten in staat zijn om het enzym PARP-1 te remmen. Cafeïnemetabolieten zoals 1,7-dimethylxanthine, en in mindere mate theofylline en theobromine (afbraakproducten van cafeïne die in het lichaam gevormd kunnen worden na consumptie van cafeïne of cafeïne bevattende producten zoals koffie en chocolade) zijn uitstekende kandidaten. Ook flavonoïden zoals fisetine, tricetine, quercetine en flavone, die vooral voorkomen in appels, druiven, uien, ginkgo biloba, haver en dille, zijn in staat om PARP-1 te remmen. Niet alleen remming van het zuivere geïsoleerde enzym, maar ook enzymremming in humane longepitheelcellen en vasculaire endotheelcellen zijn kenmerkend voor deze componenten. Daarnaast vermindert 1,7-dimethylxanthine in vitro de door oxidative stress geïnduceerde celnecrose in humane vasculaire endotheelcellen en verschuift het celdoodproces in pulmonaire epitheelcellen naar apoptose. Omdat celnecrose ook leidt tot inflammatie, wordt een verschuiving van het celdoodproces naar apoptose als gunstig gezien. De flavonoïden fisetine, tricetine, quercetine en flavone verminderen in vitro de LPS-geïnduceerde inflammatoire respons in longepitheelcellen. Tot slot verlaagt de flavonoïd flavone in vitro de LPSgeïnduceerde NF- $\kappa B$ gemedieerde transcriptie en productie van IL-8 en verhoogt het de transcriptie van $I_{\kappa B}$. Op basis van deze resultaten wordt een indirect effect, zoals een effect op de co-activator functie van PARP-1, het meest waarschijnlijk geacht.

De geselecteerde componenten 1,7-dimethylxanthine, fisetine, tricetine en flavone laten niet alleen in vitro veelbelovende resultaten zien, maar ook uit de in vivo en ex vivo studies (hoofdstukken 5 en 6) blijkt dat deze componenten mogelijkheden bieden voor mogelijke toepassingen bij de mens. De muizenstudies beschreven in dit proefschrift laten zien dat zowel 1,7dimethylxanthine als fisetine de LPS-geïnduceeerde acute longinflammatie als ook de systemische inflammatie bij muizen kunnen verminderen. Op basis van de resultaten die beschreven zijn in dit proefschrift, kan geconcludeerd worden dat PARP-1 remmers afkomstig uit de voeding, zoals 1,7-dimethylxanthine en

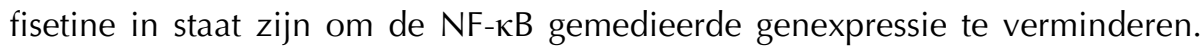
Op die manier laten ze anti-inflammatoire effecten zien, zowel in vitro, als ook in vivo in de muis. Wanneer in witte bloedcellen van COPD patiënten ex vivo met LPS een inflammatoire respons wordt opgewekt, blijkt deze ook geremd te kunnen worden door 1,7-dimethylxanthine (hoofdstuk 6). Aanvullend onderzoek heeft laten zien dat deze ex vivo respons ook geremd kan worden door fisetine, tricetine en flavone. Gebaseerd op deze bevindingen, zou suppletie met deze componenten in aanvulling op de reeds toegepaste behandeling van inflammatoire aandoeningen zoals COPD veelbelovende efecten kunnen hebben. Tot nu toe is er nog steeds geen succesvolle behandeling voor COPD ontwikkeld. Door het toepassen van PARP-1 remmers 
afkomstig uit de voeding, zoals 1,7-dimethylxanthine of fisetine zou mogelijk zowel de inflammatie in de longen als de systemische inflammatie verminderd kunnen worden en de kwaliteit van leven van COPD patiënten verbeterd worden. 


\section{APPENDIX}

Dankwoord

About the author

Publications 


\section{DANKWOORD}

Het mag dan wel 'mijn boekje' zijn, maar zonder de hulp, ideeën en interesse van velen was het nooit zo ver gekomen. Ik wil dan ook graag al deze mensen, en een aantal in het bijzonder, bedanken!

Allereerst zou ik mijn copromotor Geja Hageman en promotores Aalt Bast en Miel Wouters willen bedanken voor de kans die ze me gegeven hebben om te promoveren op dit onderzoek. Ik heb veel van jullie geleerd.

Geja bedankt! Voor je enthousiasme, je vele ideeën en je kritische blik op het onderzoek. Voor je hulp en aansturing in de afrondingsfase van het proefschrift gedurende de tijd dat ik al in Utrecht woonde en werkte.

Aalt bedankt! Voor je positieve instelling en enthousiasme, dat werkte altijd erg motiverend. Je altijd aanwezige humor tijdens onze werkbesprekingen en alledaagse gesprekken was erg prettig en relativerend.

Miel bedankt! Ook al kwam je er pas in een later stadium als promotor bij, je was al langere tijd betrokken bij Geja's STW-project. Bedankt voor de snelle verbeteringen van de manuscripten en de prettige samenwerking.

Alle collega's van het STW-project mogen hier zeker niet ontbreken. Bedankt voor de hulp en al het werk wat iedereen gedaan heeft! Hierbij nog een speciaal woord voor Karen en Jane: Karen, met name gedurende de laatste maanden heb je nog veel analyses gedaan, dat heb ik zeer gewaardeerd. Jane, thanks a lot for all the work you did for us.

Mijn collega's van de vakgroep Farmacologie en Toxicologie wil ik hartelijk bedanken voor de hulp op en rond het lab, de fijne samenwerking, maar vooral ook voor de gezellige en aangename werksfeer.

Voor de uitvoering van de muizenstudie heb ik veel hulp van Astrid Haegens gekregen. Astrid, heel erg fijn dat ik velen malen mocht meekijken tijdens jouw studie. Hierdoor werd het voor mij iets gemakkelijker om zelf mijn eigen experimenten uit te voeren.

Mijn nieuwe collega's van het NVIC wil ik graag bedanken voor hun interesse en bovenal de zeer prettige werksfeer, waardoor ik me vrij snel op mijn nieuwe werkplek thuis voelde.

De mensen die buiten het werk om zo belangrijk voor mij zijn mogen natuurlijk niet vergeten worden. Een speciaal woord voor een aantal van jullie. Lieve Merlijn en Ellen, superfijn dat jullie tijdens de verdediging achter me staan! Merlijn, het is al weer ruim 10 jaar geleden dat we elkaar in Wageningen ontmoet hebben. Ondanks dat we een verschillende richting zijn uitgegaan, hebben we elkaar gelukkig nooit uit het oog verloren. Bedankt voor al je vrolijkheid en de vele plezierige afspraken met jou en Peter. Nog even, en 
dan sta jij er ook! Ellen, ik vind het fijn dat we weer dicht bij elkaar wonen. Bedankt voor je interesse in mij en mijn werk, je gezelligheid en je steun.

Saskia, naast al ruim 5 jaar mijn collega, ben je gelukkig onderhand ook een erg goede vriendin. Bedankt voor het delen van het lief en leed van het AIObestaan en al je hulp.

Femke, Olga en Mirjam, ook jullie erg bedankt voor de waardevolle vriendschap.

Marina, Andrea, Saskia en Anouschka, we kennen elkaar nu toch al flink wat jaartjes. Bedankt voor alle afspraken: van fijne etentjes, hardlooprondjes, opde-bank-hangen-en-relaxen-avondjes, tot de goede gesprekken toe! Nu woon ik alweer ruim een jaar in Utrecht, maar gelukkig staat dit het maken van nieuwe afspraken niet in de weg.

Jeroen en Maria, verhuizen van Sittard naar Utrecht betekende dat ik dichter bij jullie ben komen wonen. Bedankt voor al jullie hulp en gezelligheid.

Mam en pap, fijn dat jullie echt altijd voor me klaarstaan. Bedankt dat jullie me de mogelijkheid gegeven hebben datgene te doen wat ik maar wilde doen!

Liesbeth 


\section{ABOUT THE AUTHOR}

Liesbeth Geraets was born on March 9th 1980 in Brunssum, the Netherlands. She completed her secondary education (gymnasium) at Scholengemeenschap Serviam in Sittard.

From 1998-2003 she studied Nutrition and Health at Wageningen University with a specialization in Toxicology and Physiology. After completing her research projects at the departments of Toxicology of Wageningen University, Human Biology of Maastricht University and an internship at Notox Safety \& Environmental Research in 's-Hertogenbosch, she obtained her MSc in 2003. In september 2003 she started her PhD research at the department of Pharmacology and Toxicology of Maastricht University under supervision of $\mathrm{Dr} \operatorname{Ir} \mathrm{G}$ J Hageman (Health Risk Analysis and Toxicology), Prof dr A Bast (Pharmacology and Toxicology) and Prof dr EFM Wouters (Respiratory Medicine, University Hospital Maastricht). During these 4 years, she completed the Postgraduate Education in Toxicology, which will result in the registration as Toxicologist.

Since September 2007 she works as researcher and consultant in Clinical Toxicology at the National Poisons Information Centre of the National Institute for Public Health and the Environment (RIVM), Bilthoven. 


\section{PUBLICATIONS}

Van Zanden JJ, Geraets L, Wortelboer HM, van Bladeren PJ, Rietjens IMCM, Cnubben NHP. Structural requirements for the flavonoid-mediated modulation of glutathione S-transferase P1-1 and GS-X pump activity in MCF7 breast cancer cells. Biochemical Pharmacology, 2004, 67, 1607-1617

Moonen HJJ, Geraets L, Vaarhorst A, Wouters EFM, Bast A, Hageman GJ. Theophylline prevents $\mathrm{NAD}^{+}$depletion via PARP-1 inhibition in human pulmonary epithelial cells. Biochemical and Biophysical Research Communications, 2005, 338, 1805-1810

Geraets L, Moonen HJJ, Wouters EFM, Bast A, Hageman GJ. Caffeine metabolites are inhibitors of the nuclear enzyme poly(ADP-ribose)polymerase- 1 at physiological concentrations. Biochemical Pharmacology, 2006, 72(7), 902910

Geraets L, Moonen HJJ, Brauers K, Wouters EFM, Bast A, Hageman GJ. Dietary flavones and flavonoles are inhibitors of poly(ADP-ribose)polymerase-1 in pulmonary epithelial cells. Journal of Nutrition, 2007, 137(10), 2190-2195

Geraets L, Moonen HJJ, Brauers K, Gottschalk RWH, Wouters EFM, Bast A, Hageman GJ. Flavone as PARP-1 inhibitor: Its effect on lipopolysaccharide induced gene-expression. European Journal of Pharmacology, 2007, 573, 241 248

Geraets L, Haegens A, Brauers K, Haydock JA, Vernooy JHJ, Wouters EFM, Bast A, Hageman GJ. Anti-inflammatory effects of specific PARP-1 inhibiting flavonoids in a mouse model of lipopolysaccharide induced acute pulmonary inflammation. Submitted, 2008

Geraets L, Haegens A, Weseler AR, Brauers K, Vernooy JHJ, Wouters EFM, Bast A, Hageman GJ. The caffeine metabolite 1,7-dimethylxanthine inhibits the lipopolysaccharide-induced inflammatory response in mouse lungs and ex vivo in blood of COPD patients. Submitted, 2008

Weseler AR, Moonen HJJ, Geraets L, Manders R, van Loon LJC, Pennings HJ, Wouters EFM, Bast A, Hageman GJ. Flavonoids significantly attenuate cytokine release in blood from patients with chronic obstructive pulmonary disease and diabetes mellitus type II. Submitted, 2008 